\title{
Deutrde Zૈedfldieibung
}

pon

\author{
Dr. $\mathscr{f} \mathfrak{r a t z} z \mathfrak{Q a u f f}$.
}

\begin{abstract}
3

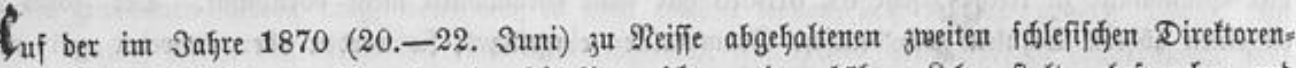
fonferenz wurbe vie gewöfnlid, aud wieber ber bentifje lunterridjt an ben höhern Sefranftalten bejprodjen unb

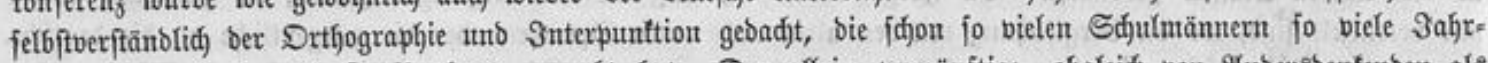

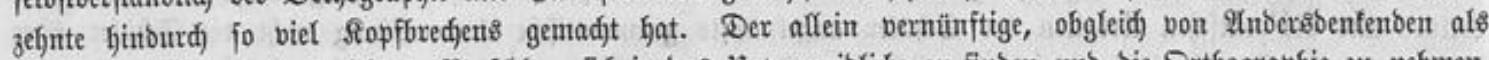

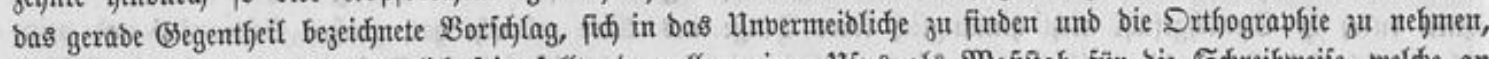

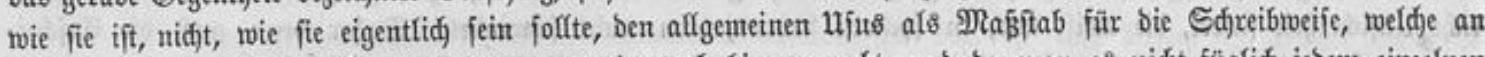
Sdjulen bejolgt werben joll, anzumefumen, wurbe aud hier gemadjt, unto ba man es nidjt füglid jebemt einjelnen \&egrer überlaffen fann, feine Sd)reibmeife als bie allein rifftige umb zugleidj bem alfgemeinen Mjus entipredjenbe

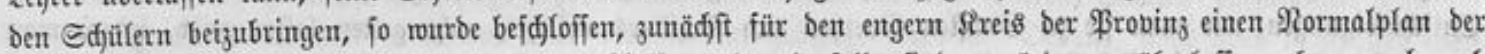
Drthograpfie ju entwerfen utb es bant bem 2 (ntlang, ben berjelbe finten wirtbe, jut itbertaffen, ob er aud) nod)

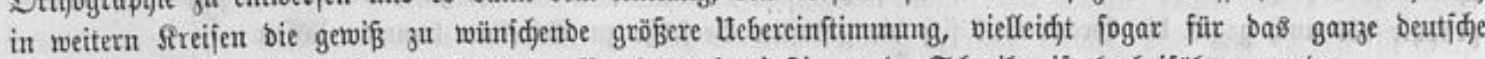
\$olf eine wenigftens in allen wejentlidfen \$untten itbereinftimmente Sdjreibweije herbeifüthren werbe.

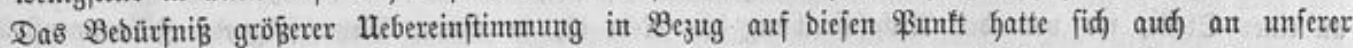

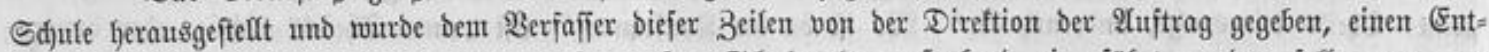

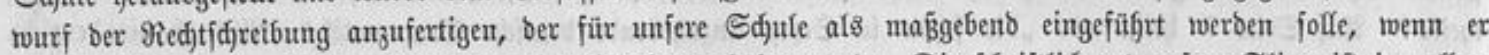

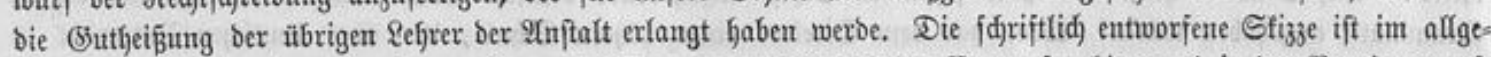

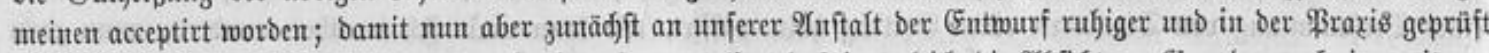

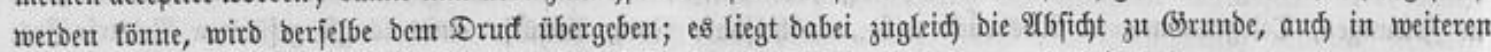

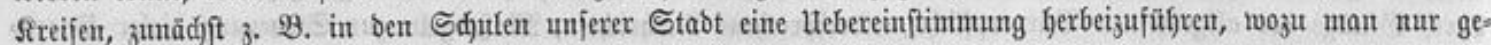

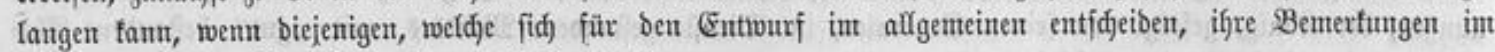
eimzelnen an ben Berfafier gelangen lafjen wollen.

Der Berfaffer ift bemüht gewejen, möglidjt alle netrere Sdjriften, bie fid) mit biejem (Begenftanbe befafien, zu benuţen, um baburd, bas oben bezeidjnete Biel, ben allgemeinen Sdjreibgebraud) feftzuftellen, ju erreidjen.

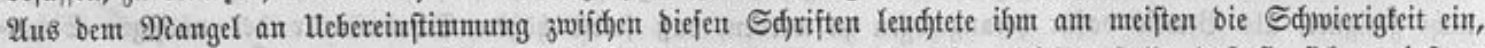

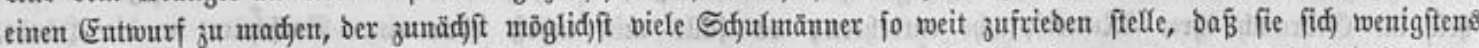

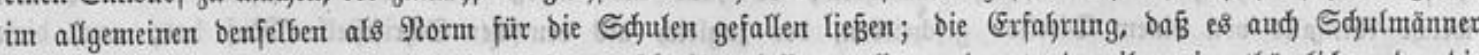

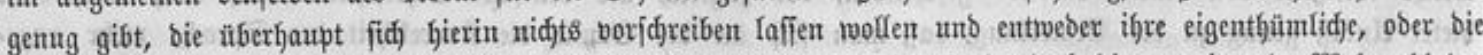

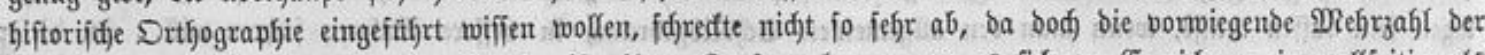

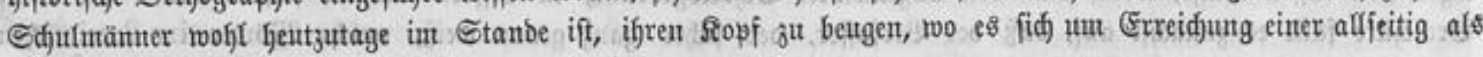
nothpenbig anerfanuten llebereinftinumung banbelt.

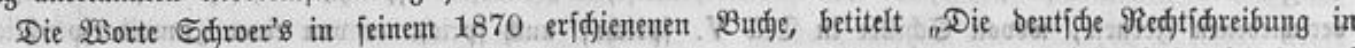

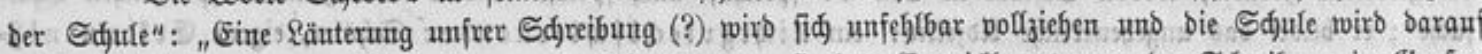

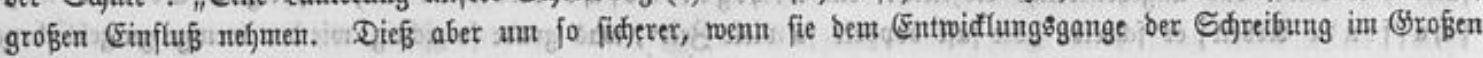




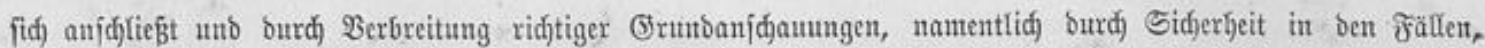

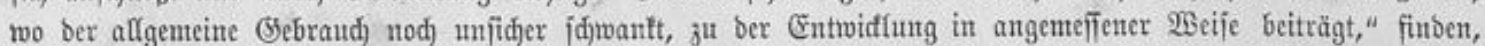

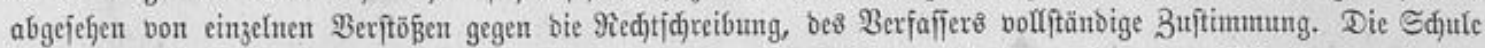

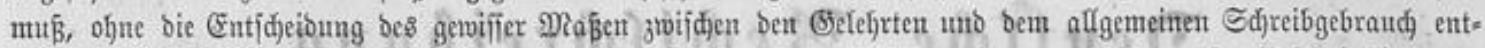

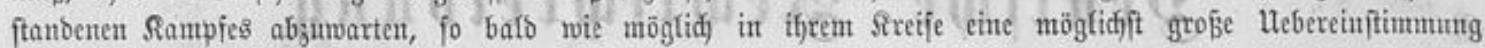

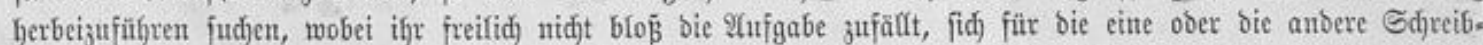

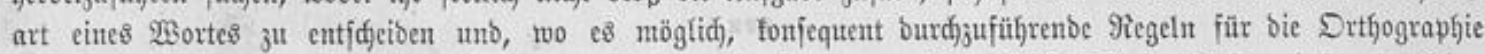

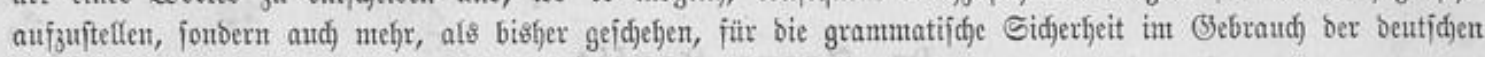
Epradje ju forgen.

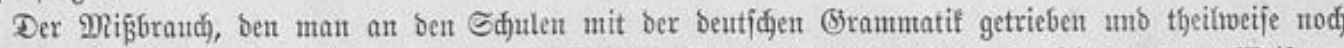

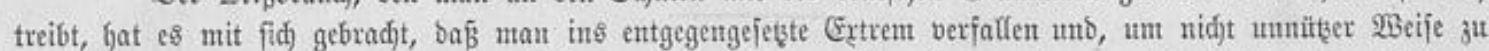

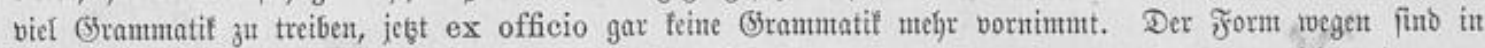

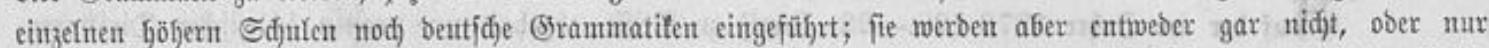

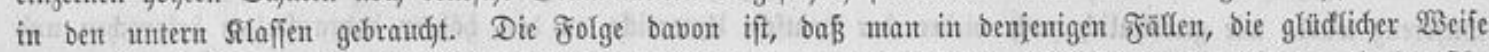
nutr verciuzelt fint, wo bie 2 bergleidjung mit bent alten unb neuten Spradjen ober bie gelegentlidje an bic bentidje

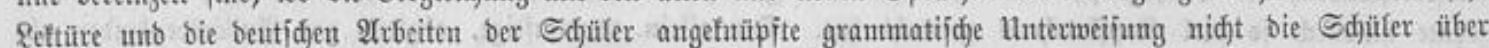

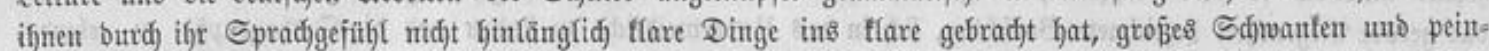

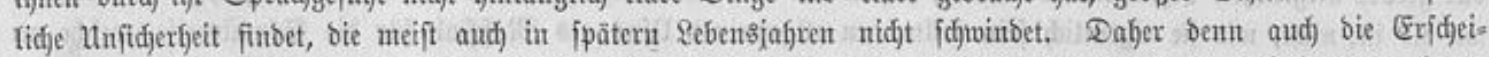

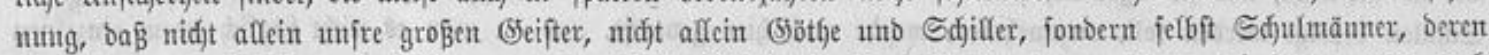

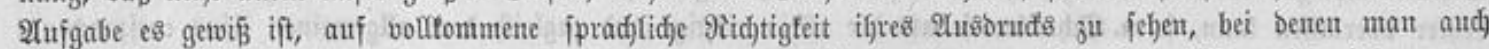

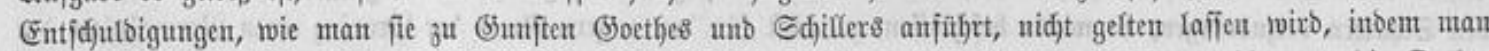

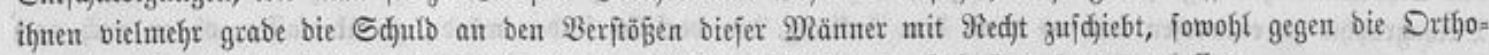

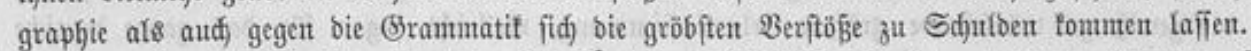

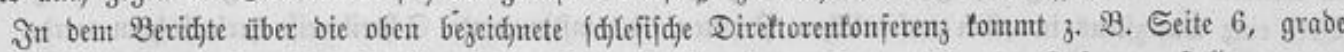

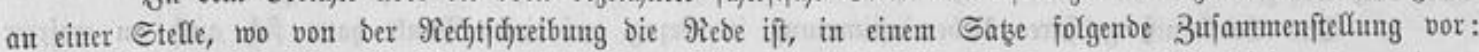

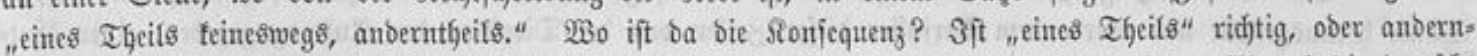

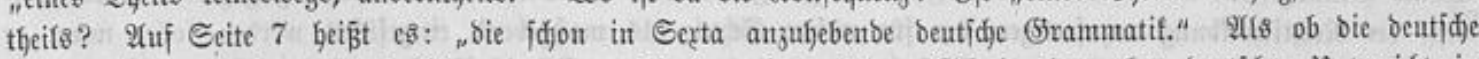
(5rammatif angefyoben twitrbe! Wenn bas bem Direftor einer höhern Sdjule, ber über beutjdjen Unterridft in

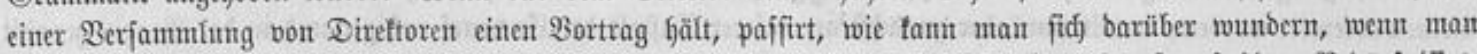

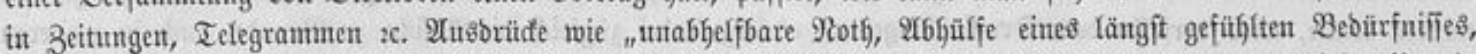

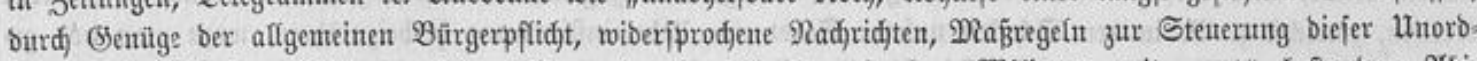

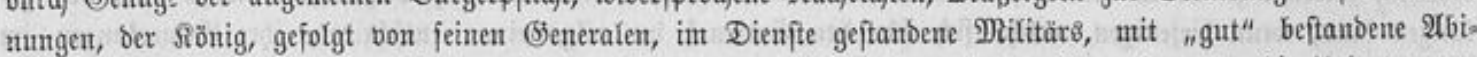
turienten, ber Safhn fam ungejdeitert in ben Fort, unter Prittheilung beffen Signalements, bie Mebertragung

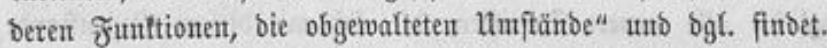

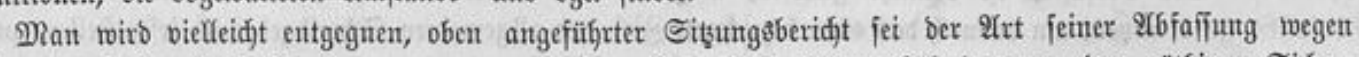

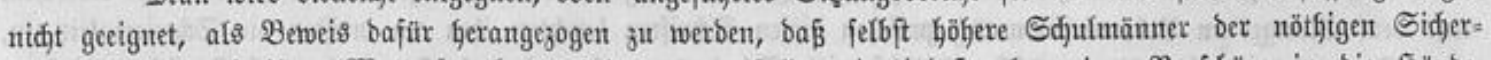

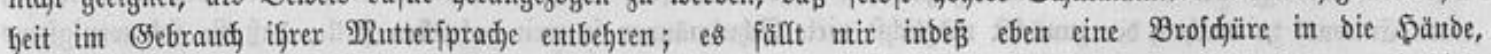

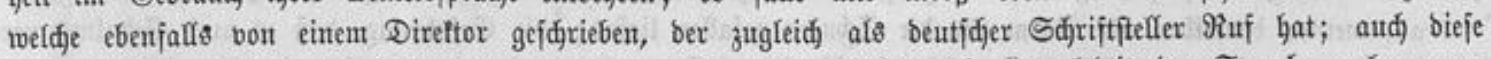

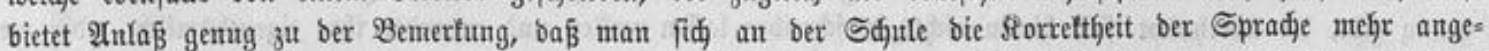

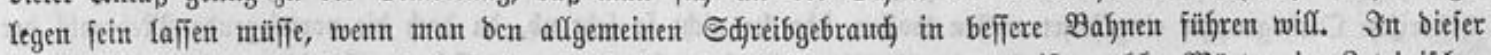

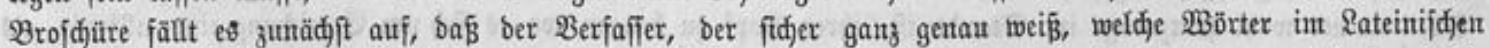

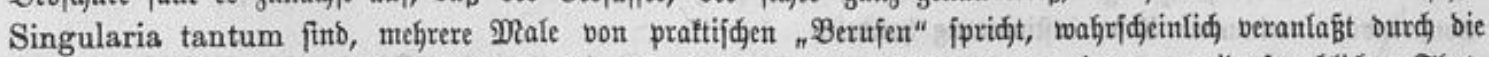

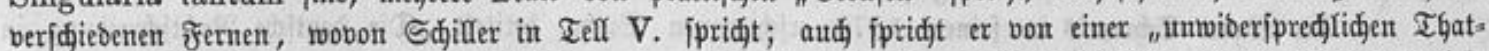

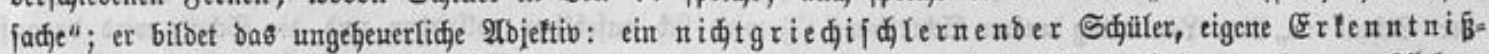

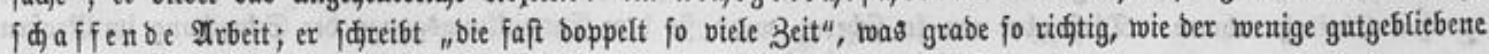




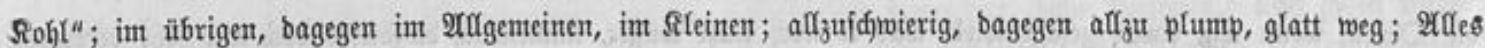

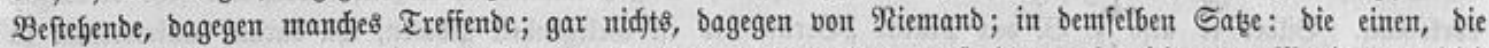

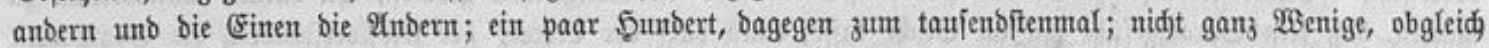

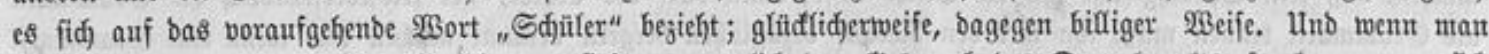

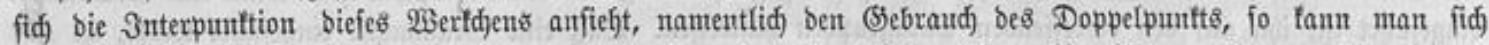

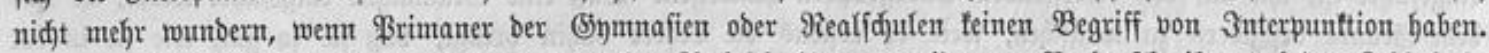

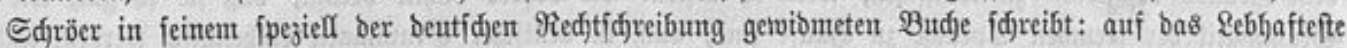
(XVII (Eint.) im Befondern, im (5roß̧en; bagegen auf bas forgfältigfte, vor allem antern; er bilbet ba\& Wort: Der 9idjtjojriftfteller.

Dod) wozu bies? Derartige Dinge Iaffen fid) bei jebem Sdjriftfteller nadjweifen unb funt oft gentug

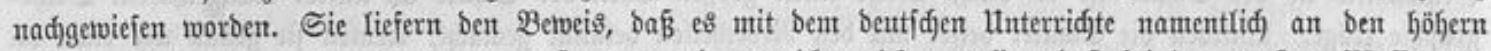

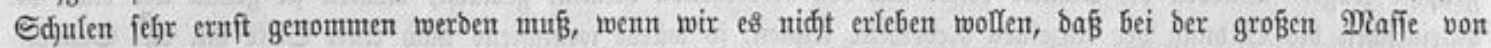

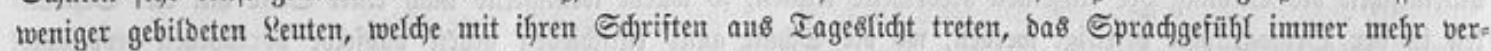

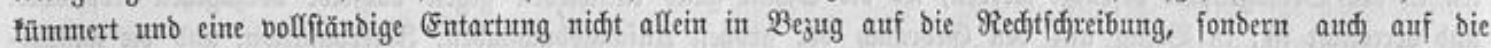

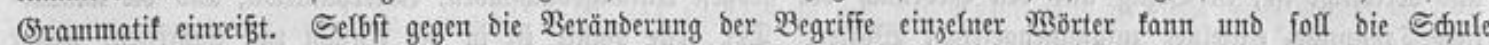

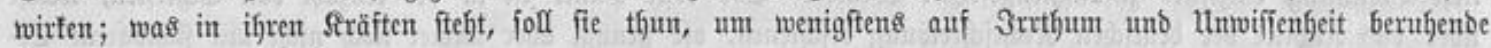
झenberungent jut verfintern.

Bei bem gropen Einfluife, ben bie Edjule in unjerer Beit bat, ift von biejem Beftreben jebenfalls

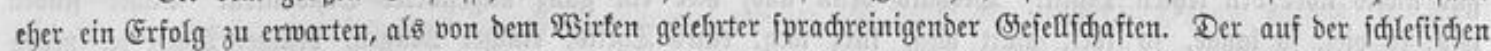

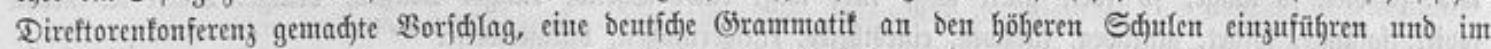

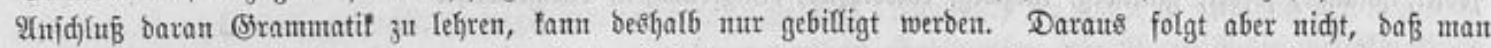
fyftematijd alle Ifyeile ber (Srammatif mit ben Sdjüfern burdjgefen müific: Die Sdjüter follen in ber Sdjule nidjt

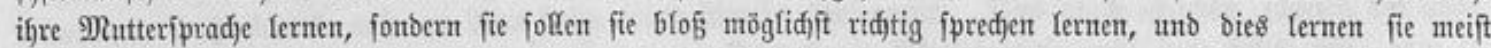

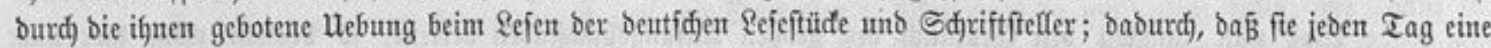

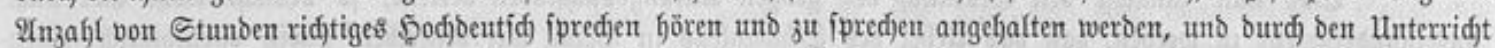

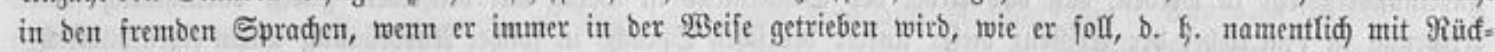
fidt auf bie Putteripradje.

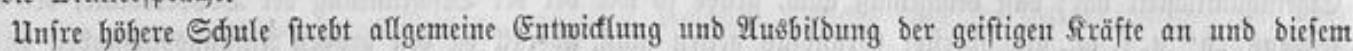
Biele arbeitet jeber Eefjer entgegen, weldjer feirten Unterridjt\&gegenftanb als Enbjwed betrađjtet. WGer einen

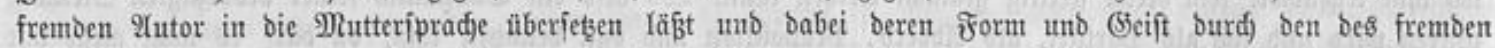

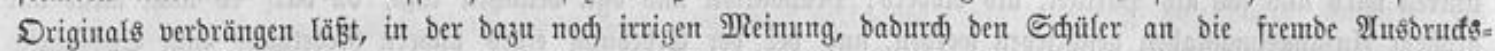

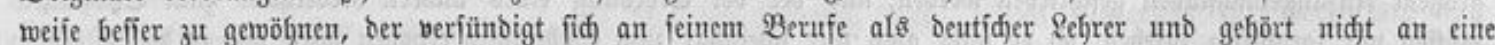

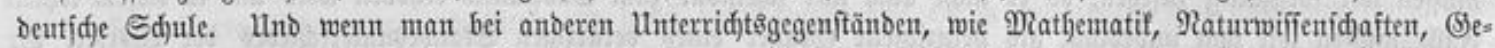

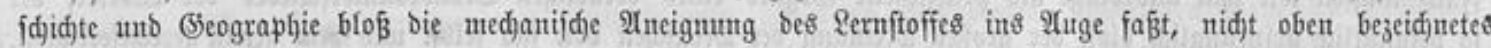

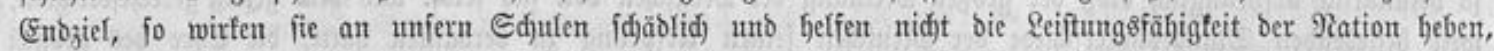

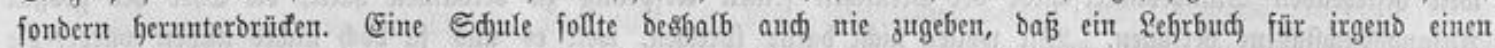

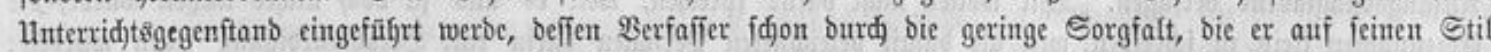

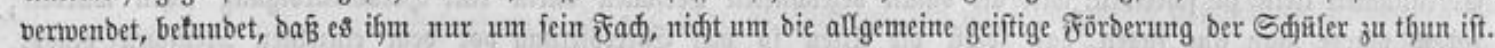

$29 \mathrm{em}$ alfo, um zu unjerm (5jegenftanbe zurüđjutefyren, bie ganze Sdjule gleidjjam ben Unterridjt in ber Mut=

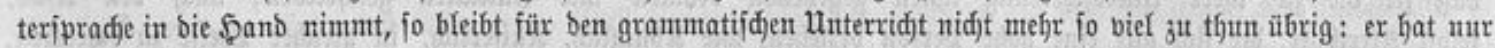

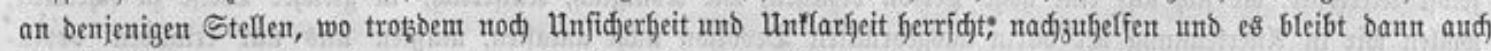
bie (Sefahr fern, weldjer ber grammatijdje Unterridjt jeine Bertreibung von ber Sdjule zu verbanten hat, baß́ er gauz frudjtiog ben Edjülern bie toftbare Beit wegnimunt, ohne fie aud) nur im geringften ju förbern. Qebrt

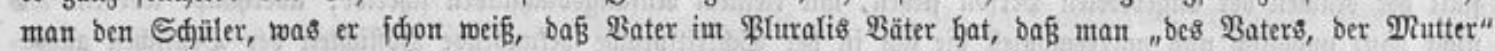

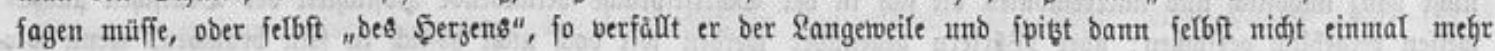




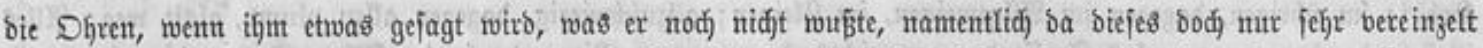

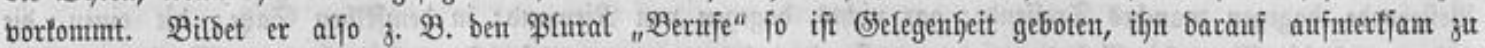

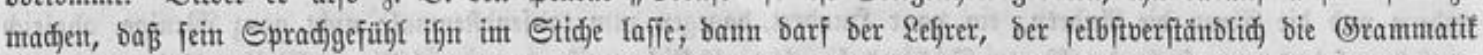

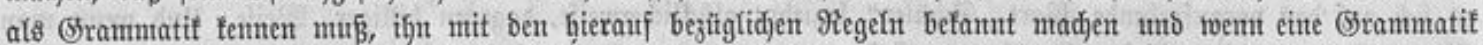

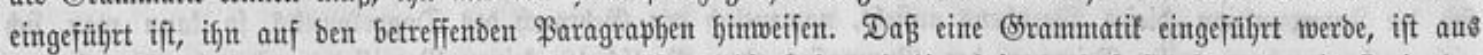

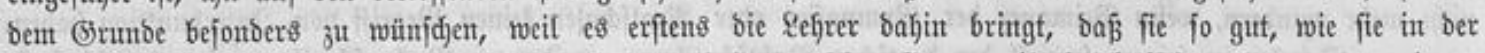

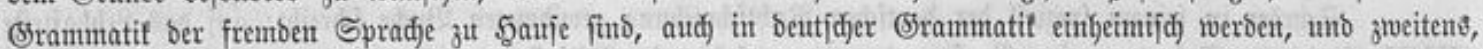

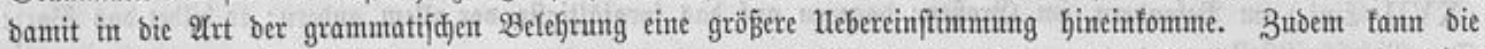

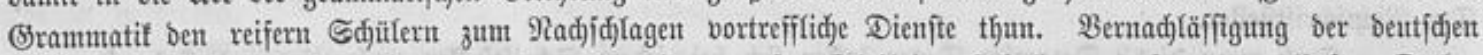
(Srammatif in ber Sdjule ift es audod, weldje cinen grofent Theil ber Sdjulb an unjrer mangelfaften Drtho=

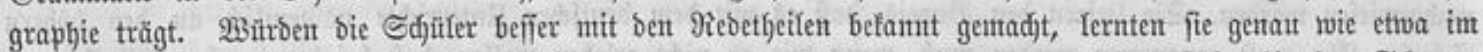

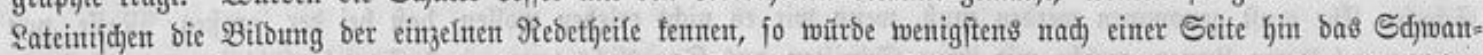
fen in ber Drthograpfie bejeitigt werben, wo bie Sdjule gantz entidjiebent gegen ba\&jelbe borzugehent verpflidjtet

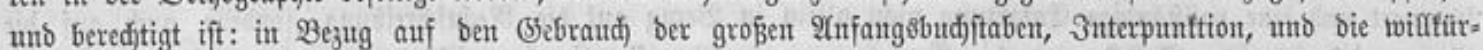

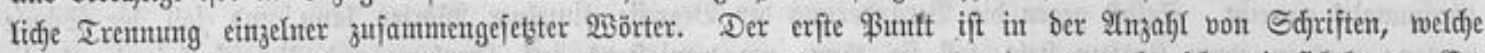

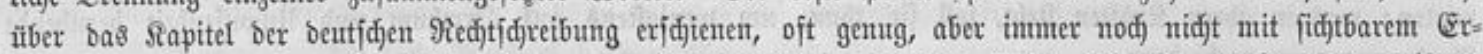
folge befprodjen worben. Daşjelbe gilt bon ber Snterpunttion; bagegen finbet fid fejgr wenig ober meiften:

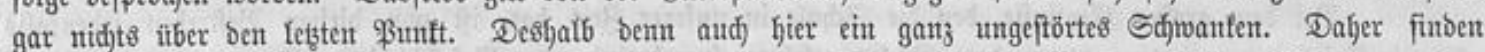

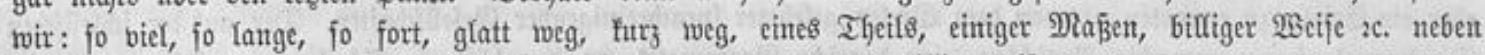
foviel, jolange, fofort, glattweg, futrjtweg, einestheils, einigerntaßent, billigertweije.

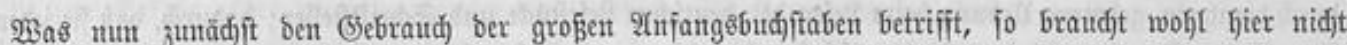

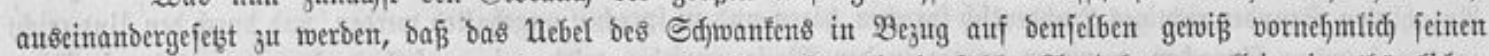

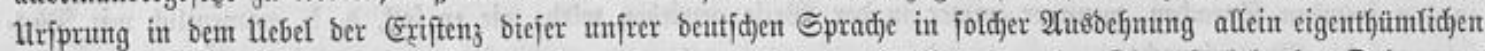

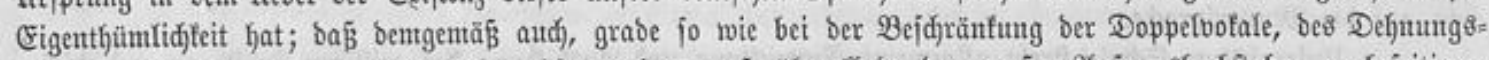

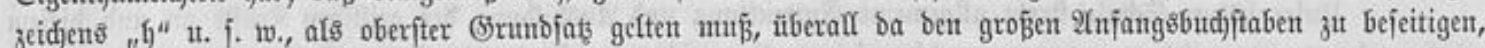

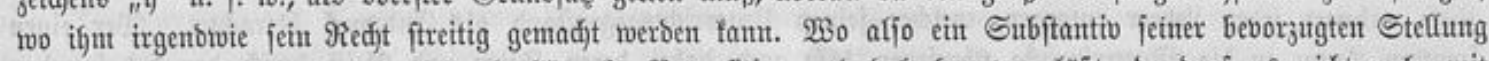

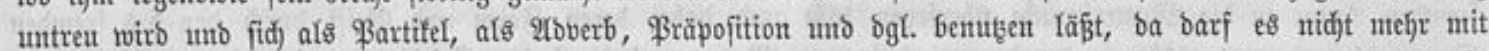

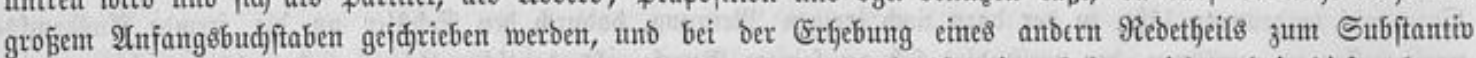

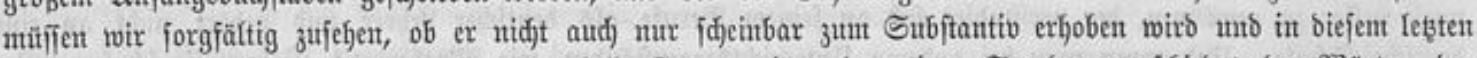

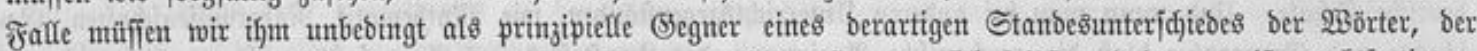

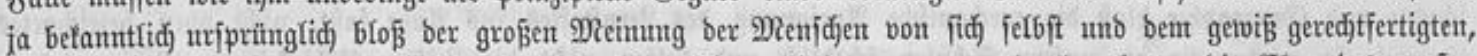

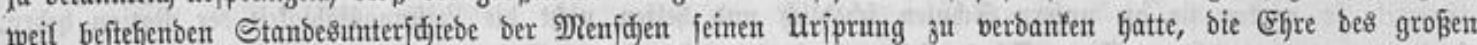

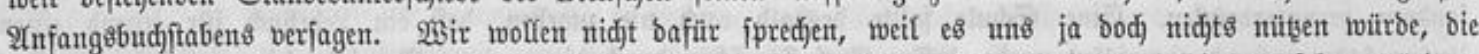

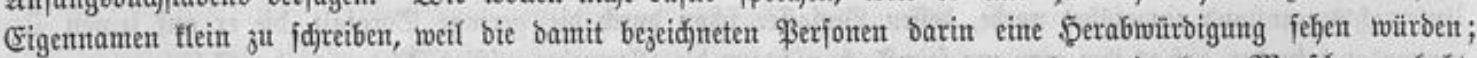

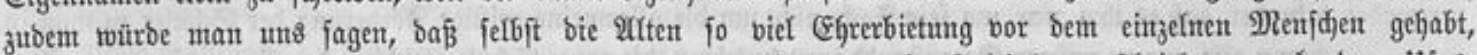

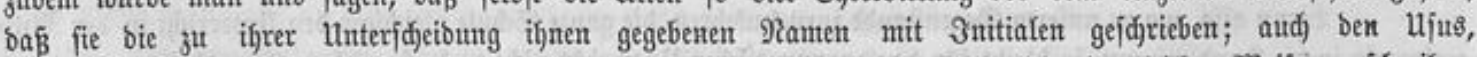

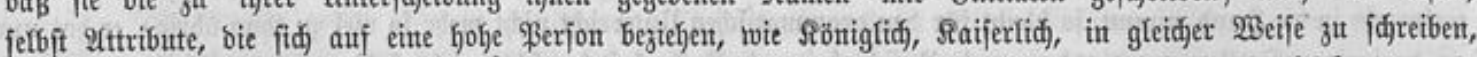

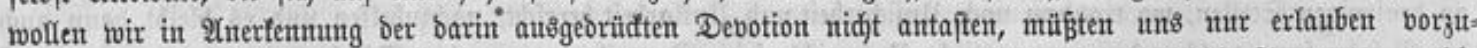

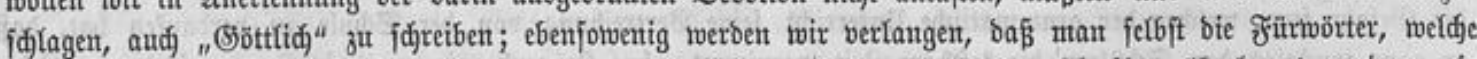

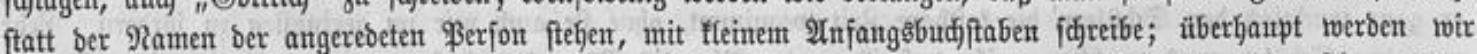

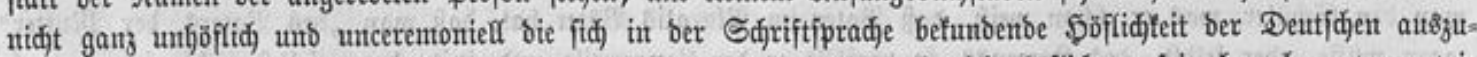

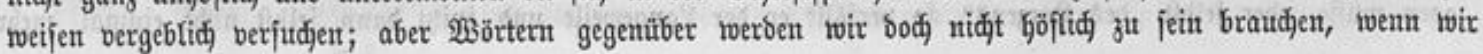




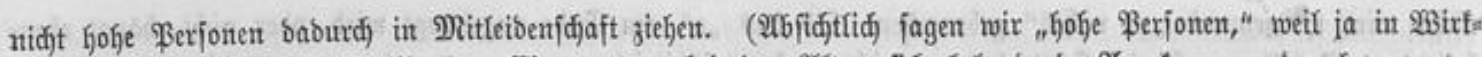

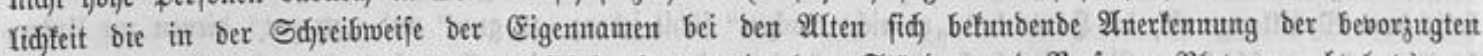

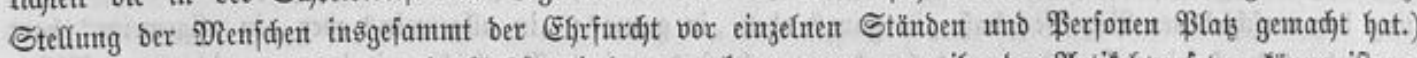

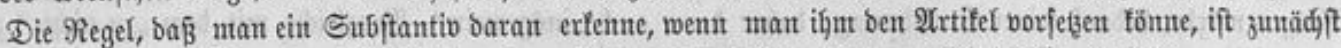

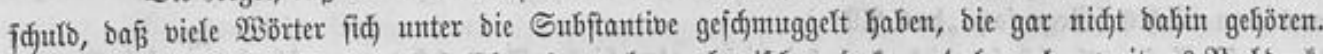

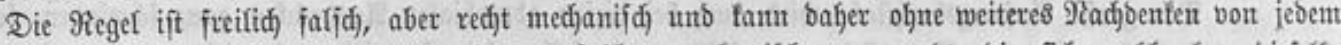

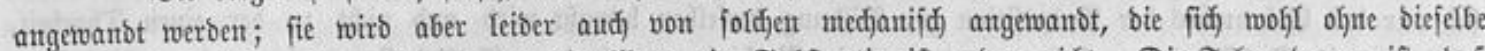

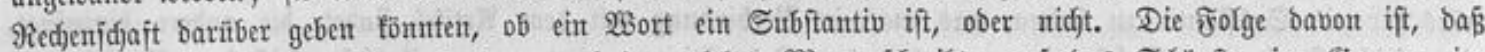

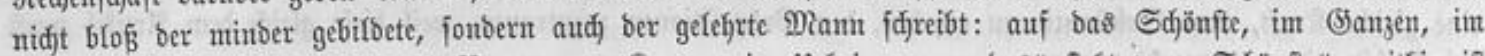

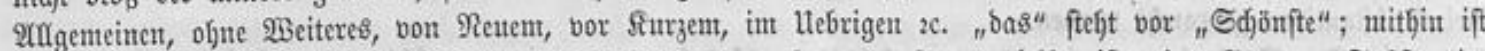
"Sdjönfte" ein Subftantiv; "im" ift aus "it bem" jujammengejest; miffjin ift "im Sanjen" Subftantiv: "Imt meiften" finbet mant mun aber baneben, fowoht went es plurimum, af: tvent es maxime entiprid)t;

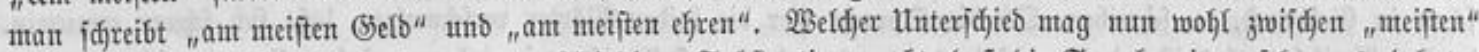

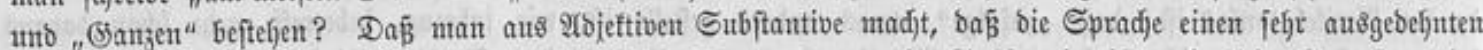

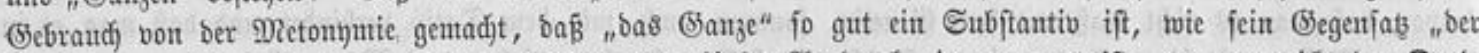

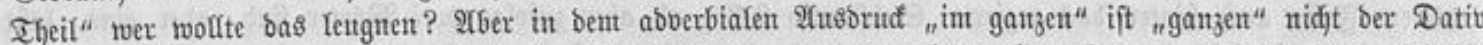

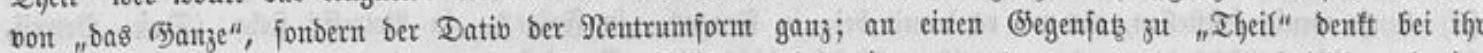

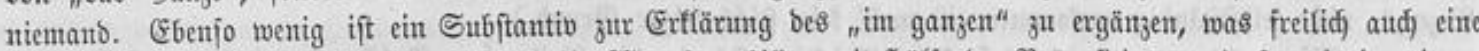

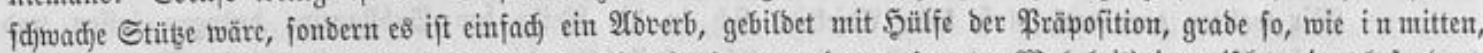

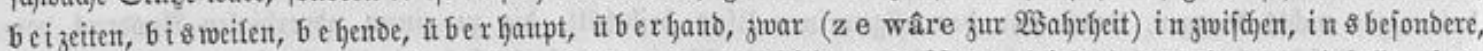

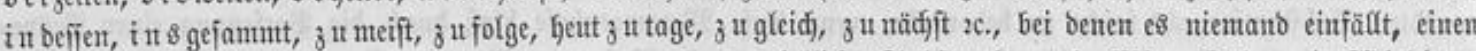

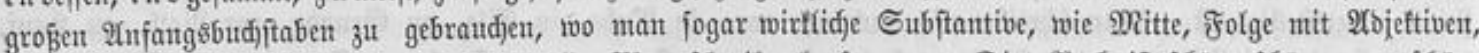

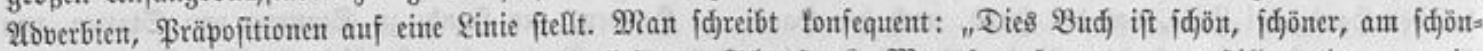
ften" ; warum follte man mun fojreiben: ex lieft an Sdjönften? Man jagt jo gut "gant ftill", wie "ganz int

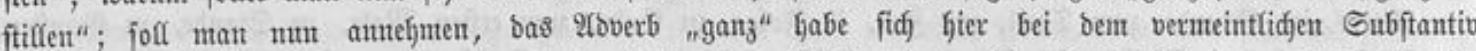

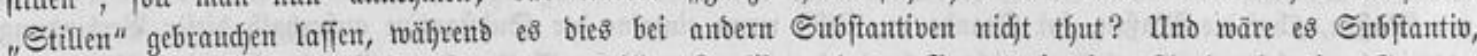

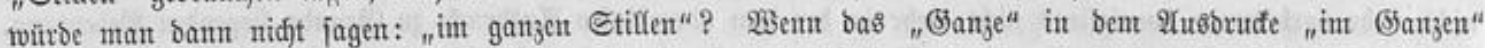
ein Subftantio toäre, würbe man aud) einent bon ifym regierten (Senetio baneben ftellen tömten, wie mant

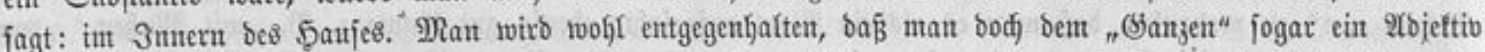
"groß́en

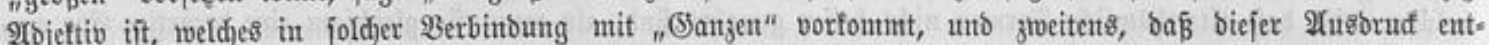

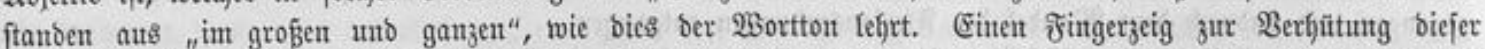

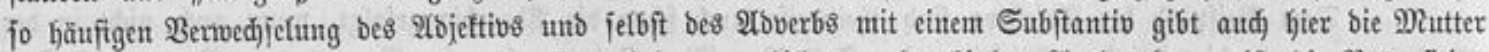

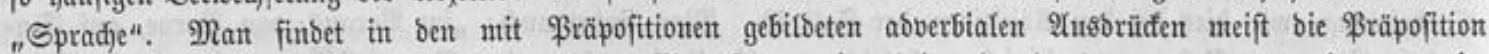

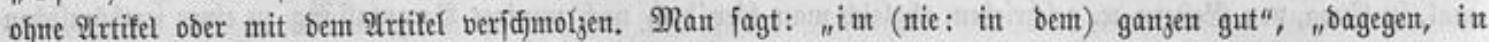

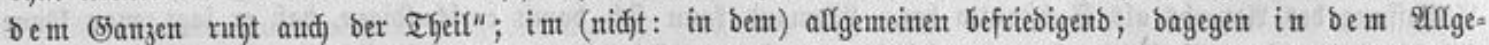
meinen ift bas sejonbere einbegriffen; intsgemein, nie in bas gemeine; in $\$$ bejonbere, nie in bas befonbere,

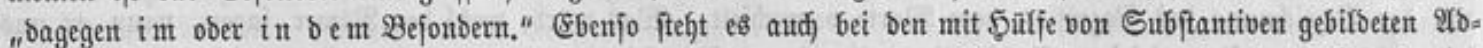

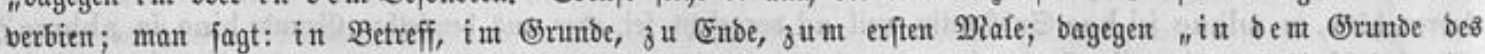

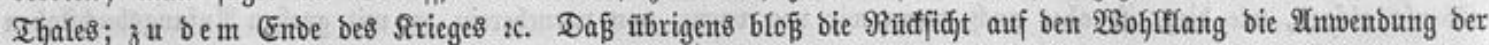

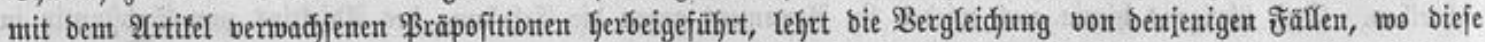

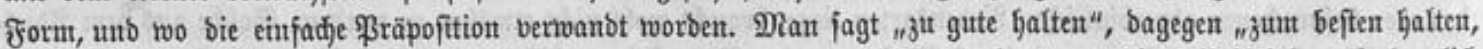

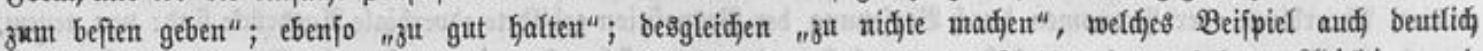

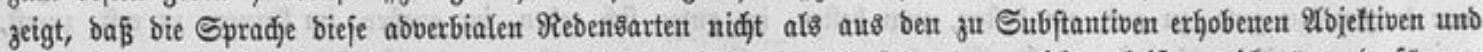

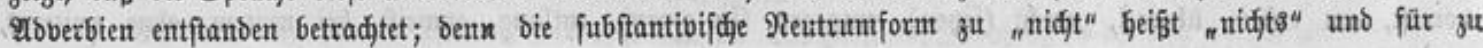




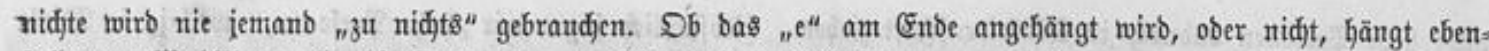

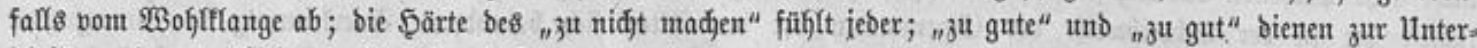
fdjeibung ber verifjiebenten Begriffc; baß̄ "in ganz" ober "in ganze" ; "in allgemein " ober "in allgemeinte Gart

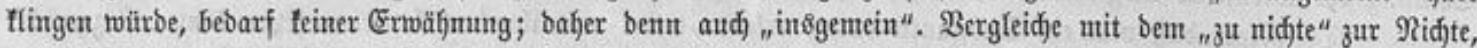

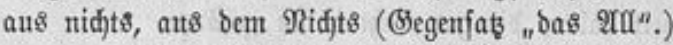

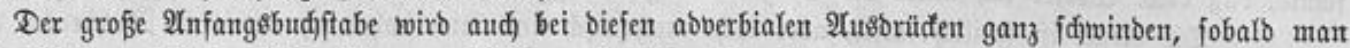

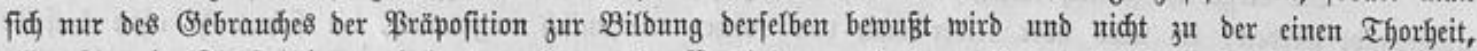
alles für ein Subftantio zu halten, was man in \$erbintung mit bem Irtifet finbet, bie anbere Gingufügt,

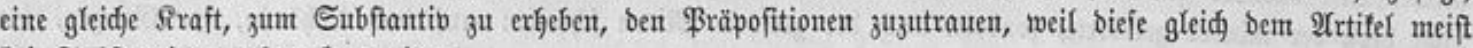
bei Subftantiven gebraudjt toerben.

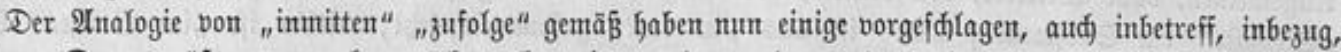

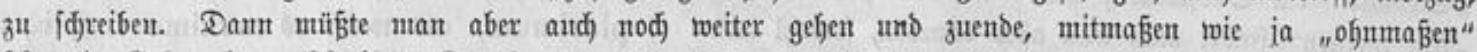

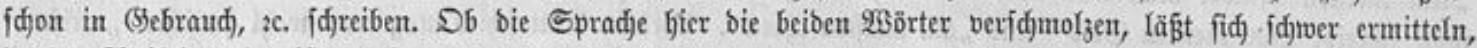

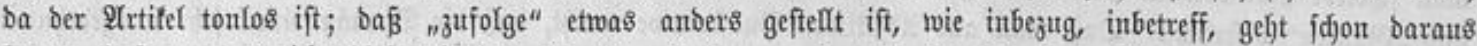

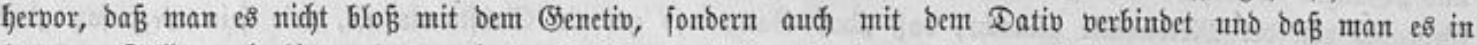

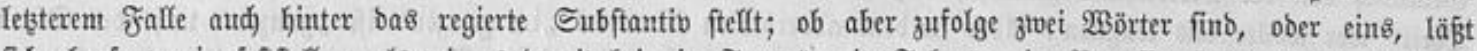
fid) ebenio wenig fetttellen, als wie e\& bantit bei "in Jrage", "in Folge", "in Betreff" ftefje. (Daß "Betreff, Bezug", niđjt felbftttänbig vorfonmen, ift twohl fein ftidjhaltiger (5rumb.)

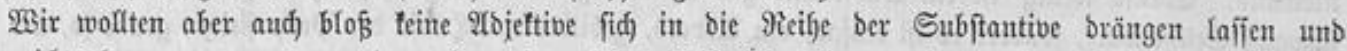

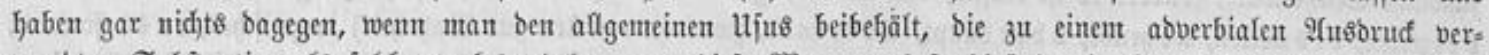

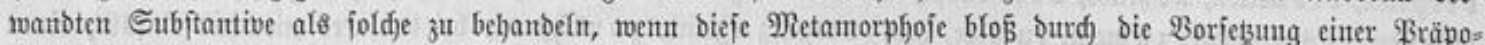

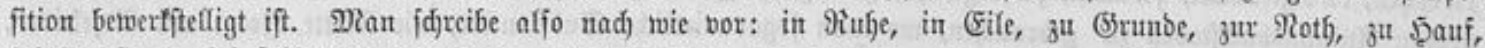

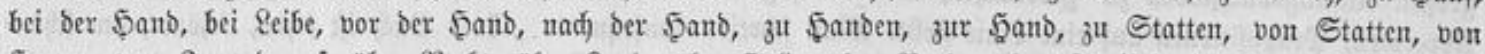

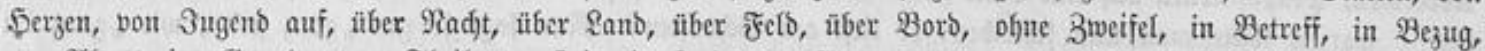

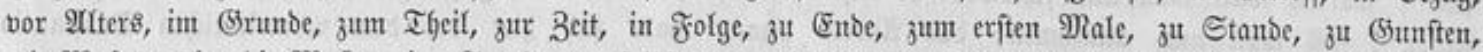

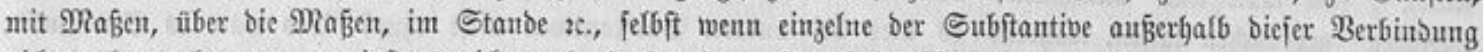

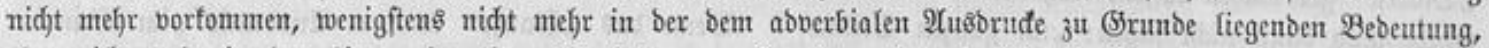

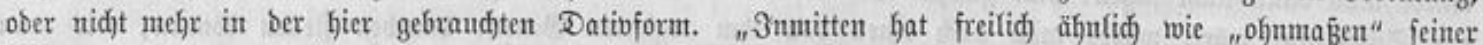

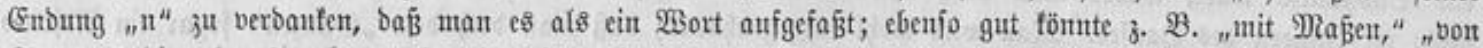

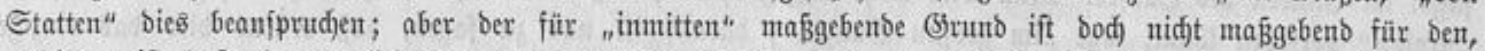

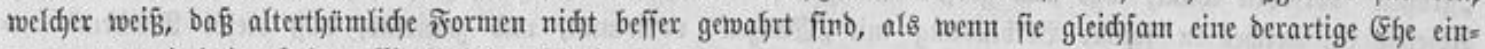
gegangen unb baburd) bem 2 santel ber Fleçionsenbungen entgangen.

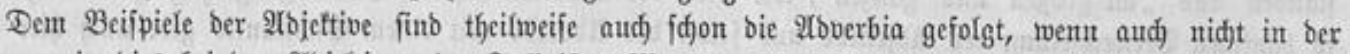

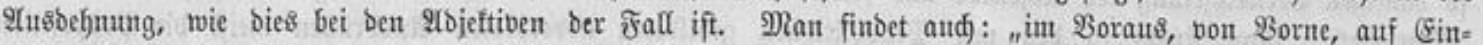

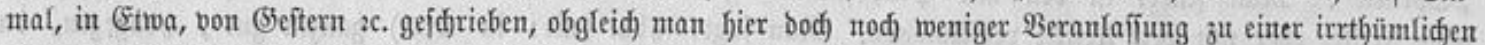

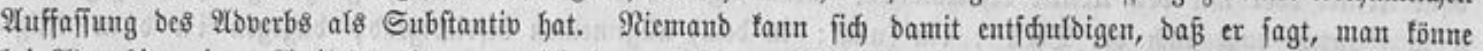

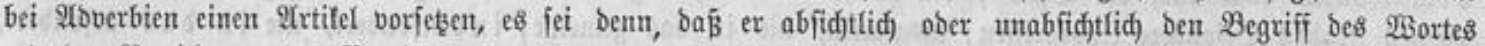

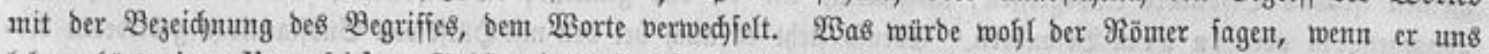

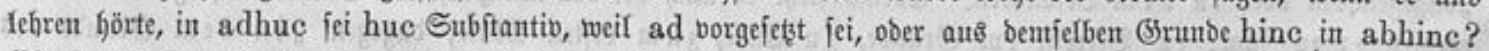
(Ebenjo abfurb, wie bies, ift aber aud), wenn wir von vorne, von vorneherein, zc. mit grobsen Anfangosbudjtaben

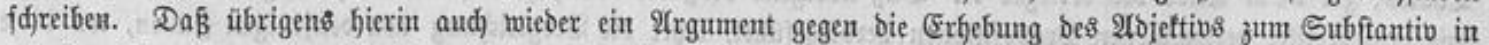

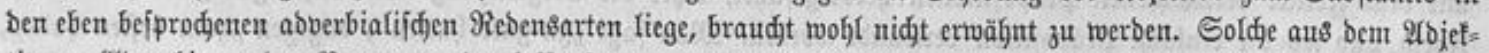

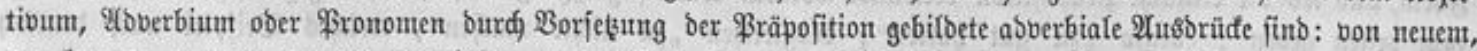
vor furzem, zu gute, ju gut, am beften, gum beften, im guten fíd geben, im großen, im fleinen, ju erft, zuerft, vorerft, aut exiten, überall, gured)t (ieţen), entgegen (in gegen), entlang, zumeift, bei weitem, ofne weiteres, 


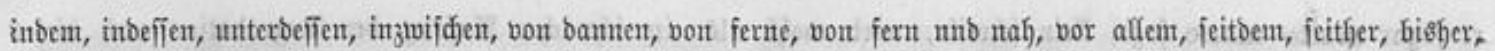
(biølang), unter anterm, ïber furz ober lang, bon weit unb breit, jutgleid), zumädjit, ins flare (bringen), int

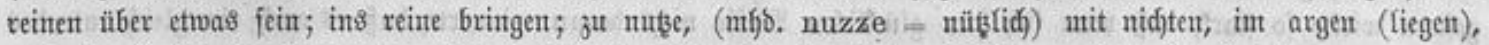
auf eimural, int einjefnen, jum guten (geftalten), bis auf weiteves, bon jelbit, ju cigen (mad)en.)

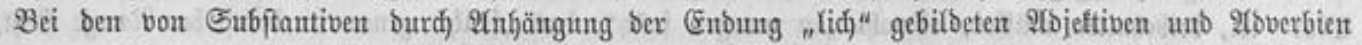

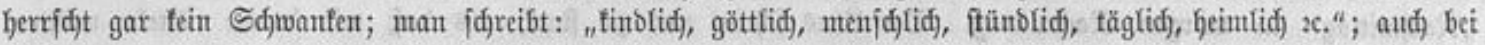

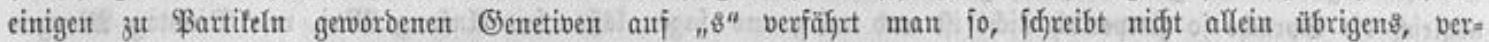
gebens, beteits, anbers, exftens sc., fonbern aud) theils, flugs, falls, zeitlebens, unterwegs, allerbings, antortweits, mittels, *) einestheils, meinerjeits, jogar trołs bes vorgejetsten 2trtitels rejp. Bronounens;

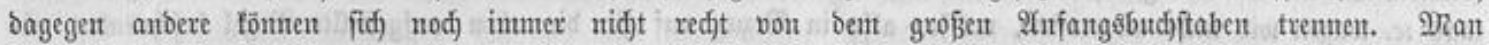

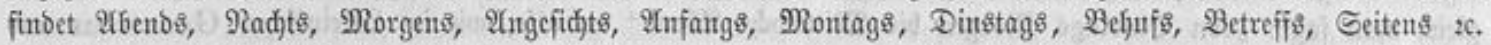

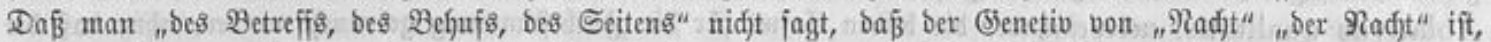

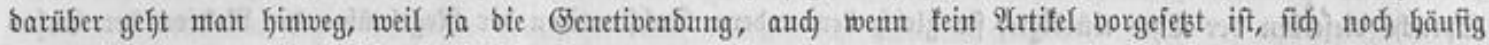

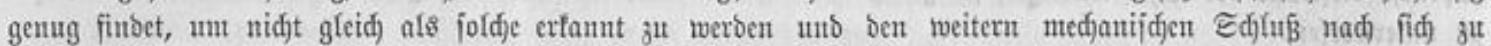

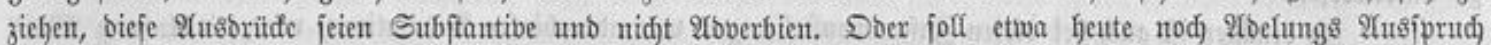

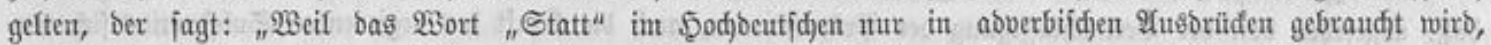

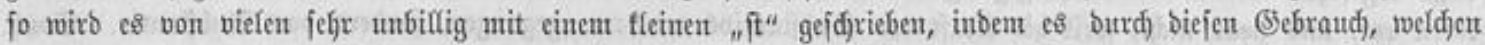

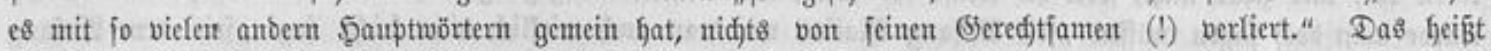

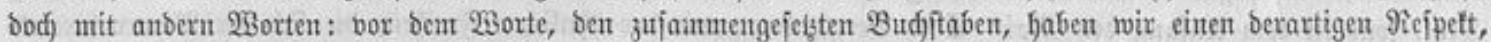

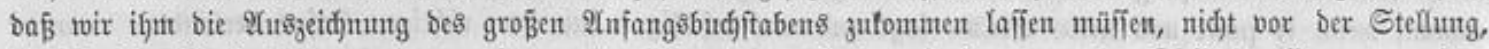
bie fein Begriff einnimunt; wir berneigen uns nidjt vor ber \$erjon, fonbern vor bem Rleibe! W3enn man beut

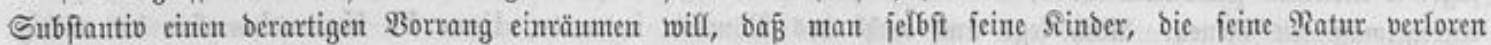

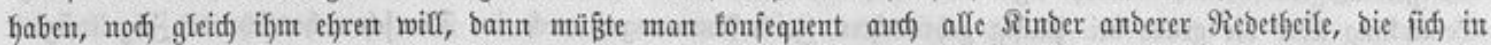

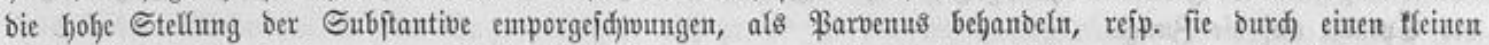
2njangsbudjitaben ftets an ifgre niebrige Serfunft erimern. Unt wie viele Wörter find cher \$artifeln gewejen, che fie Subftantive wurben?

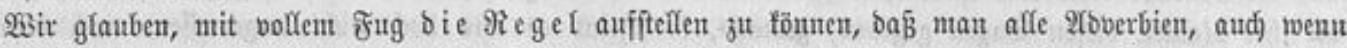

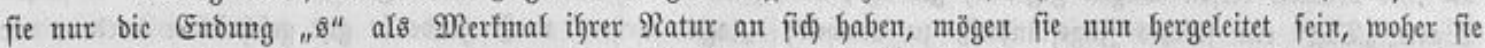
wollen, mit fleinem 2 nfangsbudjptaben jdjreibe. Die Spradje reipeftixt bie Serfunft ber von Subjtantiven abge:

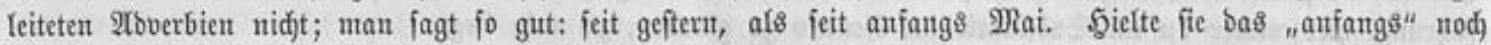
für ein Subftantiv, fo würbe fie auf feit wie in allen antern ₹rälen einen Dativ folgen Iaffen, twie fie ja aud

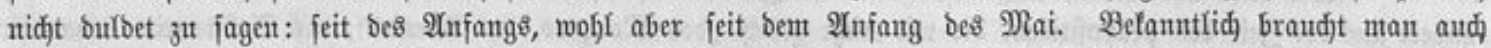

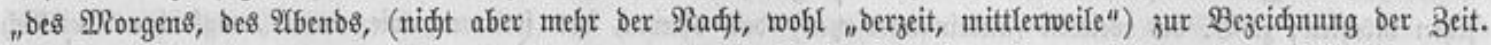

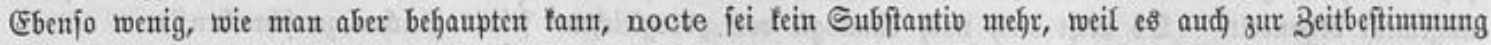

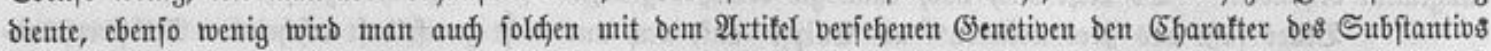

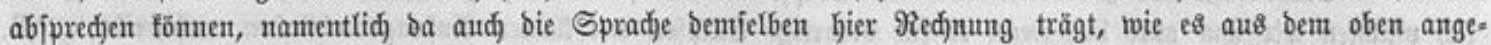

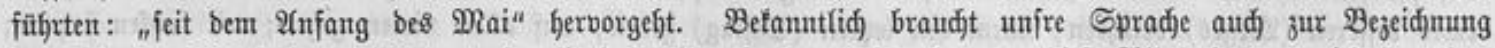
ber 3eit ben 2Affujatio gleidjbebenten mit bem Eenetio ber 3eit; ba aber bieje 2fftujatioform nidjt veraltet,

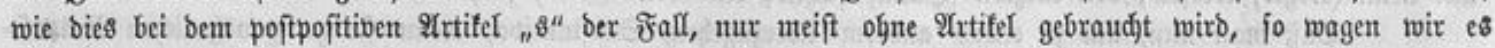

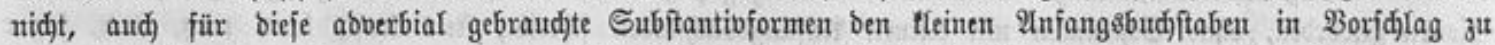

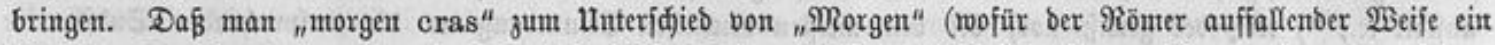

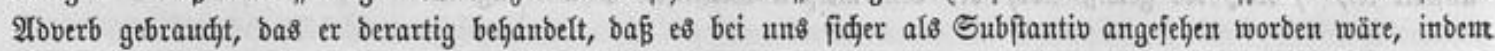

*) Daneben, unorgauifळ gebilbet, mittelfi; bagegen nur vermittelf, wabrideinlid von vermitteln. 


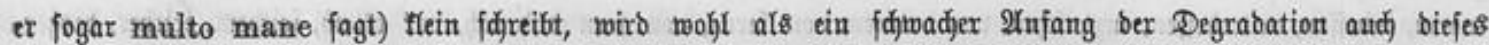

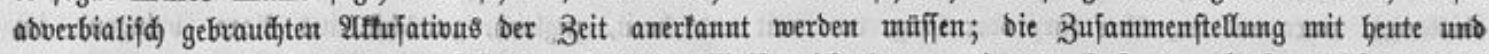

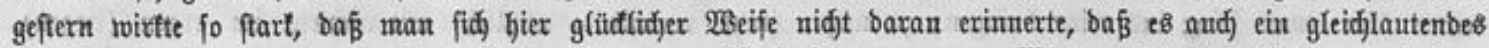

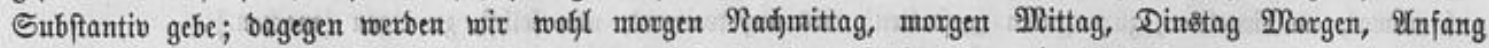

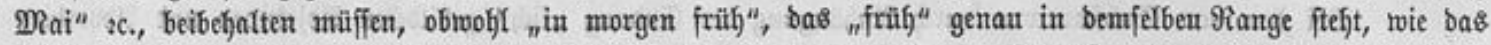

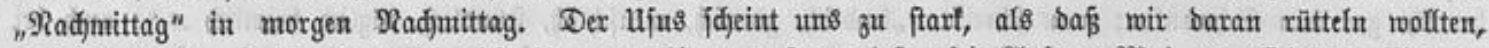

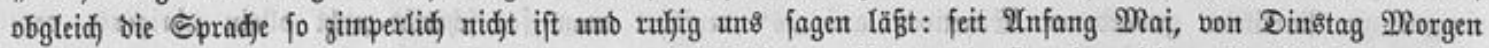
bis Montag 2tbent, two fie alfo mit feit unt von 2fftujative berbinbet, bie fie aber nidjt mefje als joldje anfieft, fonbern als inbeclinabel gleid, allen 21bverbien betradjtet unb bejanbelt. Selbft bie 2rbverbia Drontags, Dins:

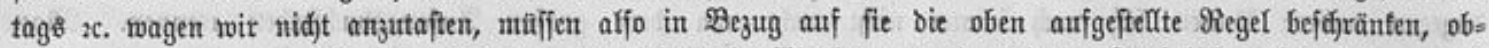

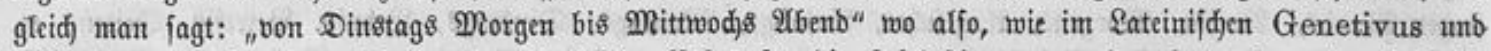
Ablativus qualitatis, nebeneinanber bie beiben (ङаjus für bie Beitbeftimmung gebraudft werbent, ohne baß̄ bie

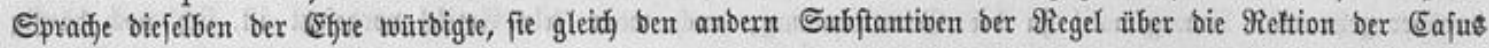
zil unterwerfen.

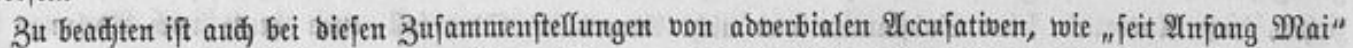

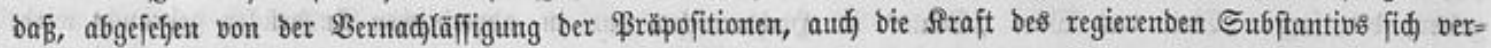
loren hat, unb jwar nidjt, weil bie Siraft bes Sutbftantibs berloren gegangen, fonbern bas Subftantiv. Sonft

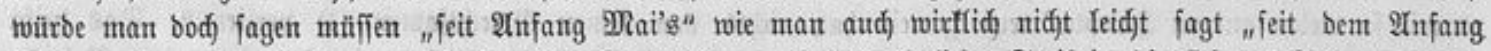

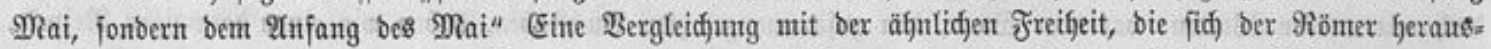
nimmt, menn er post unb ante triduo fagt unb nur jufallig a mit bent ridjtigen Sajus berbinbet, wenn er jagt: a milibus passuum octo, fant woh)l zur (Exflärung ber hier bei ber beutijjen Spradje fid jeigenben

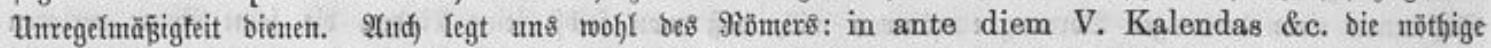
Benterfung über bie grabe bei bäufig gebraudjten Beitbeftimumungen aud im Deutjdjen Gerrjdjenbe Bügelfofigfeit ber Spradje auf bie Bunge.

Went wir nun alfo auț bieje Xfftufative ber Beit vorläufig nod) utangefodjten laffen, fogar in Bezutg

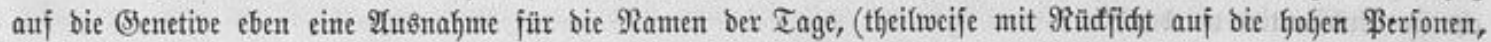

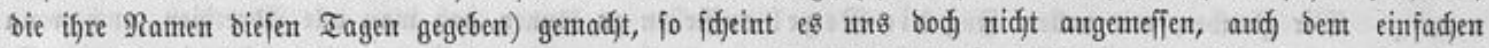

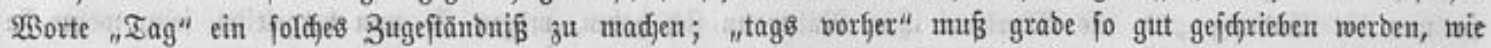

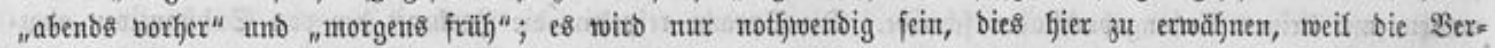
füfrrung, fier twieber an ein Subftantio im Senetio zu glauben, ju nafje fiegt.

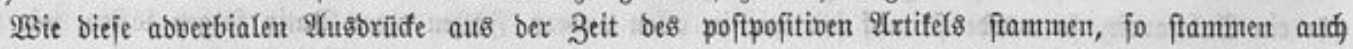
anbere auts ber Beit bes präpofitiven, bie wir nidjt gleid, "Des Mlorgens, bes 24bents", als Subftantive behanbelt

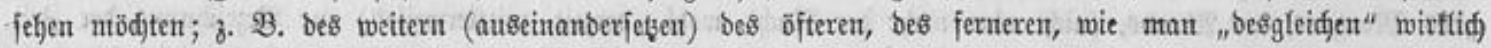
allgemein befjandelt. (Db niffjt aud) nad) Rnalogie von "besgleidjen" feines gleidjen zu fidjreibent)

Beđer faß̧t bas "bes weiteren" als Eflipje auf, was uns redjt zweifelfhajt eridjeint. Selfftwerftäno.

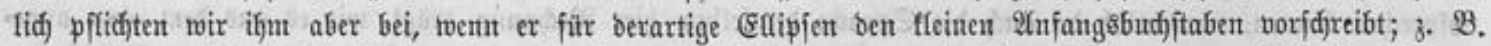
eines befleren (W̉eges) betefren; einem ben Yeşten (Ed)lag) geben; auf allen vieren gehen; mit fedjien fahren;

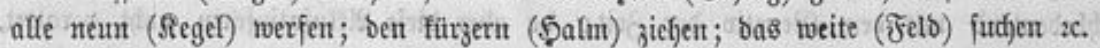

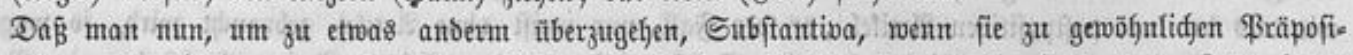

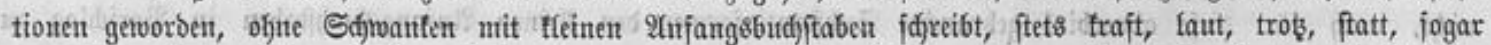
anftatt *c., *) troş ber genißß nod bei ben meiften beutlidjen Erinnerung an bie entipredjenben Subjtantive

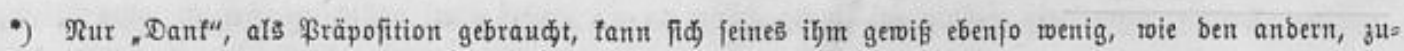
Pommenben groben ofnfaitgsbudprabens bei vieten nod nidgt enttleiben. 


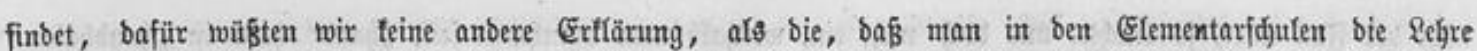

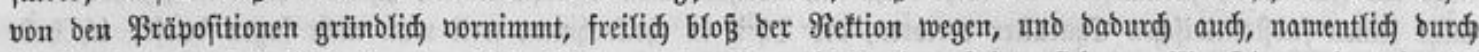
bie Berbregeln, bas 21nbenten an biefe Wörter für alfe nadjfolgenten Beiten fidjert. Ein Fingerzeig, wie vieł Nuţen wir überhaupt bon cinem grïnblidern Betreiben ber bentifjen Erammatil ju erwarten haben.

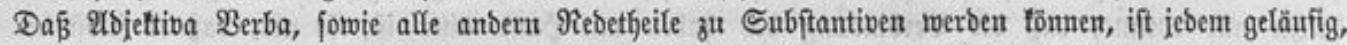

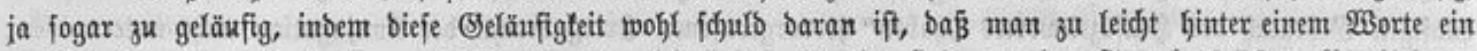

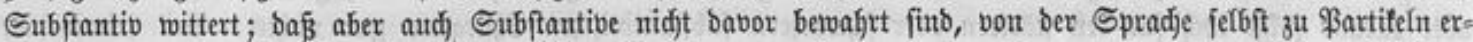

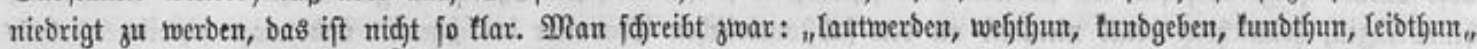

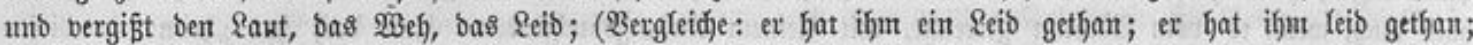
er hat ifgm fein Reib gethan; er hat ifgm nidyt leib gethan. Weldjes Reib hat er ifym gethan? wie hat er ifym

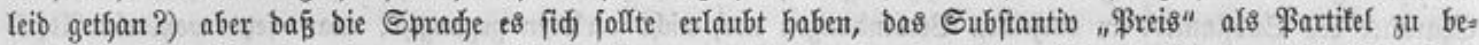

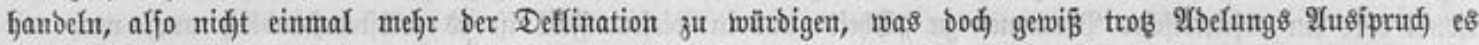

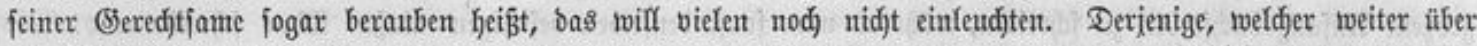

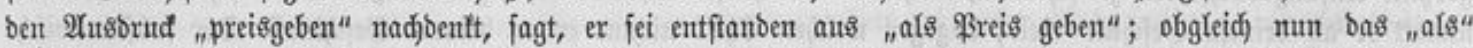
im Eaufe ber Beit weggefallen, bleibe bođ "\$reis" inmer ein Subftantib. Dentt bie Sprađje aber aud) jo?

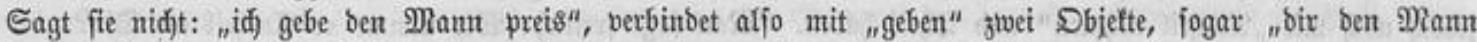
preig" alfo fogar brei Dbjefte. Nut fudje eimmal einer eine ähnlidje Berbinbung, umb wir wollen gern bem "preis̆" feine Egyre twiebergeben, bie wir ifynt vorläufig unbebingt abzufpredjen uns genöthigt fefjen. (Es - wiro

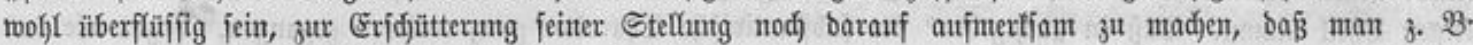

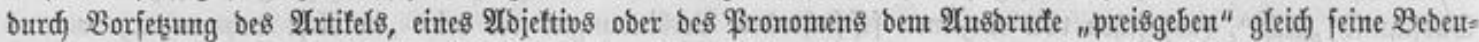

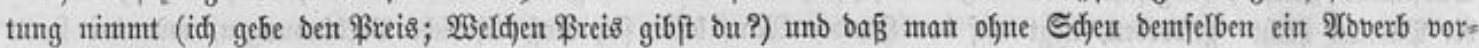

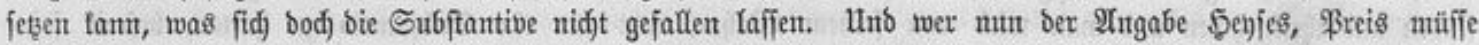

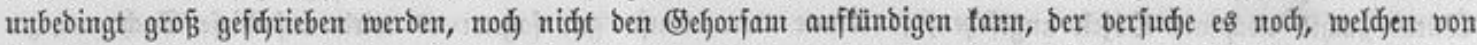

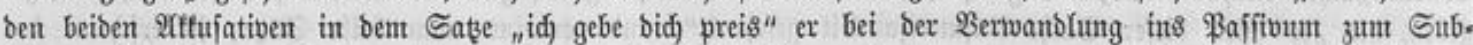

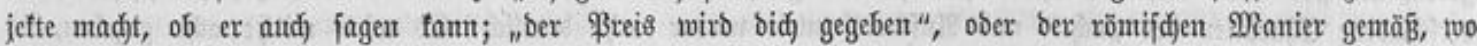

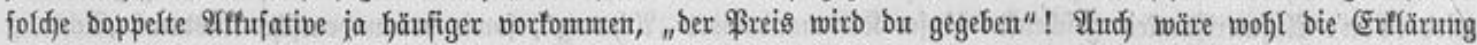

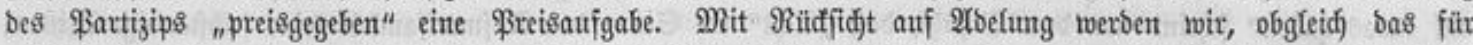

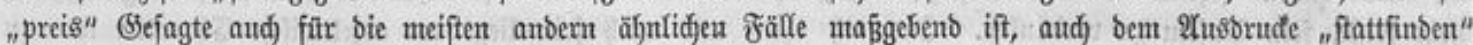

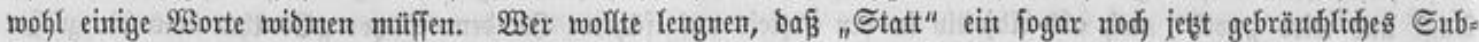

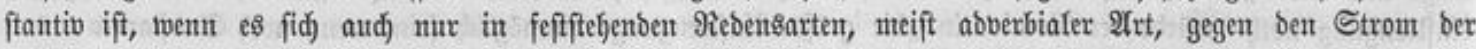

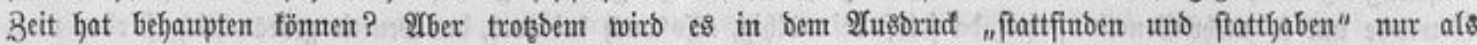

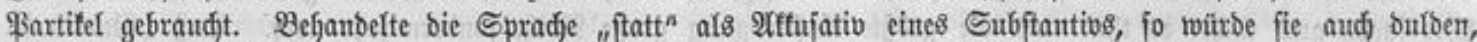

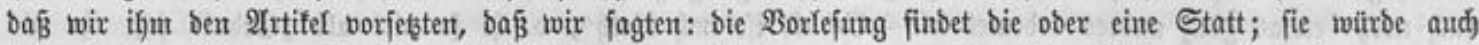
jagen Iaffen: Bon ber Borlejung ift (eine) Statt gefunben worben. Utm Bertvedjefumgen vorzubeugen, wirb

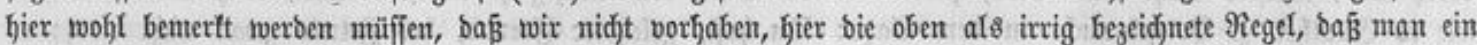

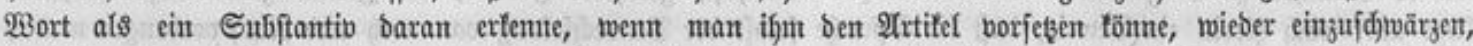
weil fie unjerem 3tweđen bient; in obigem Beijpiele liegt mur ausgefprodjen, baß twir allen benjenigen Wörtern

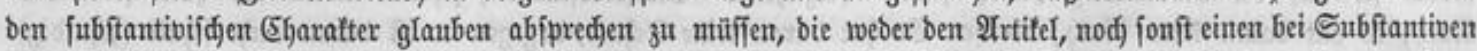
gebränd)lidjen Bufał̧ vor fid bulben, twenn fie irgenb eine Berbinbung mit einent Berbum ober cinem anbern

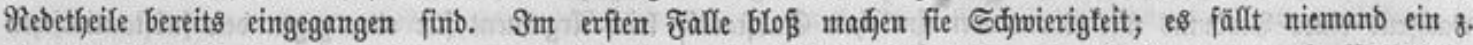

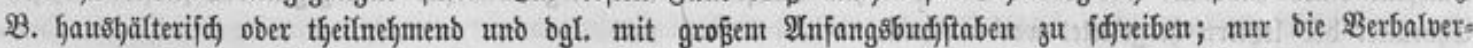

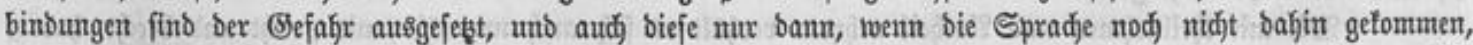
bie Berbintung mit bem \$artifel gemoroenen Subftantib feft zu madjen. (E\$ gibt fogar Erammatifen, weldje

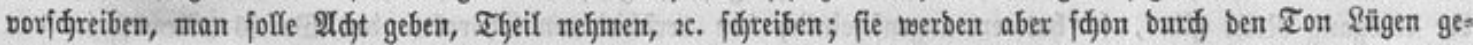
fraft, on adjt unb theil ben 5aupt= unb geben refp. refjmen blobs ben Niebenton faben. Ulno wenn bas felbft 


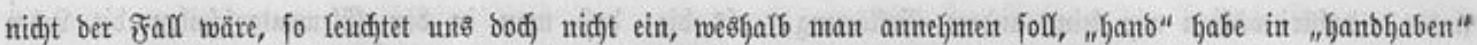
mefjt feitten fubftantivifjen (5haralter berloren, als Theil in theifnefgmen, weil man nidjt jagen bürfe: idj habe Şant, wohl aber "id nehme Theil". Man jagt grabe jo gut: twie hanbfabt utan biefe Gadje, als: häft ir

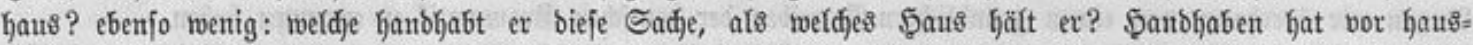

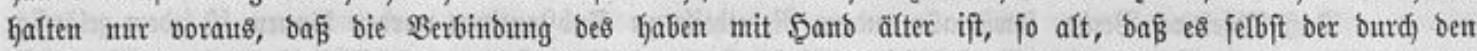

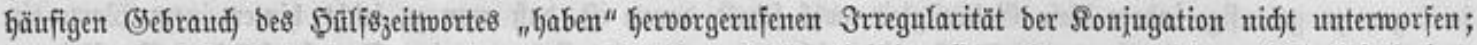

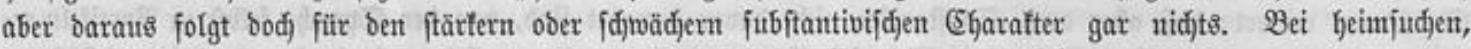

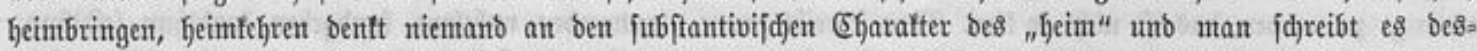

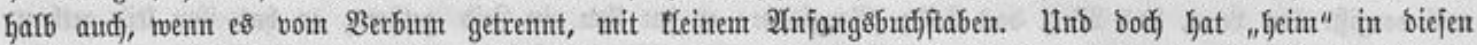
Berbintbungent bie Bebentung bes Yateinifden "domum nad) ছautje." Was theilnehmen betrifit, fo ift ber

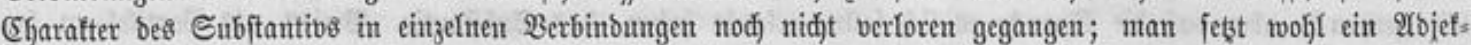

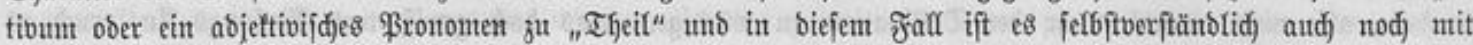

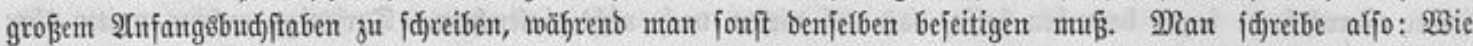
nimunt er an beinem Bejdjife theil; bagegen weldjen Theil nimut er an beinent Şejđjide? Der jubjtantivijide

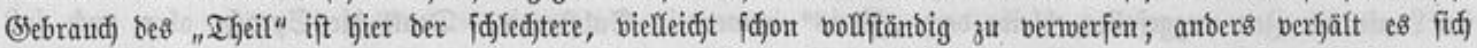

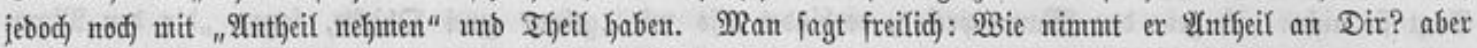

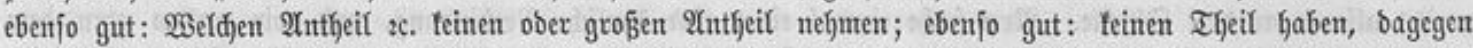

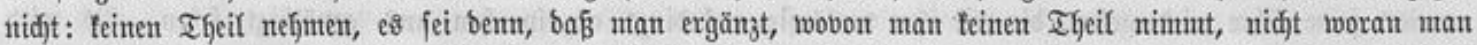

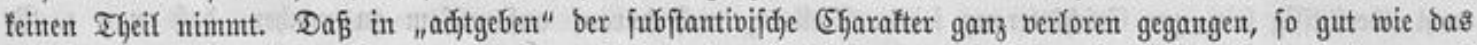

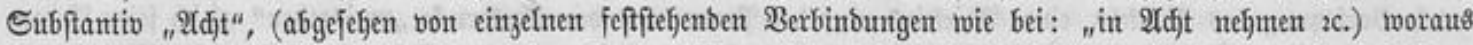

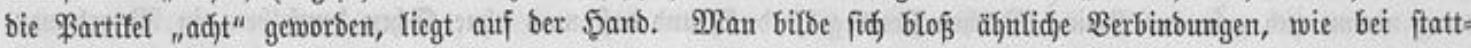

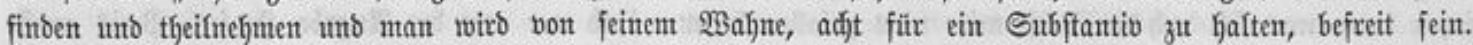
Würbe "acht ${ }^{a}$ nodj als Dbjeft angejehen, fo fömute man ebenjo gut jagen: es wiro auf bieje Sadje adjtges

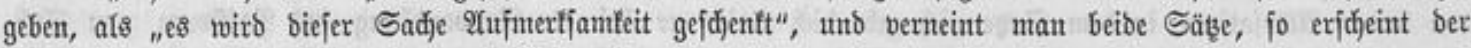

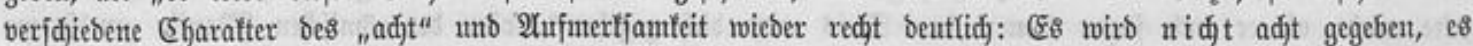

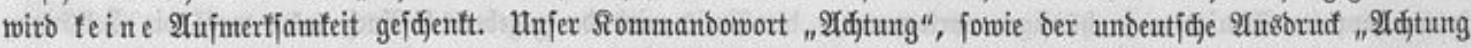

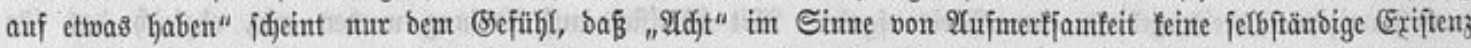
mechr frifte, fein Dajein ju verbanfen. Sn noth thun uno noth fein liegt ber abjeftivijdje (5harafter flar ju

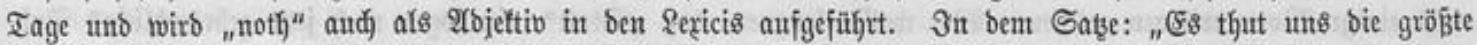

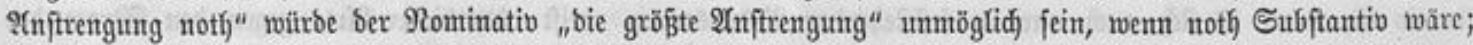

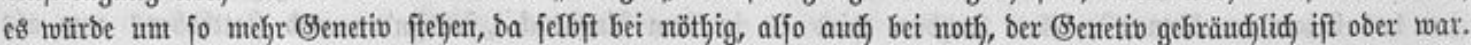

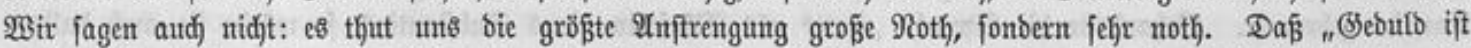

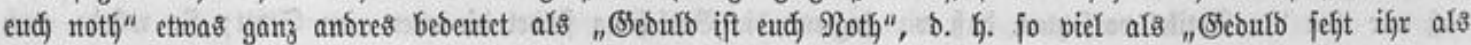

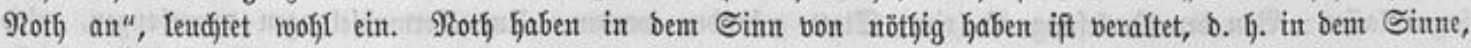

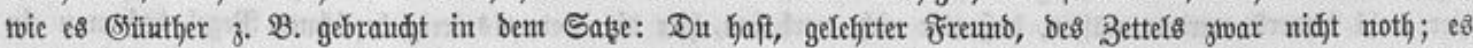

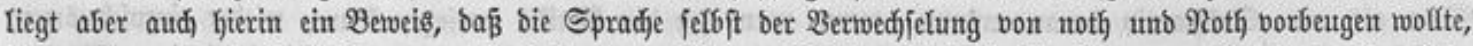

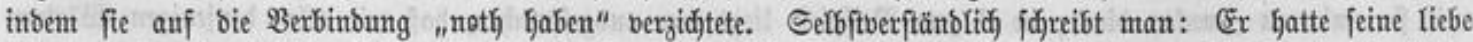

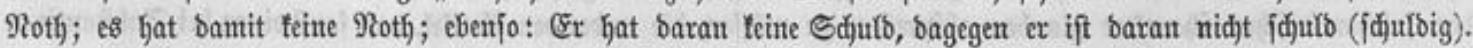

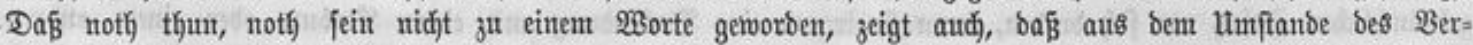

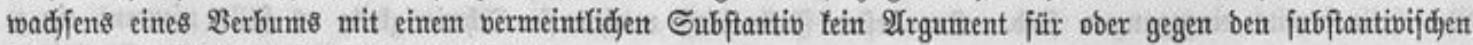
(5) Garatter bes leķtern hergeleitet werben fann.

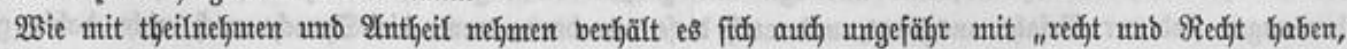

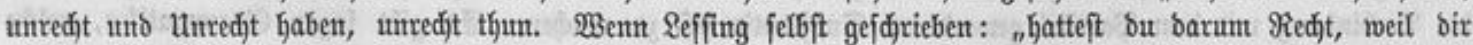

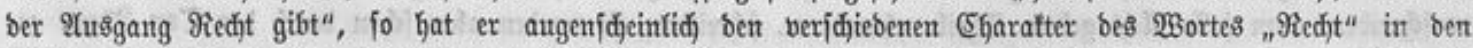

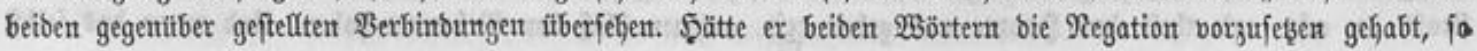


wărbe er auf jeinen 3rrthum aufmerfiam geworben fein. Sber würbe er etwa nidjt gefdjrieben haben: hatteft

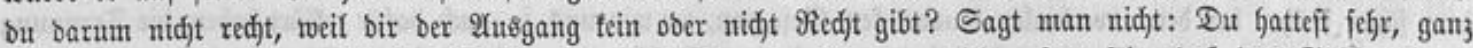
redtt? Unb bodj foll "redjt" ftets Subftantio fein? Siermit foll mun nidjt gejagt fein, baj bas Subjtantivum

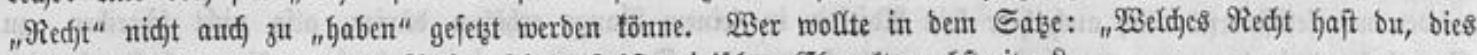

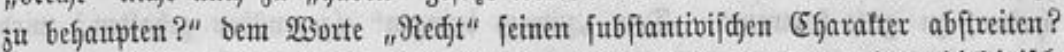

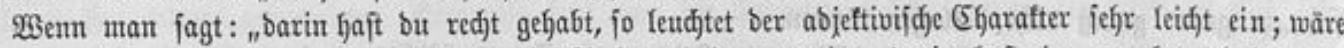

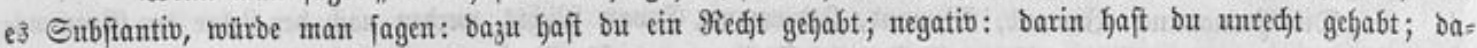
gegen, bazu faft bu fein Redjt gefjabt.

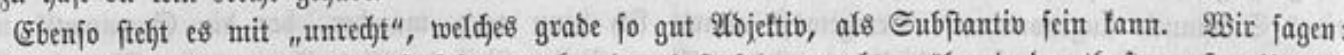

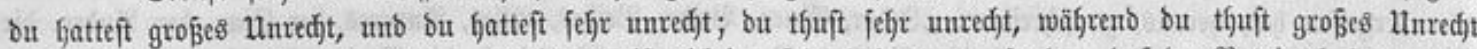

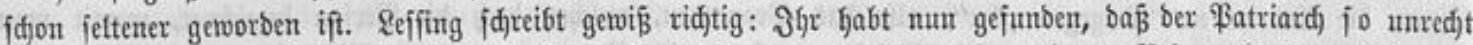

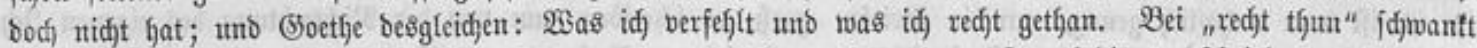

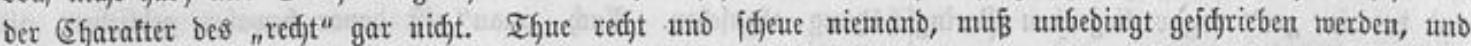

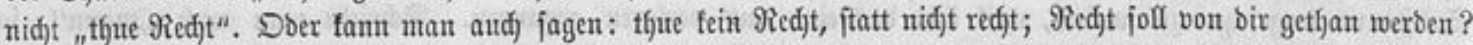

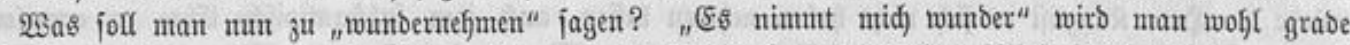
fo gut fdjreiben mü|jen, wie "er gibt bid) preis", weil ber (5ebraud) bes boppelten Ifftufatios bei nefjmen ebenjo

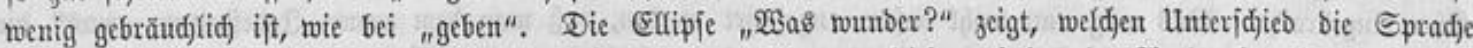

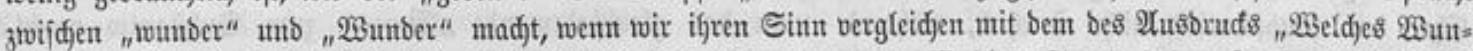

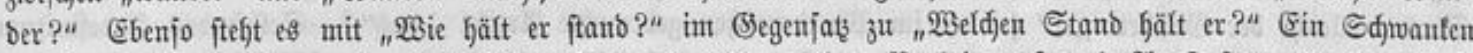

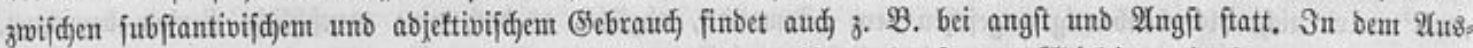

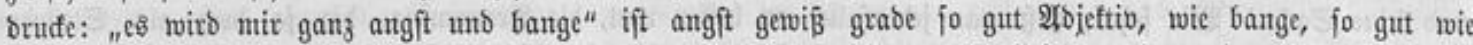

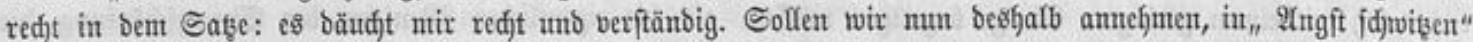

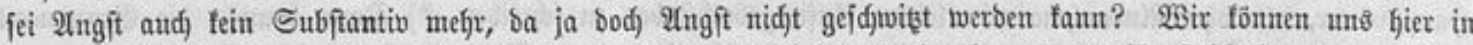

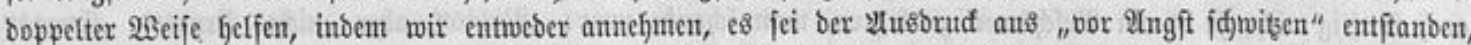

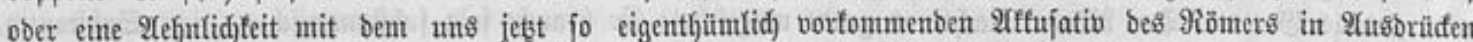
wie olere hircum unb bgl. barin entbecten. Int "freunb unb feint fein" ift bas "freumb unb feint" fidjer

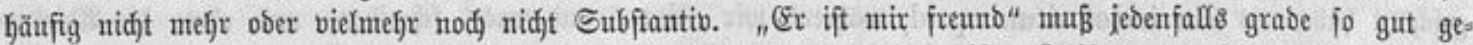

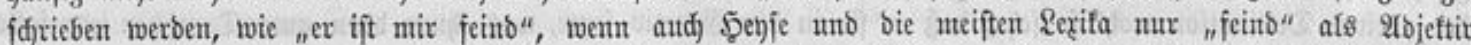

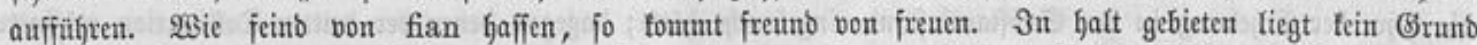

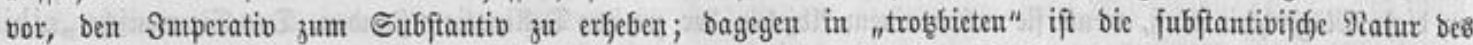
"Iroţ" nod) nidjt berloren gegangen uno man wirb besffalb audj nidjt fdjreiben bürfen: er bietet mir tros.

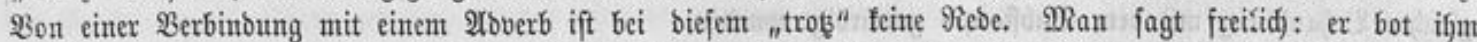

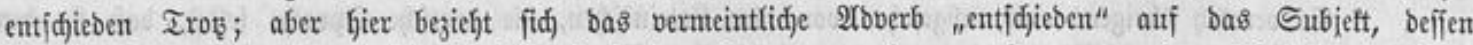

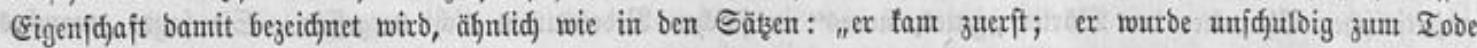
verurtbeilt".

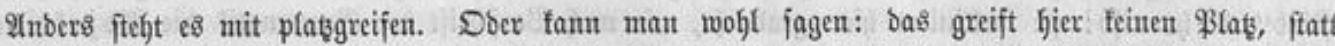

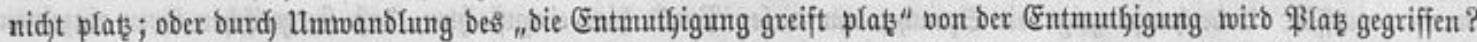

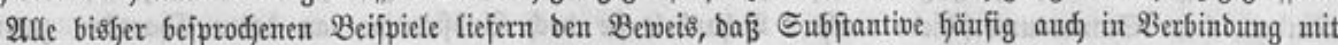

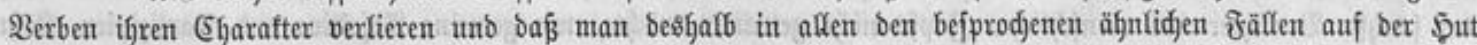

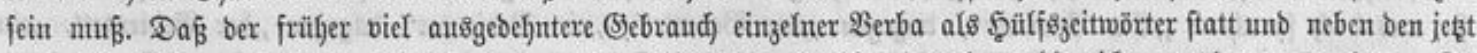

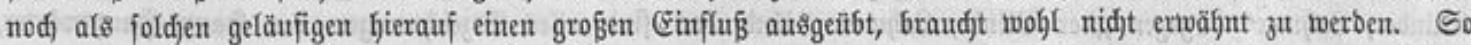
gut wie in perdo unb pereo, pessumdo unb pessumeo, veneo unb vendo, venumdo unt venumeo unb bem

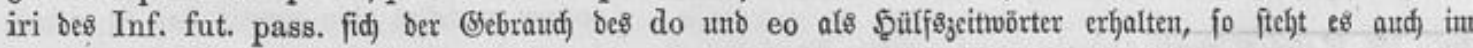

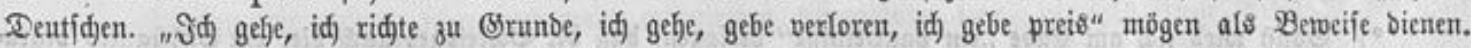
Man wiro vielleidjt fragent, ob bie Sconjequenj es nidjt exheijdje, neben adjtgeben "aud inadjt: 


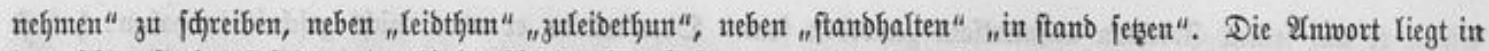

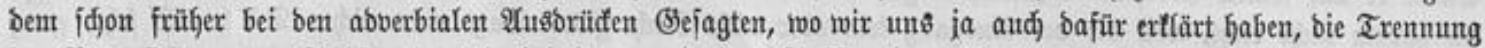
Der \$räpofition vom Subftantio beizubehalten, umb bas Subftantio aud bei feinter (Egre zu laffen. Dagegent

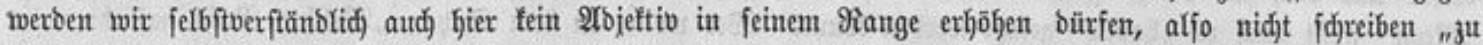

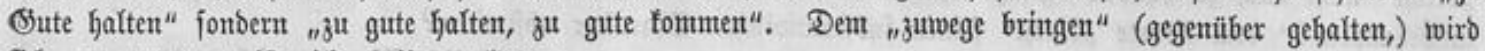

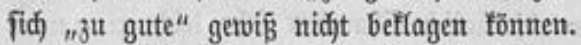

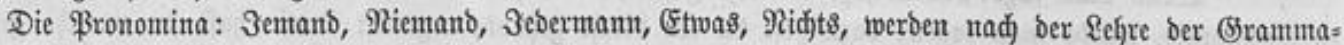
tif grō gejdjrieben; ber Srumb ift, weil fie als Stellvertreter für \$erjonentamen ftehen ober bie Bebeutung

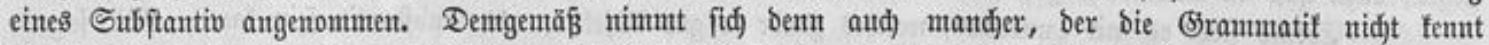

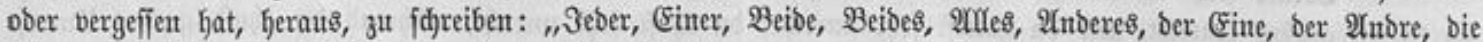

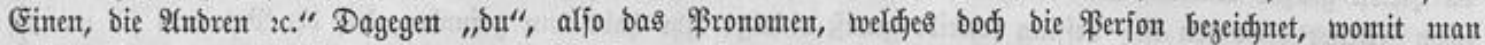

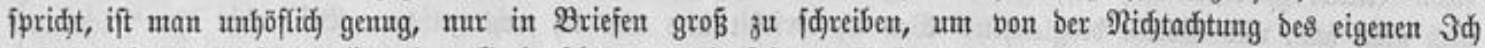

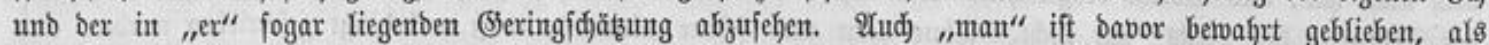
Subjtantiv angejehen ju werben, weil ifm bas eire " $\mathrm{n}^{\prime \prime}$ verloren gegangen. Sdjriebe man nod) "ntann", jo

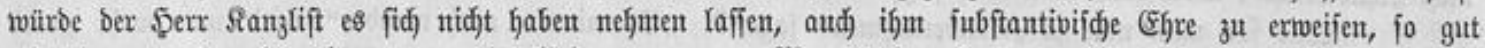

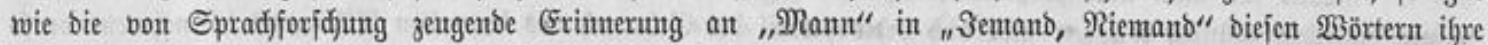

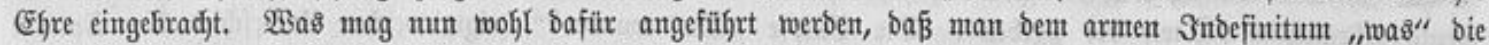

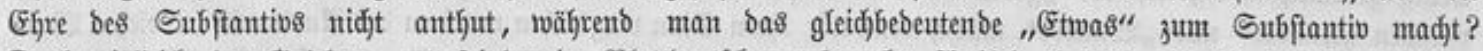

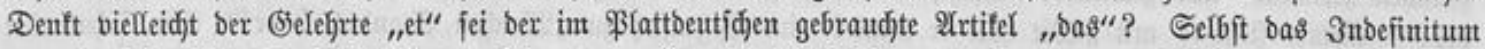

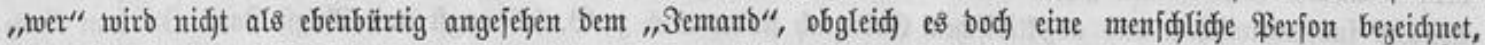
unto feine Sadje. Wir jehen, baß́ man jebenfalls am beften thut, bie ßronomina, bie ja bod) als Stellver=

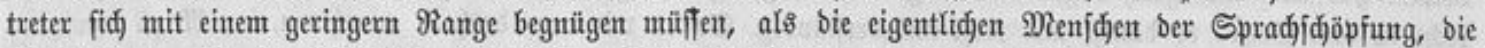

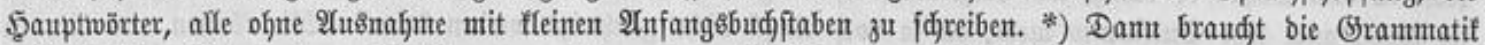

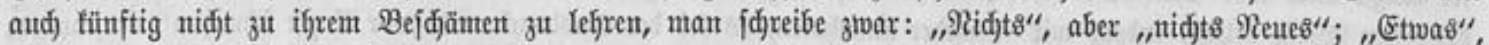

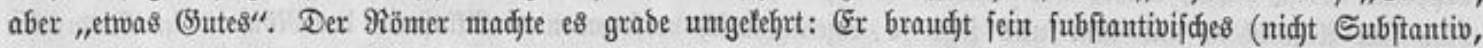

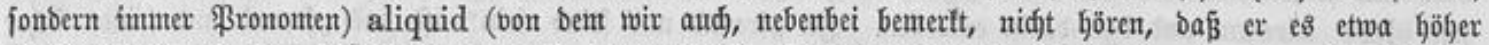

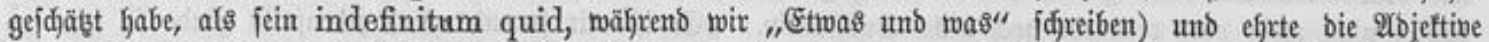

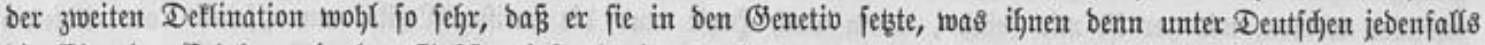

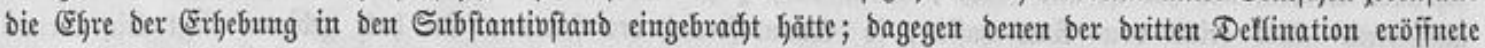

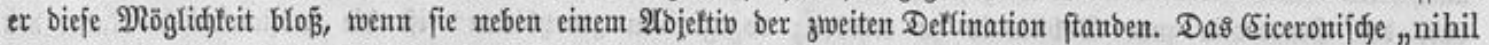

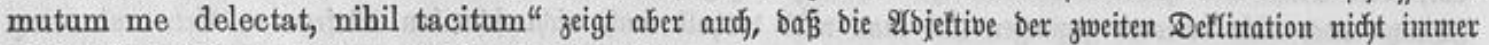
gleidjer Bebandlung mit bem Subjtantiv gewïroigt wurben.

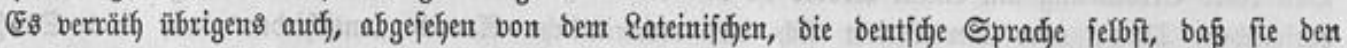

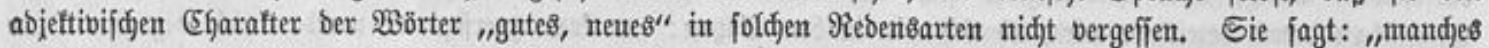
neut" im Sregeniats ju "etwas neuts" grabe fo gut, wie mandjes "gute Rino" int Segenfats zu ein "gute 8

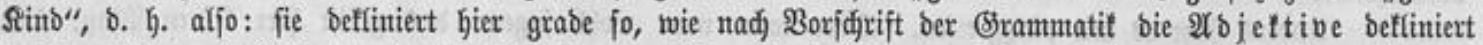

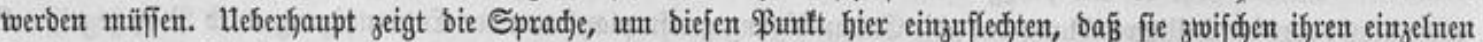

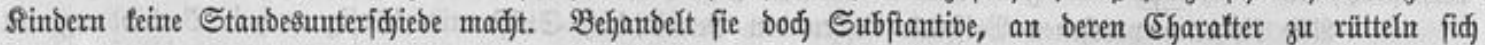

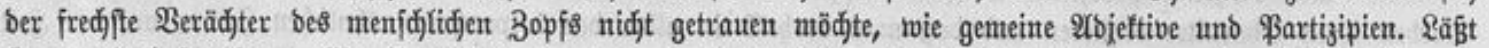
fie ums bod, ipredjen: "Ein Beamter", bagegen "Der Beamte"; "ein Bebienter" bagegen "Der Bebiente", "ein

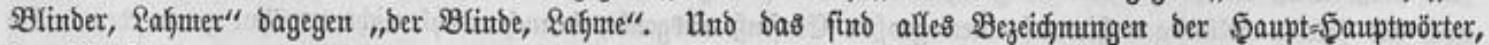
ber MRenj[jett.

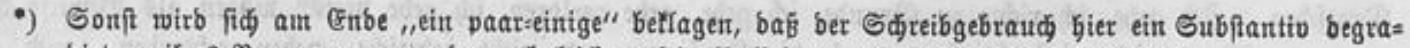

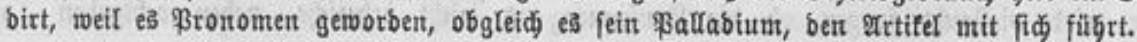




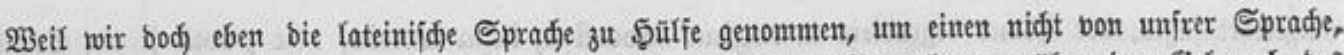

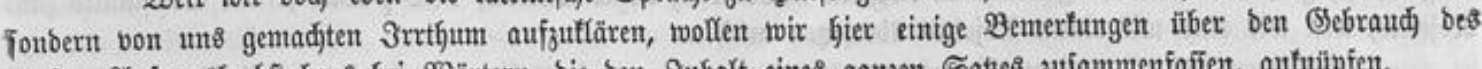
grofien 2Uf

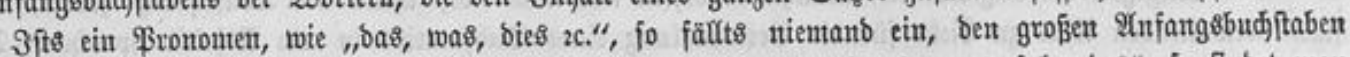

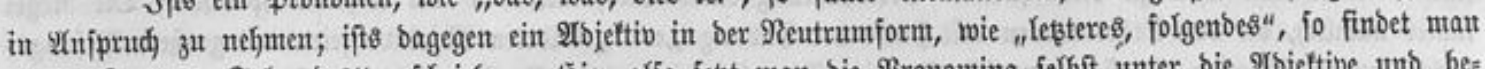

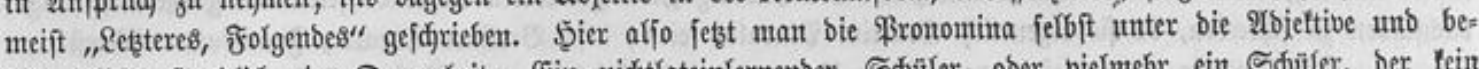

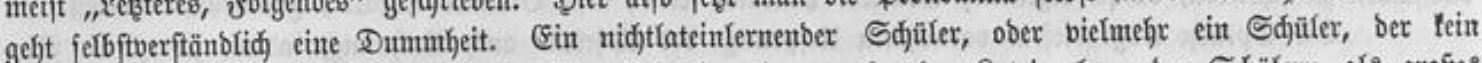

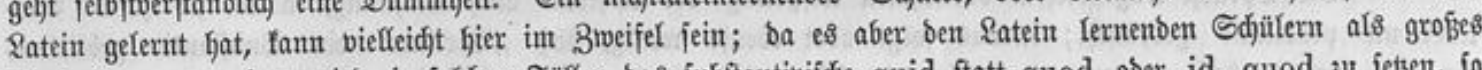
Berbredjen angeredjnet wirb, in foldjen Fällen bas fubftantivijdje quid ftatt quod ober id, quod ju feșen, io

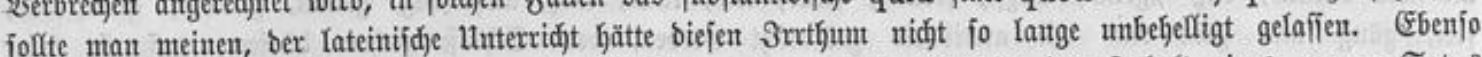

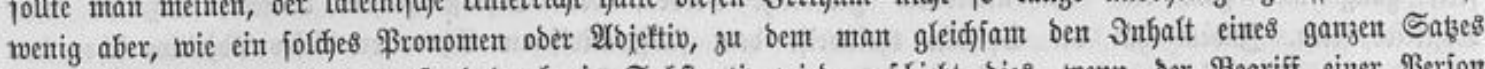

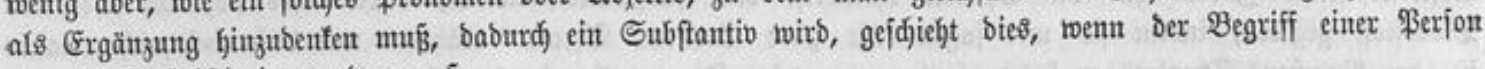
ober Sadje fubftituirt werben muई.

Db "ber exfte, bas erfte, ber eine, ber anbere, ber letste, bas eine, bas anbere" fíd auf ein uns

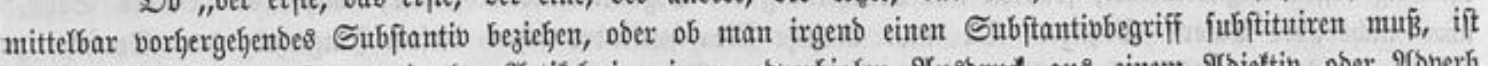

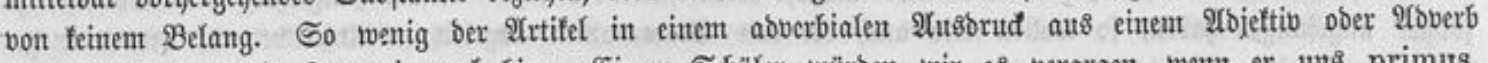

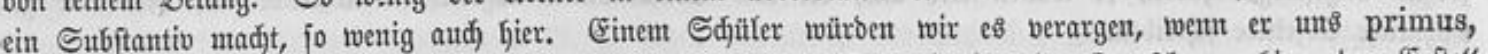
ultimus, alter, aliud al8 Subftantibe bejeidjnete; Dagegen Iaffent twir ignt iut Deutifjen rufhig "Der Erfte"

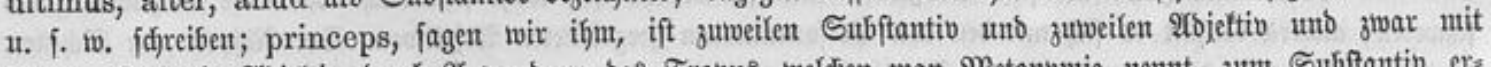

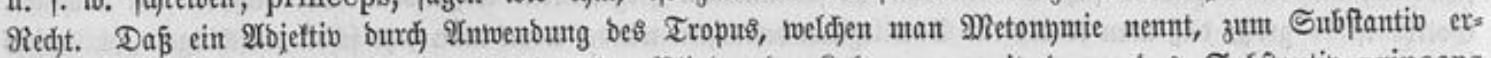
hoben werben fann, Kef̧ren bie Subftantive: Der 2 linbe, ber Rafme 2c., mit benten bas Subftantio princeps auf einer Sinie fteht. Befanntlid) aber fteht bei ber Metontymie bie Eigenjjaft für bie \$erjon ober Sadje,

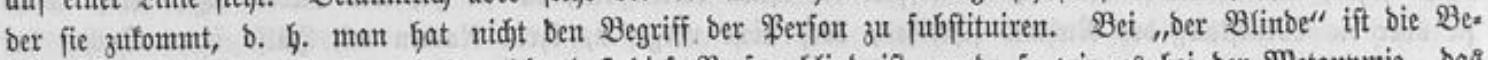

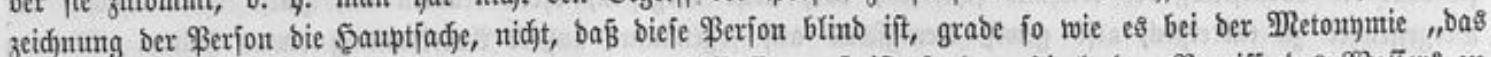

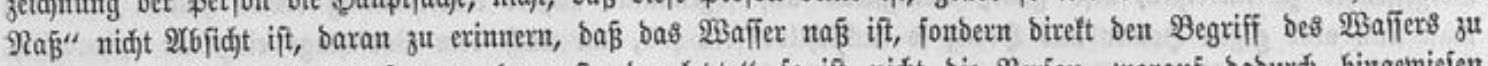
bejeidjnen. Wenn twir num fagen: "ber exfte, ber lestete", fo ift nidjt bie Berjon, worauf baburdj Gingeviejen

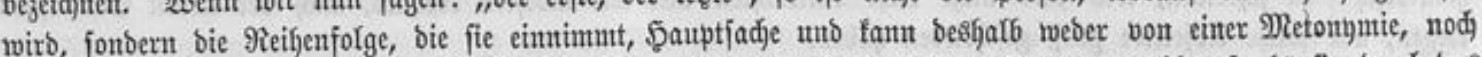

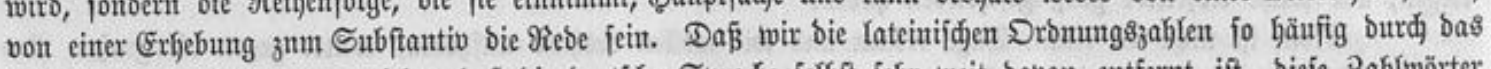

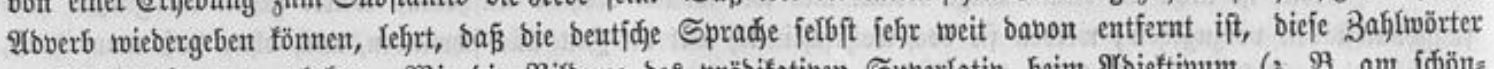

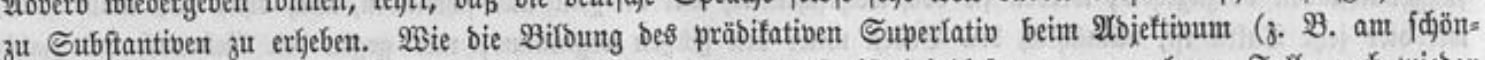

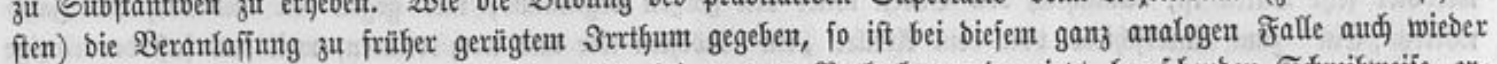

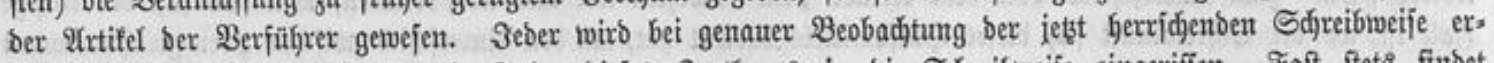

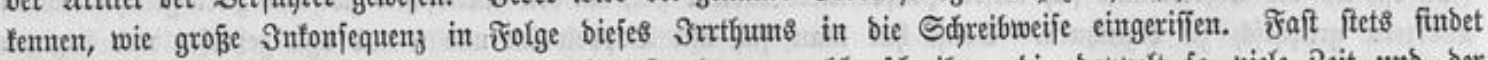

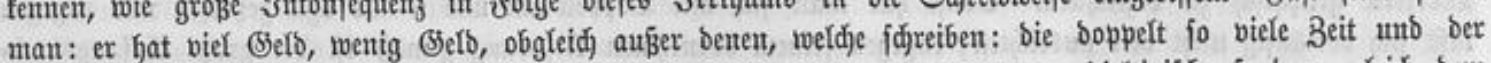

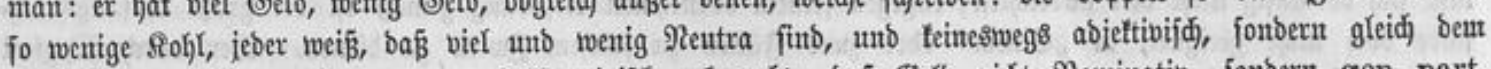

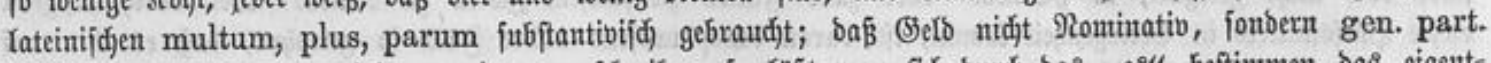

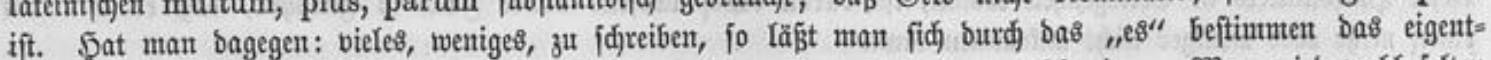

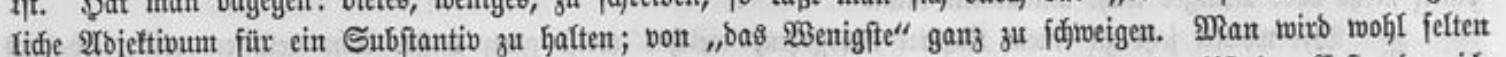
geidjrieben finben: bu bift ber Diummfte, bent idj je tennen gelernt, aber febr häufig: but bift ber Erfte, ben id, femmen geternt. Ein Srumb zu ber veridiebenen Befandlung liegt wohl nidjt vor.

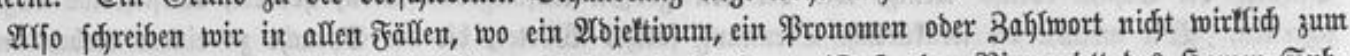

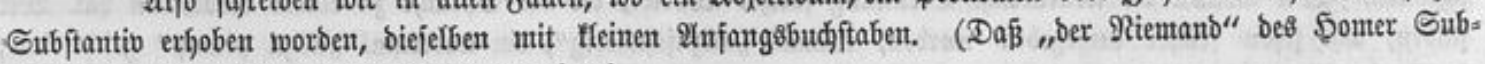
ftantiv ift, joll Giermit nidht beftritten werben.)

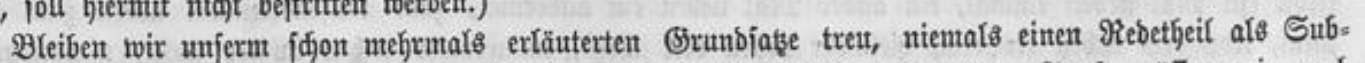

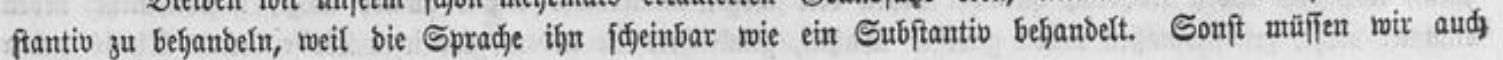


umgefért jagen, ber $\Re$ ömer begrabiere in regina sacerdos, lupa nutrix, rex poeta je ein Subftantiv jum 2rojettio, tweil twir eins mit einem 2 bjeltio überję̧en müffen.

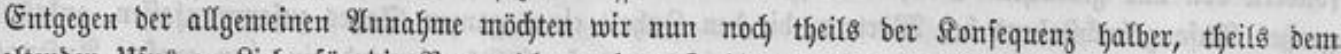

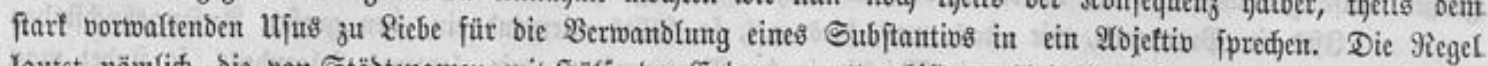

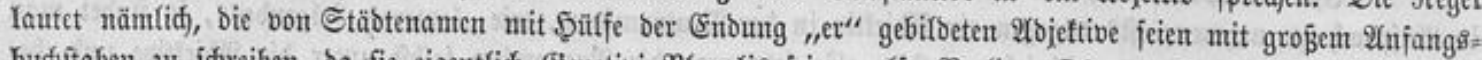

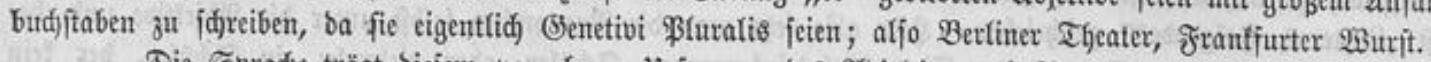

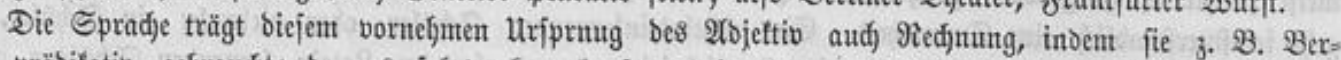
liner nie präbifatio gebraudft; baraus folgt aber ebenjo menig, baß̄ "Berliner" cin Subítantio geblieben,

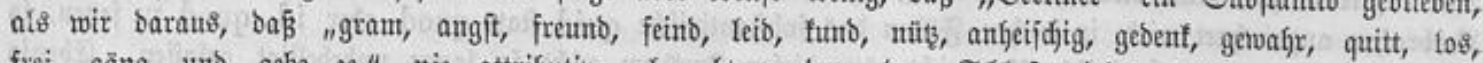

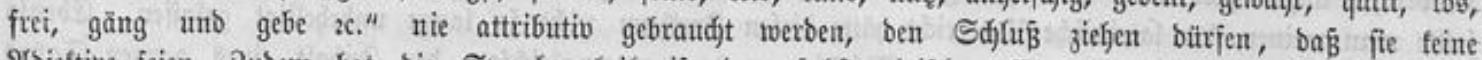

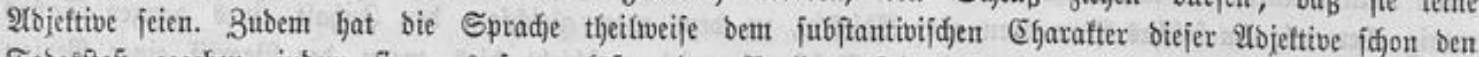

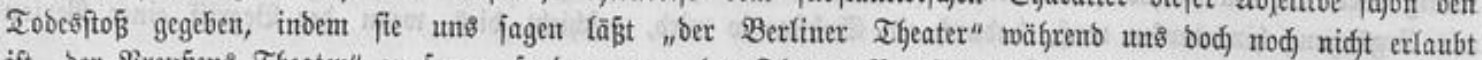

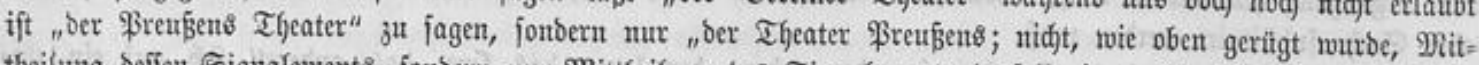

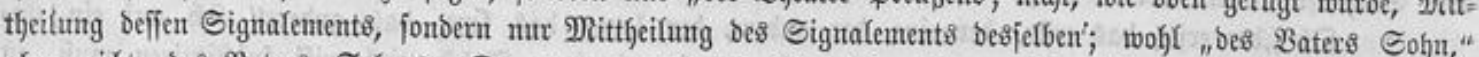
aber nidjt "Des 2 aters Sohnes. Da num mandje Meirjdentinber jdjon biejem ₹ringerzeig ber Spradje zu.

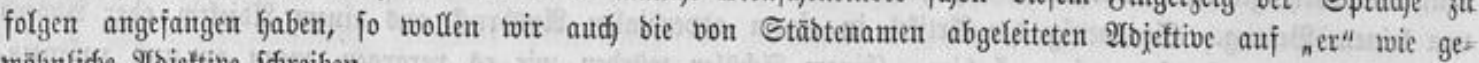
mögntidje 2 Ibjettive idjreiben.

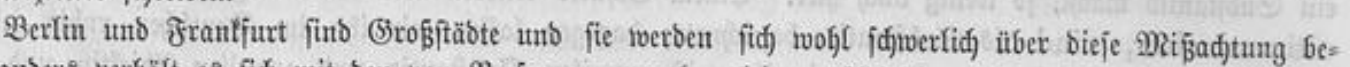

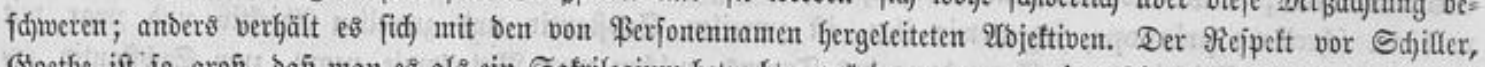

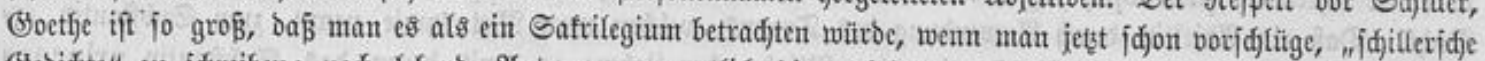
(Sebidjte" ju jđjreiben; nod) lebenbe 2utoren, namentlid bie unbebeutenben, würben exft redft eine Befeibigung

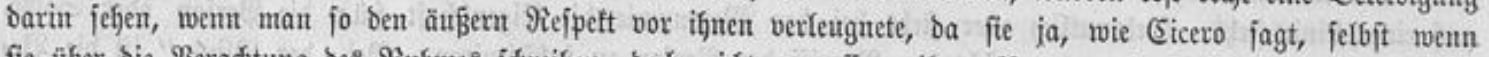

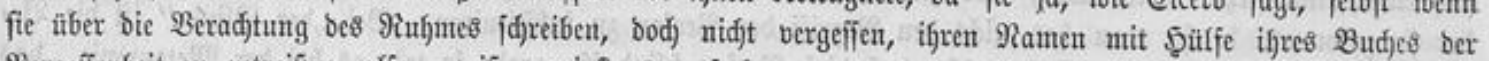

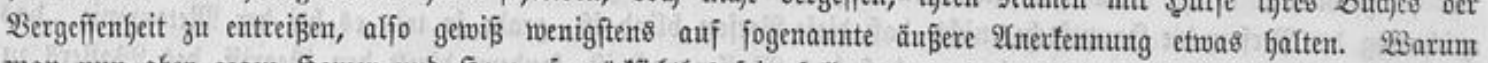

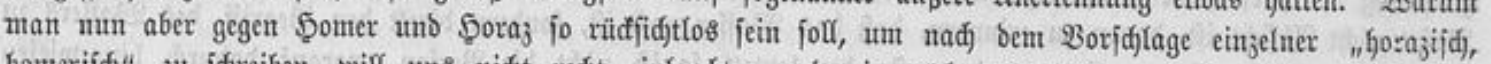

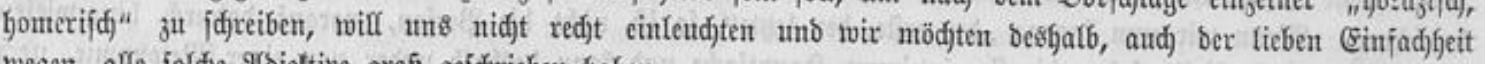
wegen, alle joldje 2lojettive großß gefdjrieben baben.

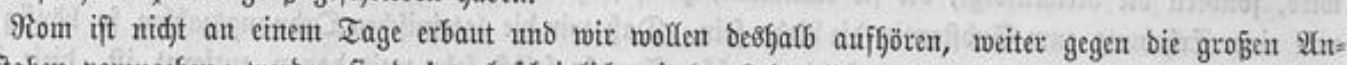

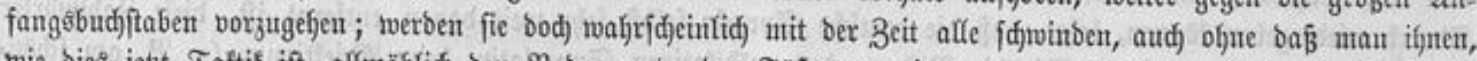

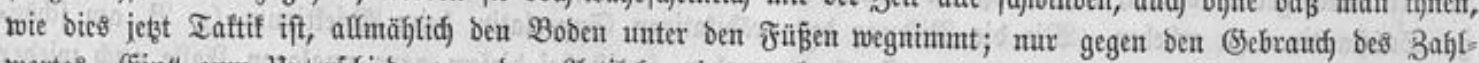

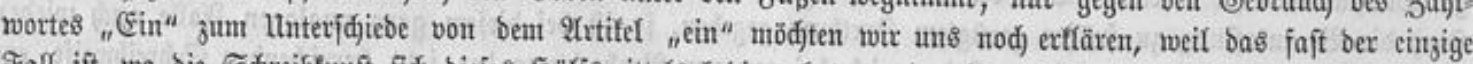

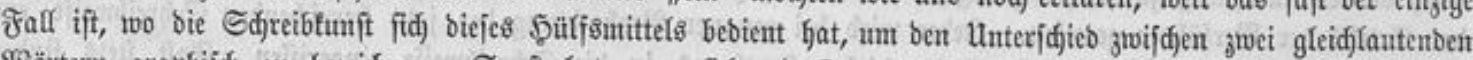

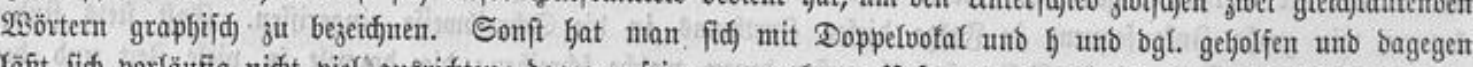

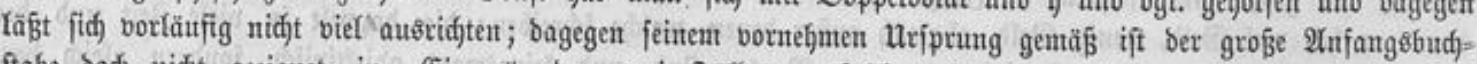

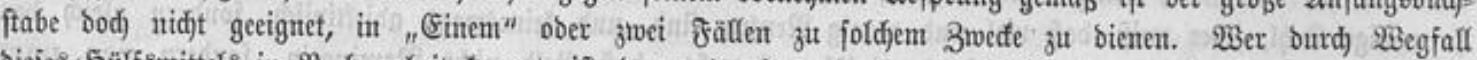

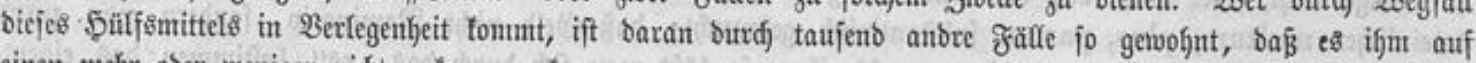
einen mehr ober weniger nidgt antommen fant.

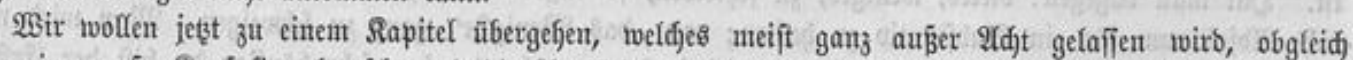

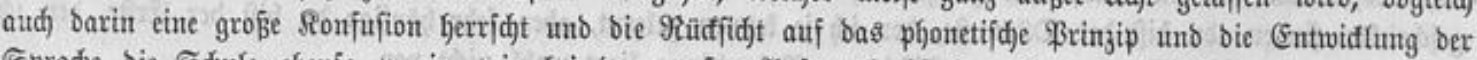

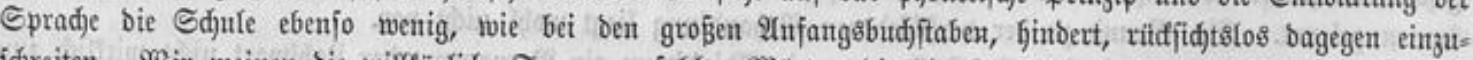

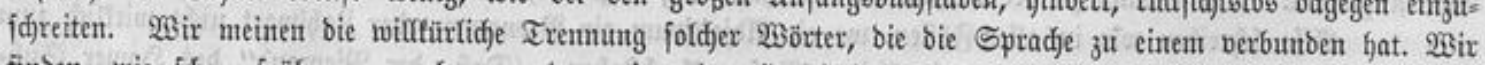
finben, wie idjon frither angegeben morben, einmal "allzifjóvierig", ein anbermal "allzu plump" geidgrieben; felbft ein $\mathfrak{M a l}$ neben einmal, ein ander $\mathfrak{M a l}$ neben cin anbermal, jum taujendftenutal neben zum taufenbjten

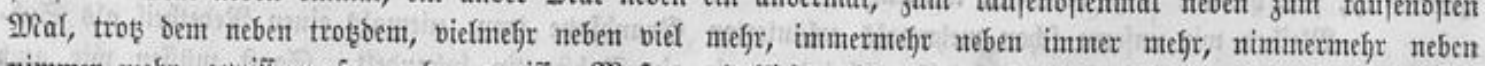

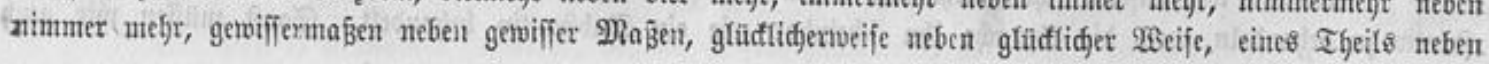




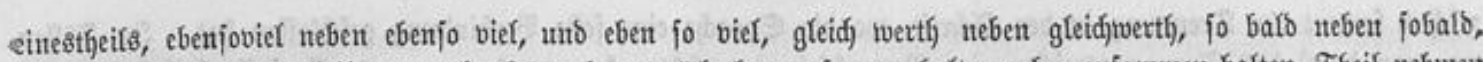

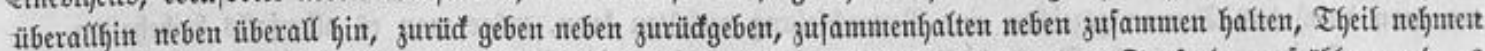
nteben theilnehmen, $2(d) t$ geben neben adjtgeben, $2 c$. Soldjer Beifpiefe tönnte man Taujenbe aufjählen unto

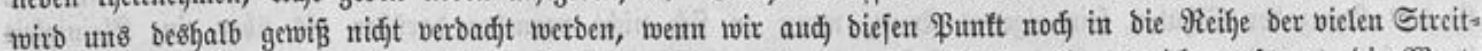

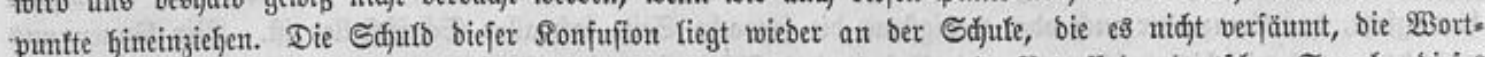

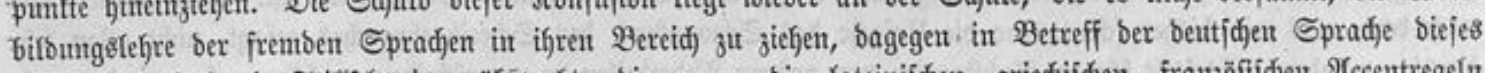

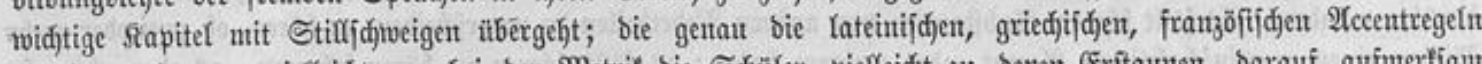

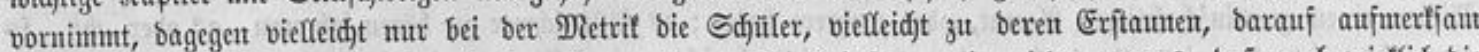

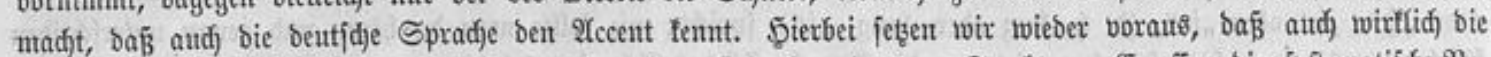

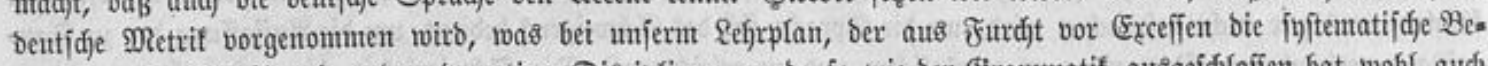

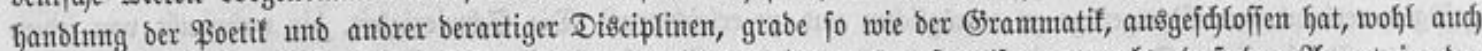

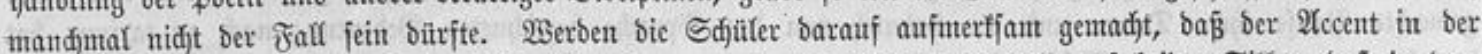

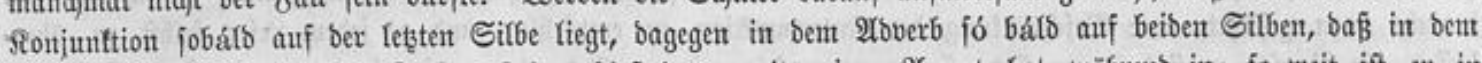

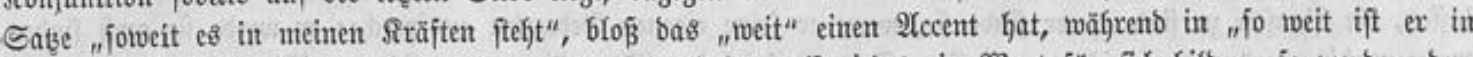

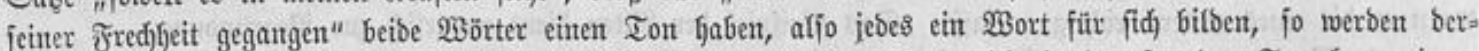

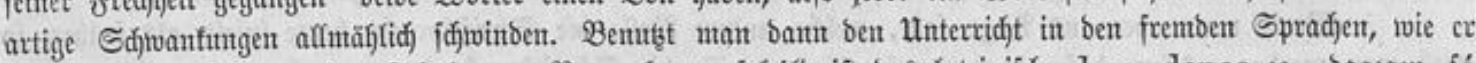

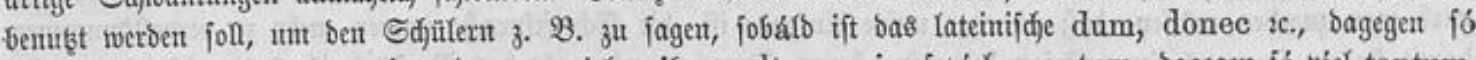
báls tam cito, vielméfjt potius, bagegen viel méfjr multo magis, foviel quantum, bagegen fó vícl tantum,

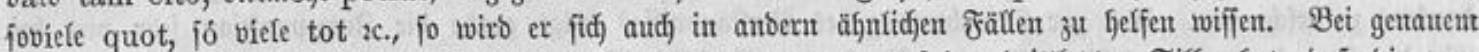

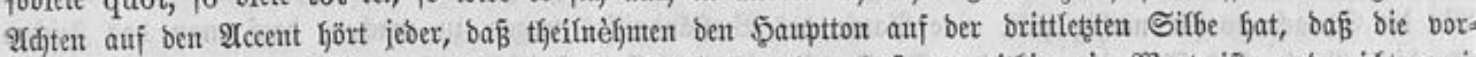

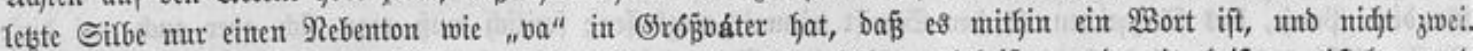

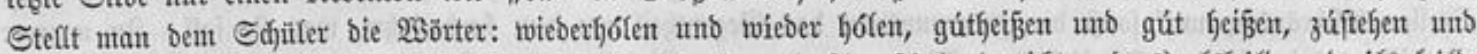

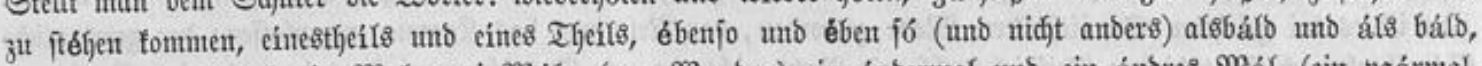

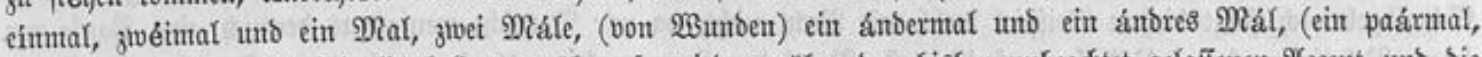

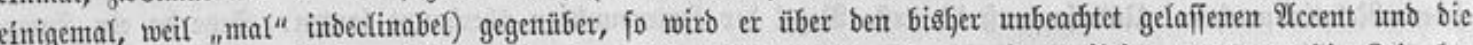
baran fid fnüpfenten Folgen fid flar werben. (Ex wirb wifien, ob ex "je nadjoém, was ums bie 3eit bc=

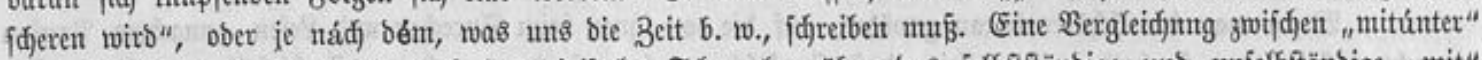

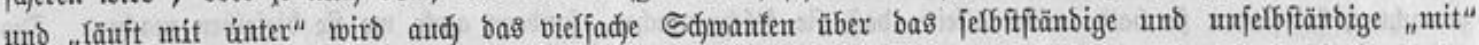

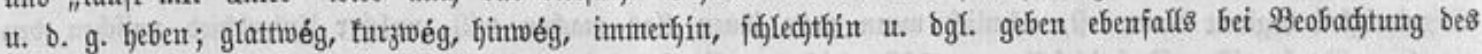

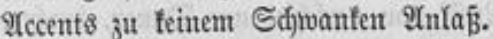

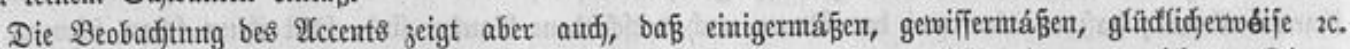
untridtig al\& zu cinem Worte vernadjfente Benetivi abjoluti aufgefaß̄t werben. Wie wir "untverridjteter Dinge,

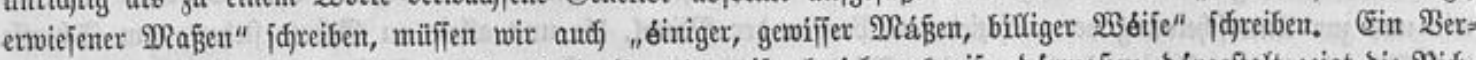

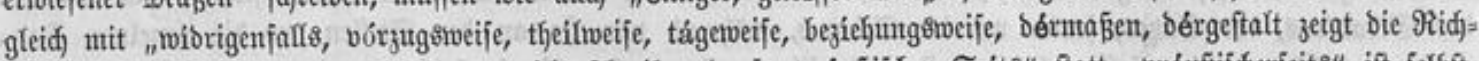

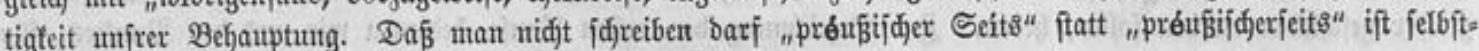
verftänblid); jonft fömnte man aud jđjreibent „סies: Seít8.

Dic Irenum von ber Spradje verbumbener Subftantive in bic einjelnen Beptanththeile und bamit

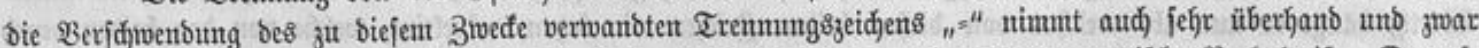

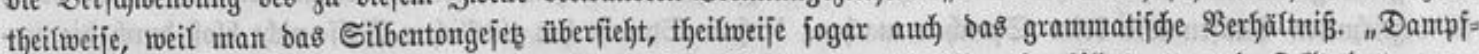

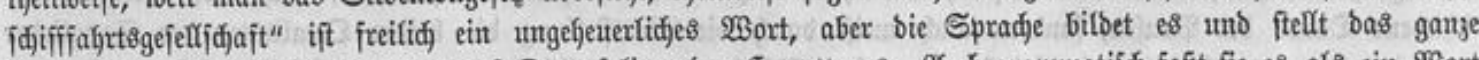

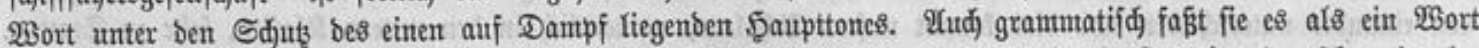

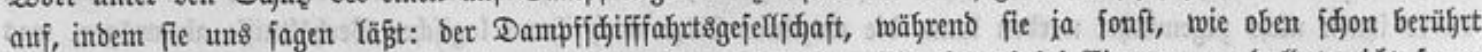

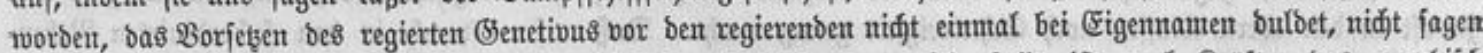

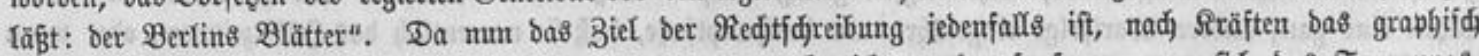

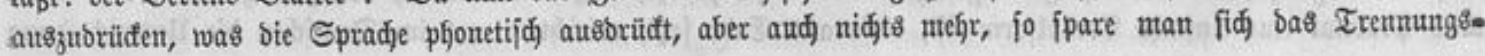




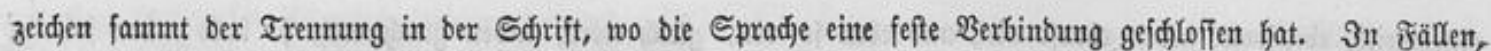

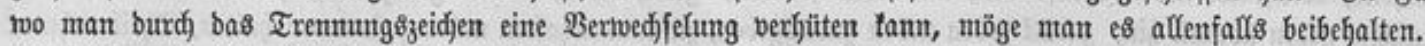

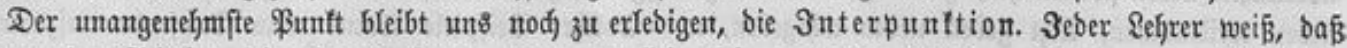

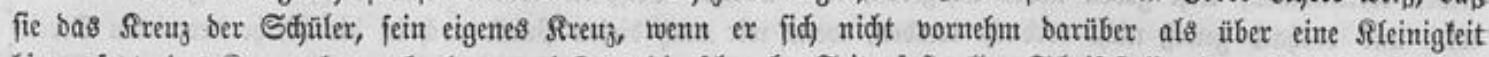

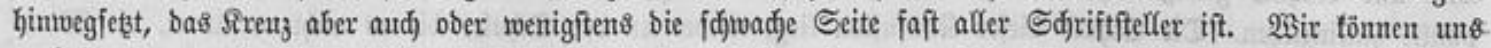

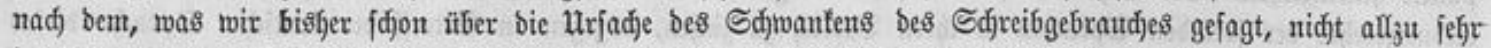

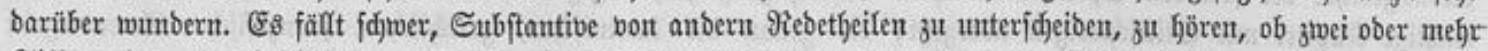

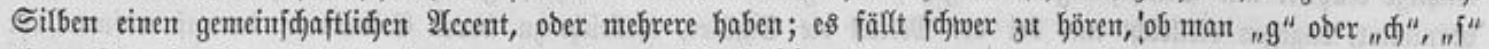

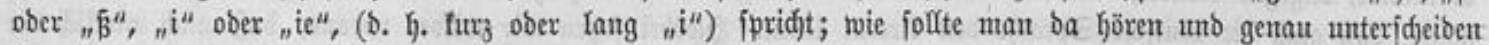

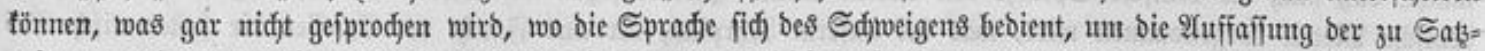

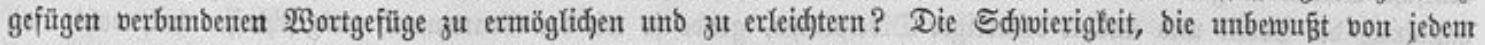
gemadjte ßauje threr Dauter unb ber baburd) von ber Spradje bezeidjuten Bebeutung und zu taxiren, hat

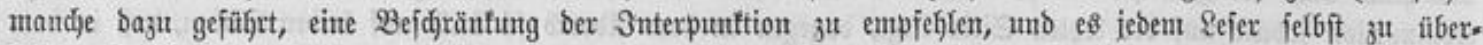

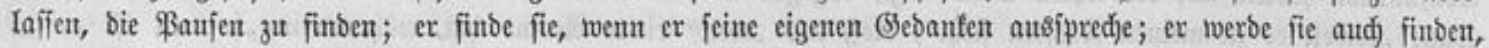
weun er bie eintes anbern ridjtig auffaffe. Das Beifpiel ber 2 ften bient natürfid) zur Begrünbung.

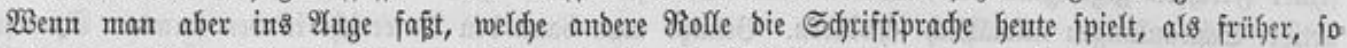

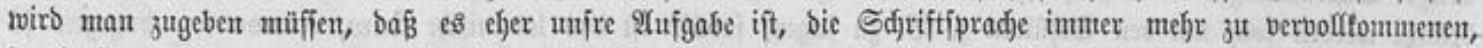

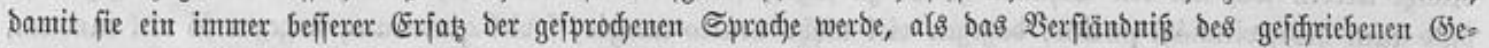

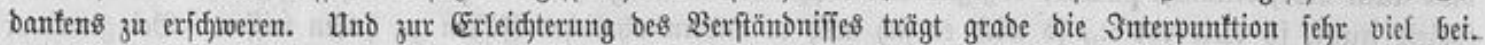

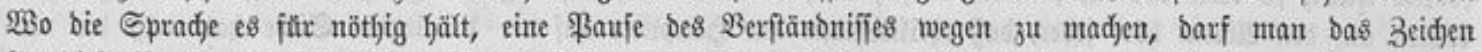

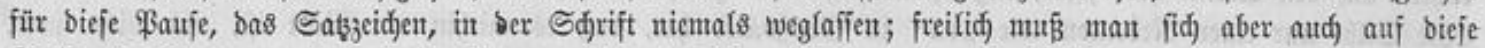

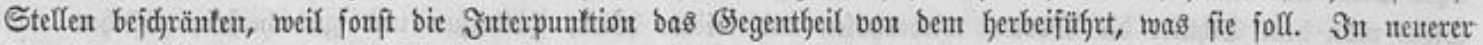

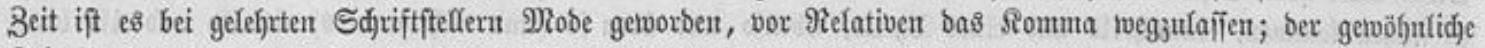

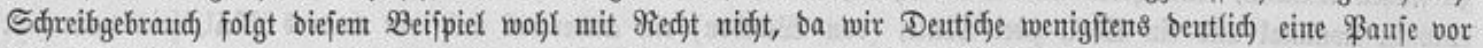

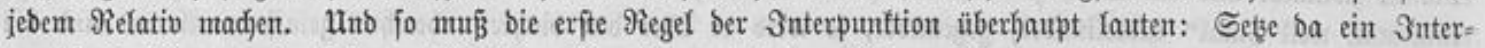

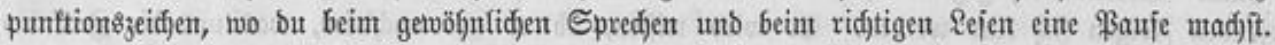

Wentm man bie Sdjüler baran getwöhnt, auf bie vont ifjten beim Spredjen uno Rejen gemtadjten ßaujent ju adjten, fo finben fie balb, nidjt allein, baß̧ fie joldje madjen, fonbern autd), wo fie biejelben utadjen. Die

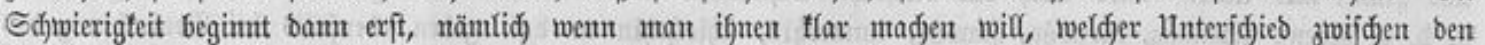

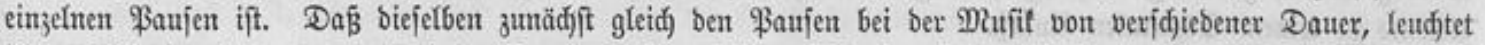

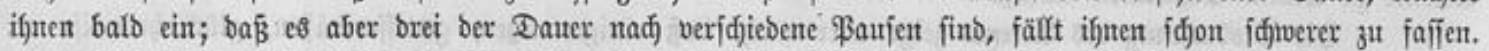
Die Unterfodeibung ber beiben fürzern von cinanber mađ̆t ifnten bie gröfite Sdjwierigleit, Beim Spredjen bebienen.

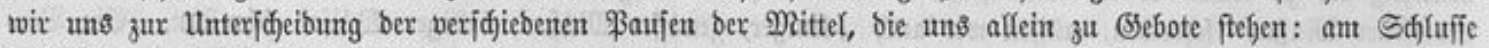

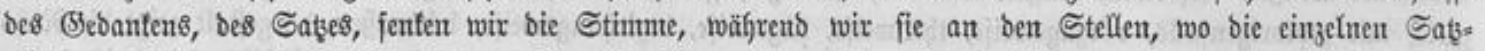

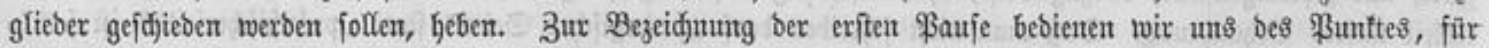
bie Tremung ber Sałgglieber haben tvir bagegen zwei Beidjen: Romuna unto Stridjpuntt.

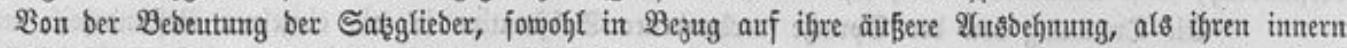

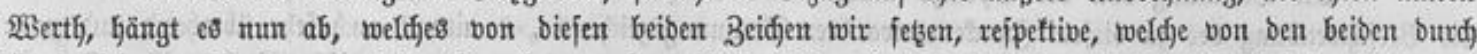

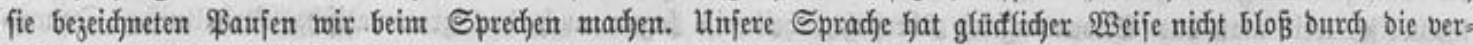
'djiebene Dauer ber \$aufen, fonbern aud meift burd, bie Wortftellung bie beiben Sualitäten ber Sabzglieber

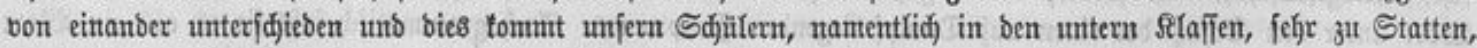

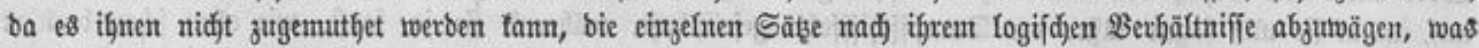

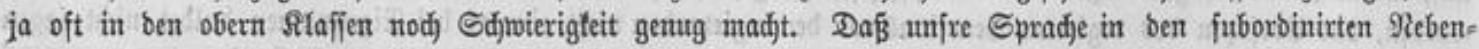

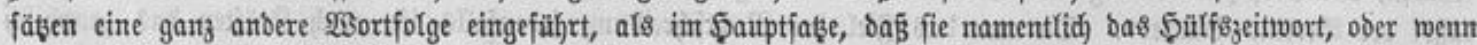

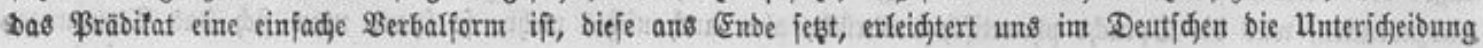




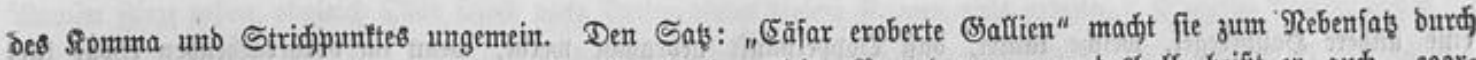

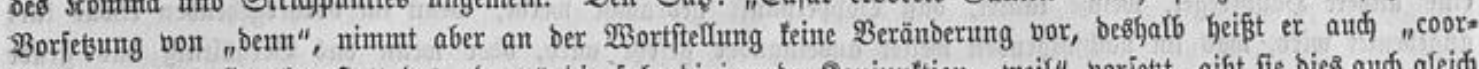

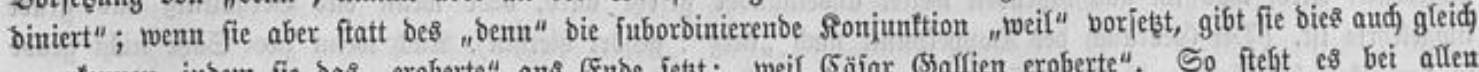
zu erfennen, inbem fie bas "eroberte" ans Enbe fetzt: "weil Eäjar Brallien eroberte". So ftefht es bei alleu

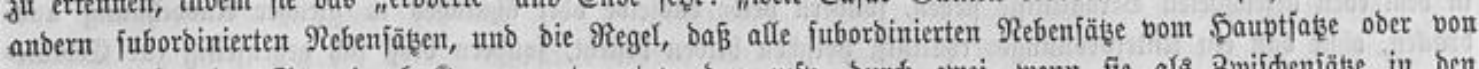

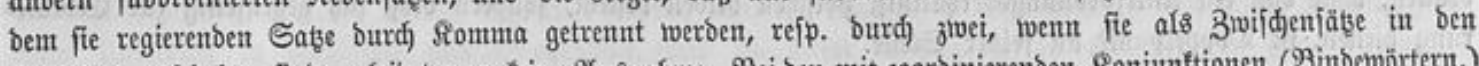

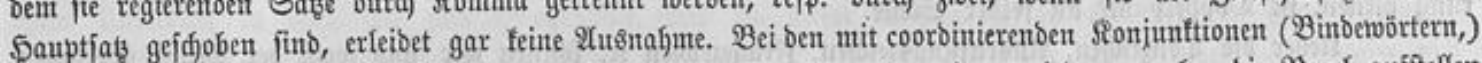

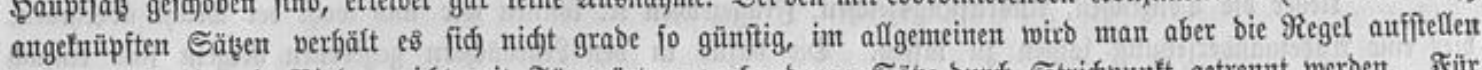

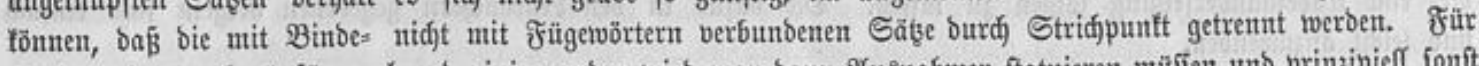

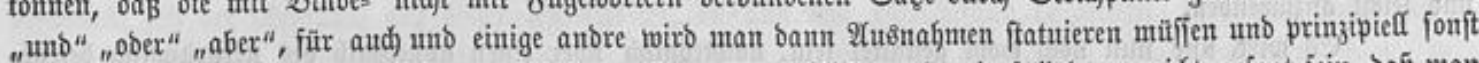

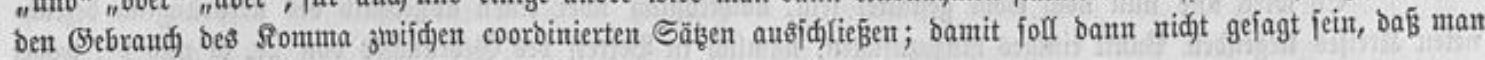
ror jebem "benn ${ }^{\mu}$ 3. B. Stridjpuntt jeţen mitfe.

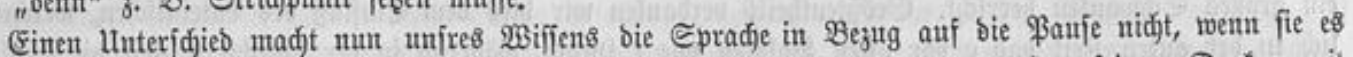

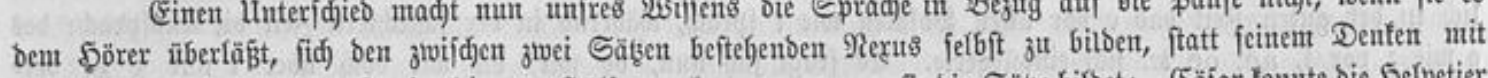

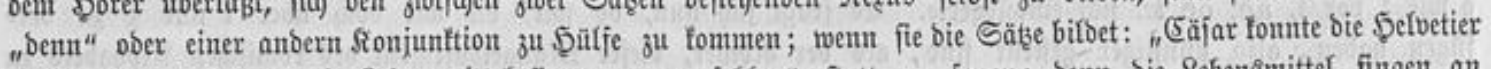
nidjt weiter verfolgen; bie Rebensmittel fingen an $z^{u}$ fehlen", ftatt ju fagen: bem bie Rebensmittel fingen an

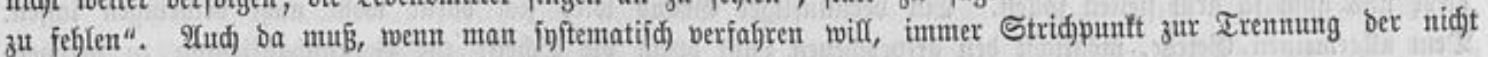

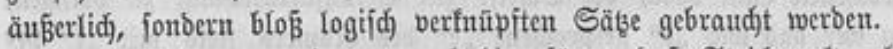

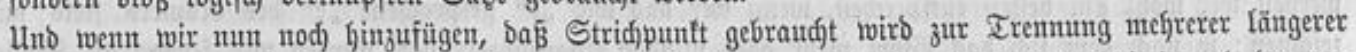

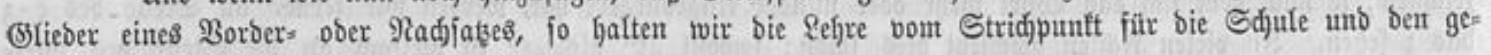
wöhnlidjen (sebrauded) abgethant.

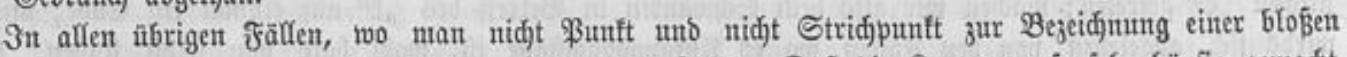

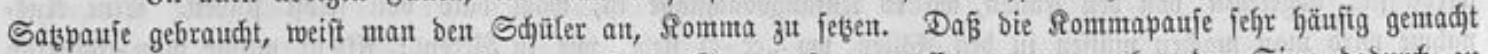

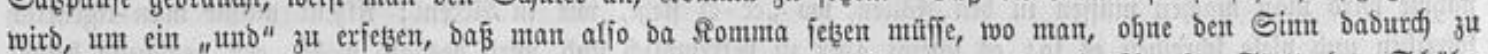

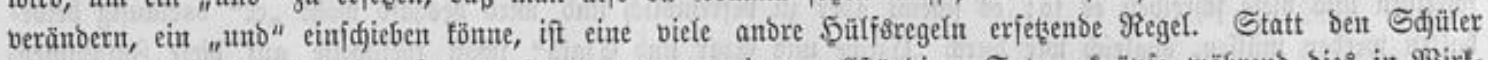

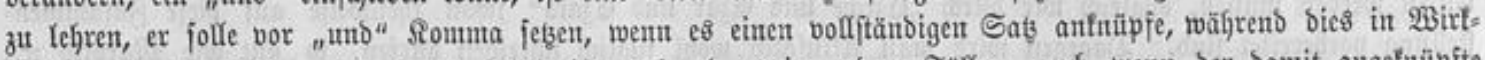

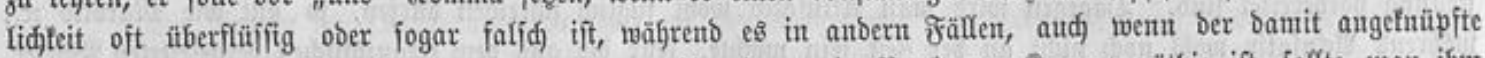

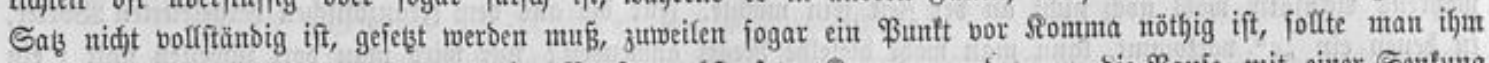

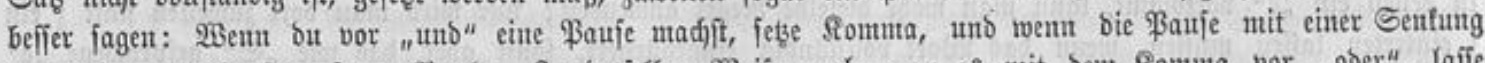

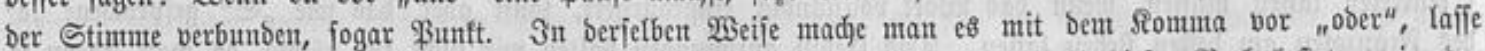

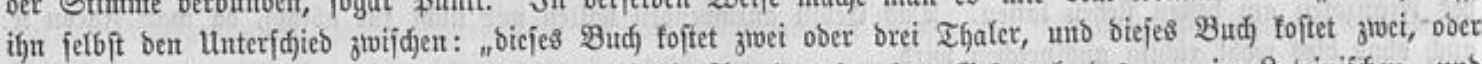

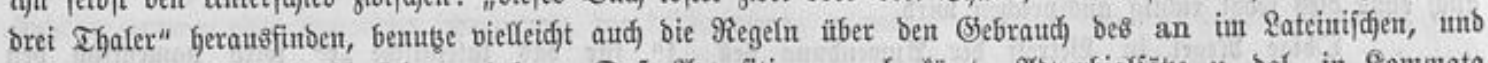

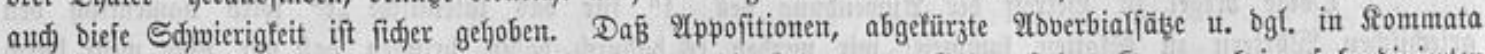

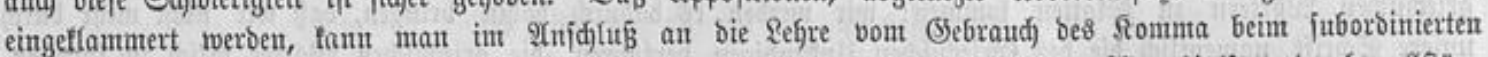

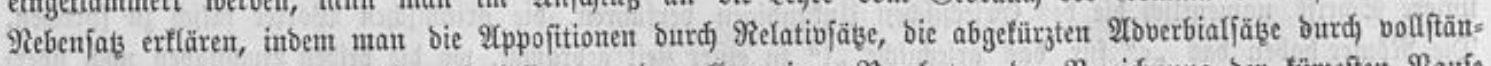

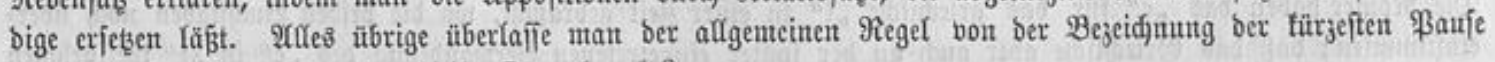
burd) ein Soumu. Wo aber bleibt Doppelpuntt?

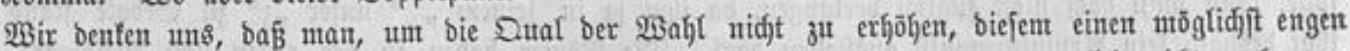

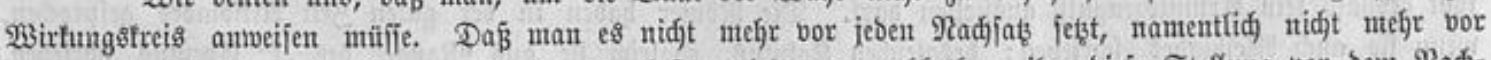

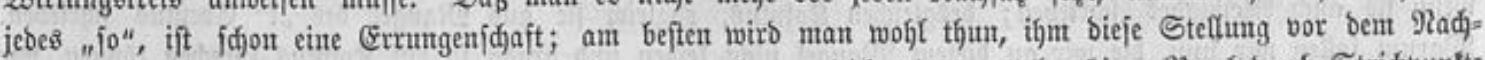

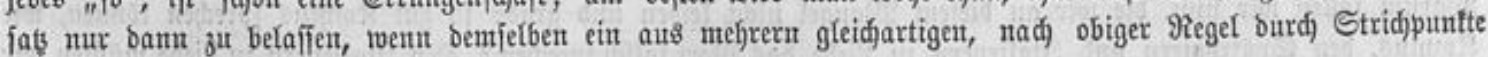
getrennten B́tiedern beftégender Borberjats voraufgeht.

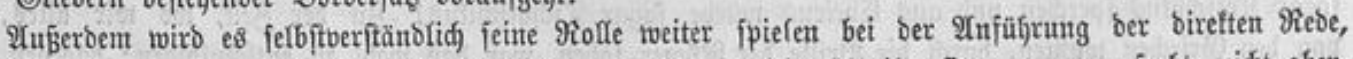

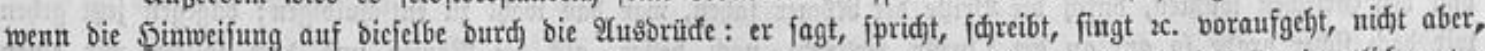

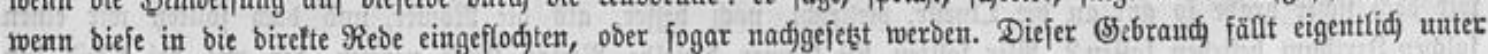




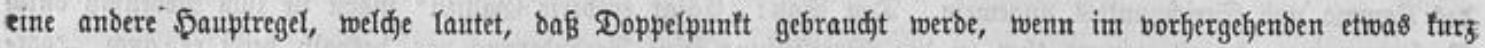

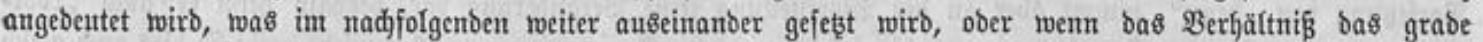

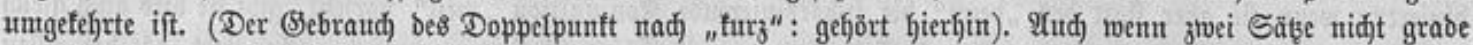

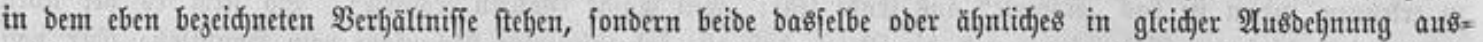

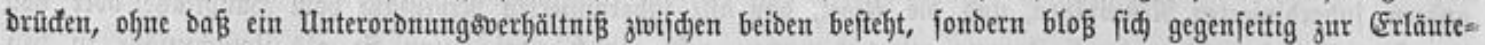
rung bienen, ift Doppelpunit an feiner Stelle.

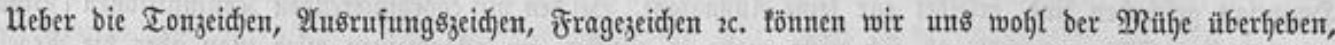

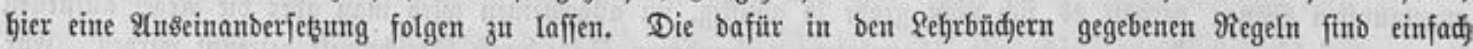
uno leidjt anzuvenden.

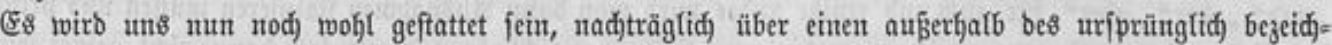

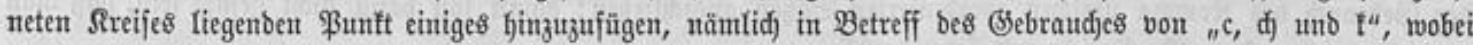

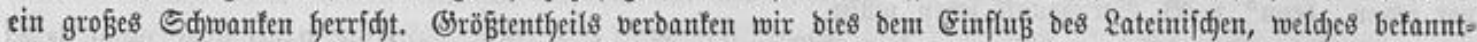

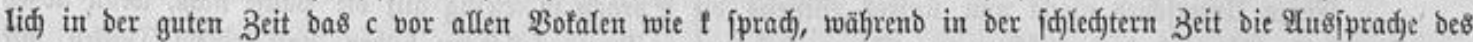
c twie $z$ vor $i$, ae, oe 2 . fíd) einbuirgerte. (Es fragt fid mun, ob tvir, bie wir bod) über $t$ unt $z$ zu ver=

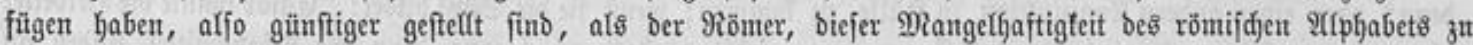

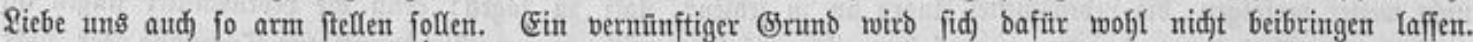

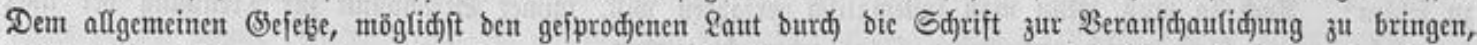

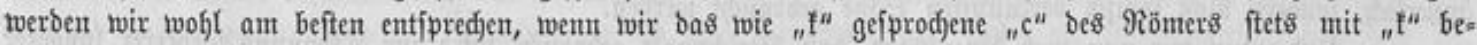

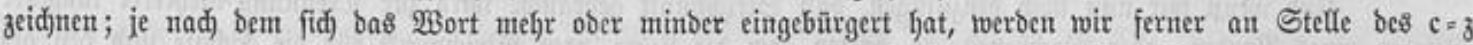

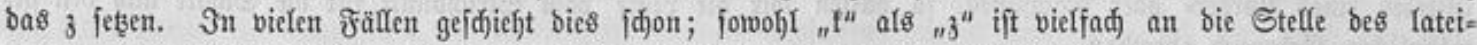
nifden "c" getreten; madjen twir aljo bem Sdjwanten in Betreff bes "t" auf eimmal ein Ende; mit bem " $\hat{\delta}^{\prime \prime}$

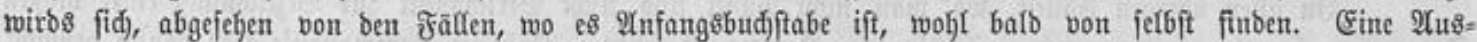

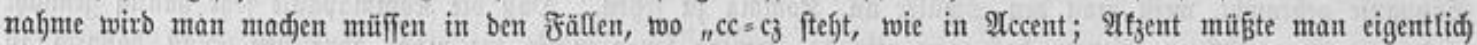

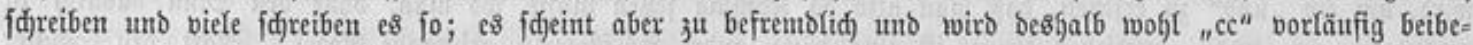

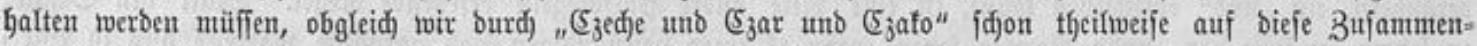

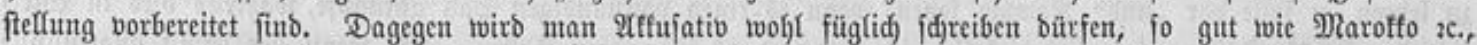

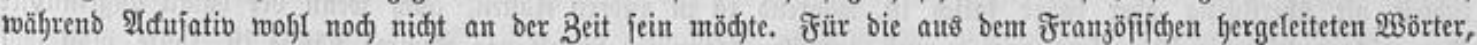
in benen ein "c $c^{n}$ vorfoumt, fann man wohl biejelbe Regel antwenben; nur wirb man bort zuweilen ftatt 3 ein

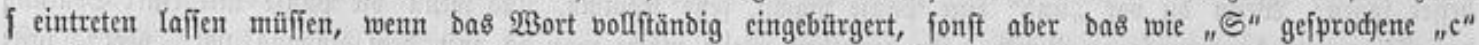

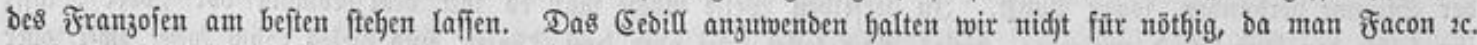

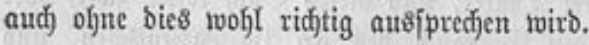

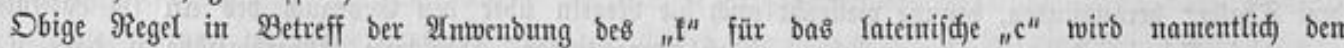

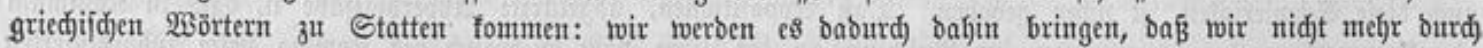

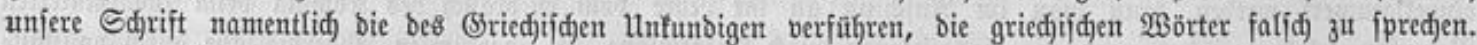

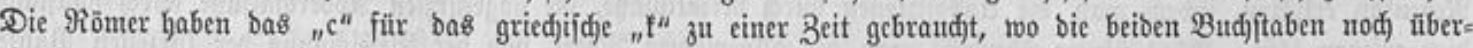

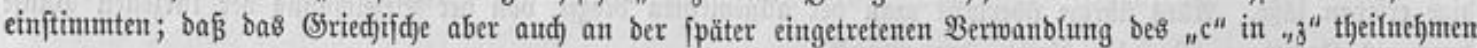

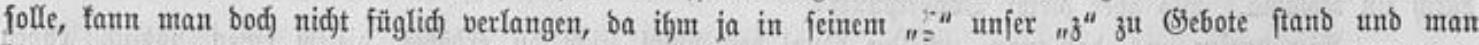

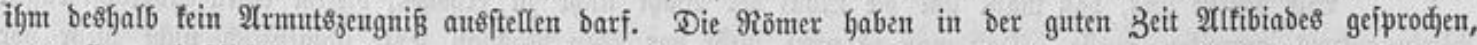

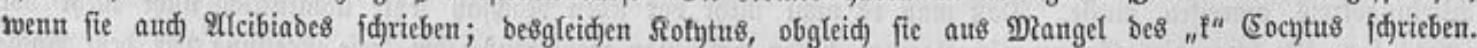

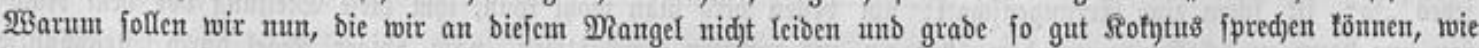

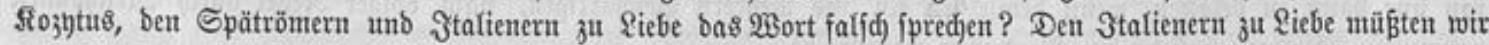

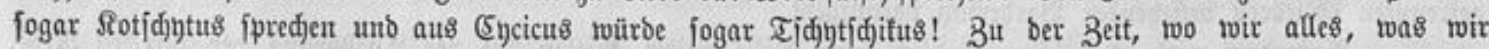

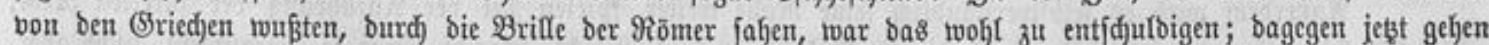

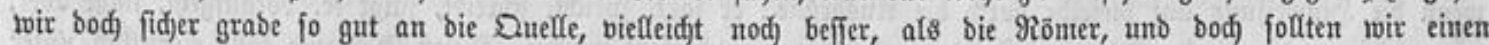

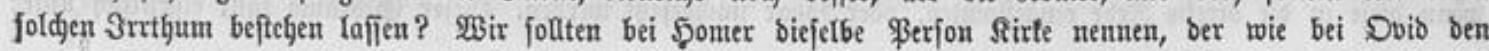




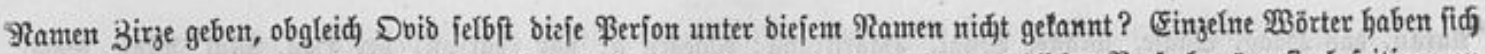

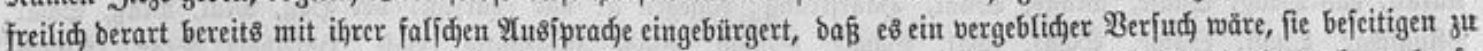

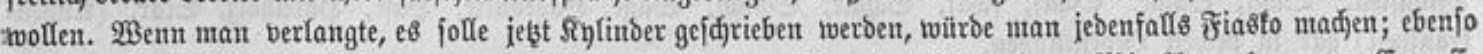

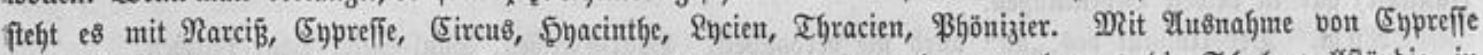

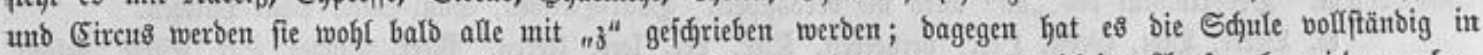

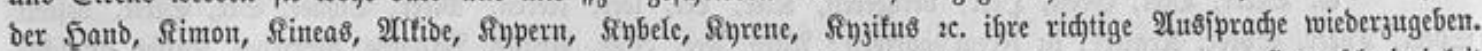

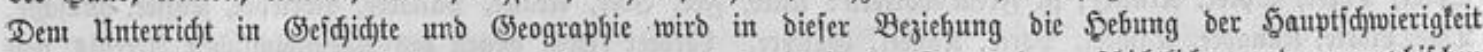

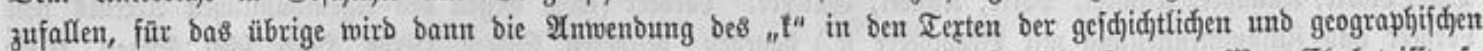

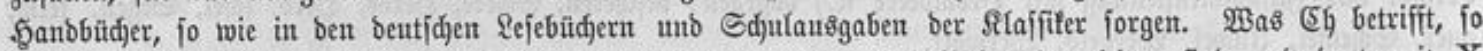

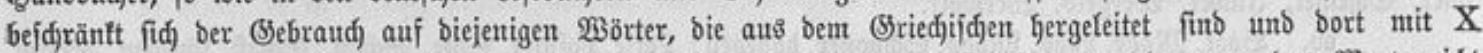

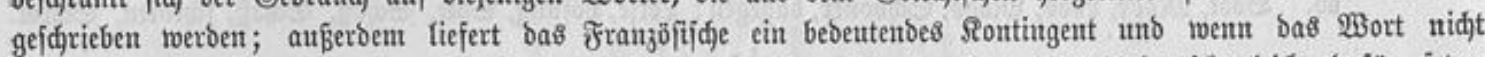
volfftänbig eingebürgert, werben wir in ben ₹ällent, wo wir " $\Omega^{\prime \prime}$ ipredjen, bießs bod) nidjt leidjt bajür ję̧ent

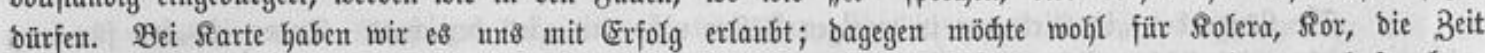

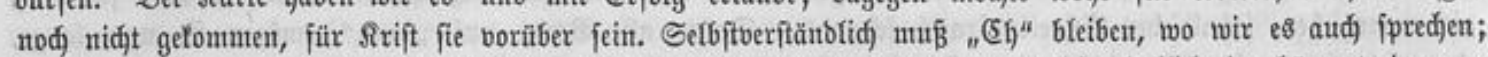

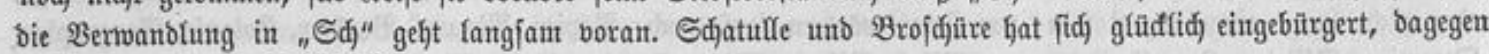
"Sdjef" wïrbe woht $\mathscr{A}$ uffeljen erregen.

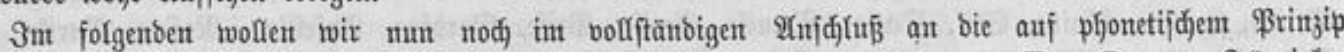

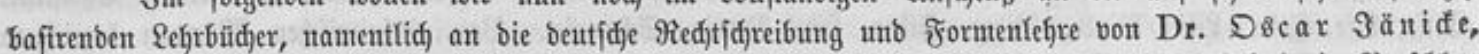

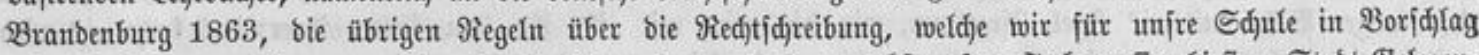

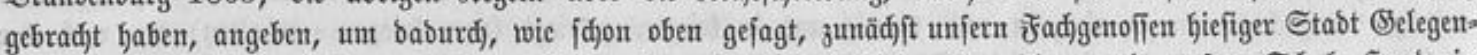

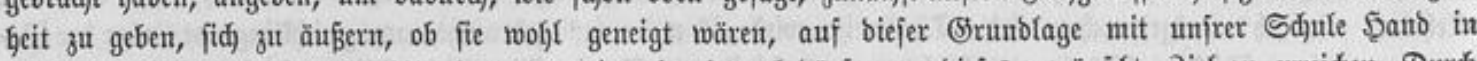

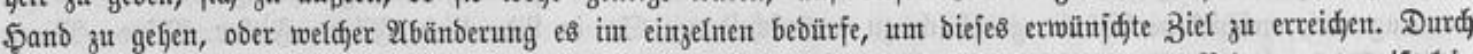

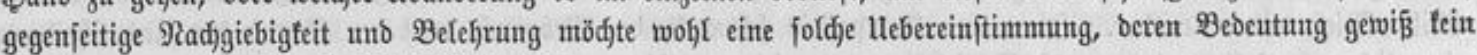
Sđjulmann unteridjăb̨t, Gerbeizufüfyren feint.

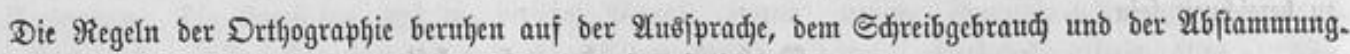

1 (5efe ts. Sdjreibe, twie bu ipridjt uno budjftabierft.

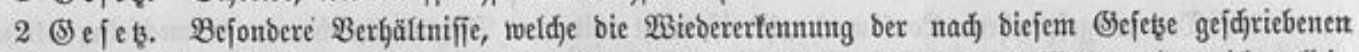

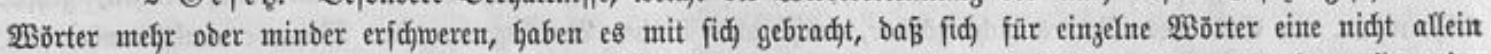

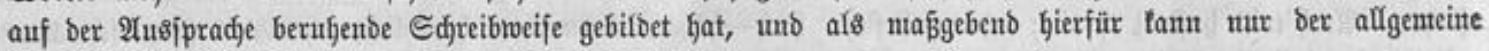

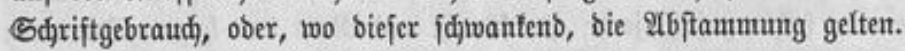

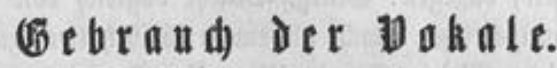

\section{Range Bofale.}

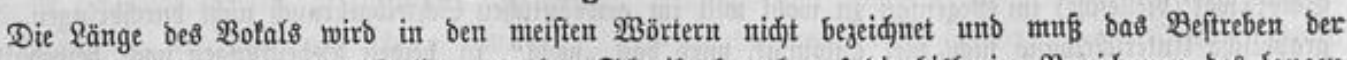

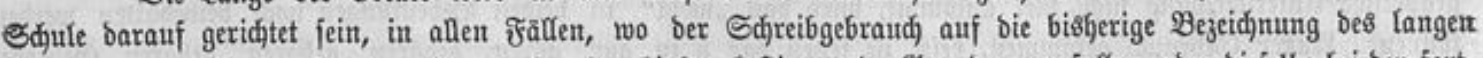

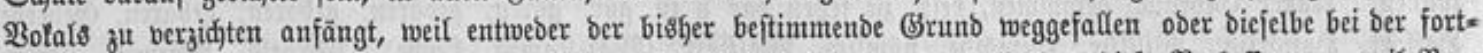

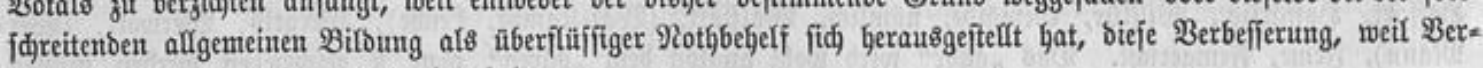
einfadjung, zu acceptieren unb einzufüfren.

Die bişber nod) angewantoten Defnumgsgeidjen finb:

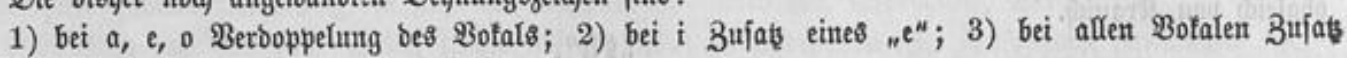

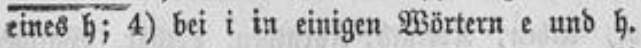

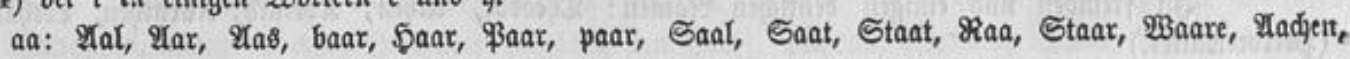




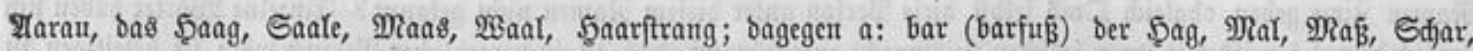

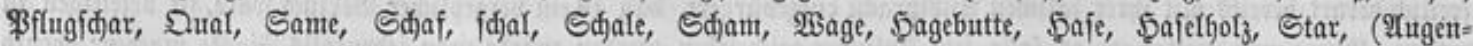
franffheit) gar in beiben Bebeutungen.

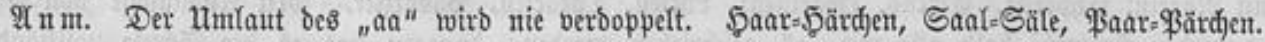

ee. Beere, Beet, Seeft, Seer, verheeren, Slee, Ree, Leer, Ieeren, Meer, Edjnee, See, Seele, bejeelt,

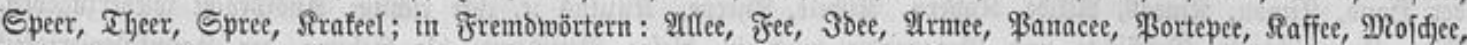

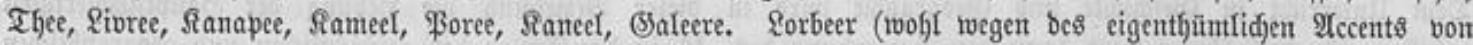

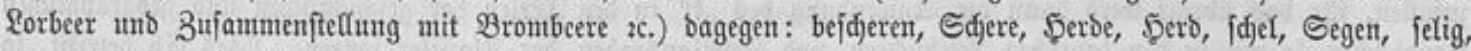
quer, Sdjemel, 3utwel, Wergelb, Wetwolf.

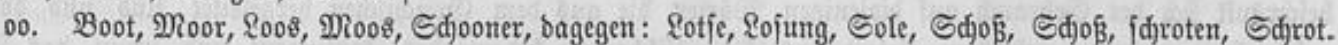

\section{ic}

Die \&änge beß " $i$ " wiro nur in wenigen Fällen niđjt mit "ie" bezeidjnet. Dafjer ift "ie" für lang " $i^{\prime \prime}$ vorzuziegen, fobalb ber Sdjreibgebraud) fdjwantt. Daher alle $B e r b a$ auf "ieven", mögen fie num lange, ober nidjt lange cingebürgert jein; von Frrembtwörtern fonft nod): \$apier, Ranter, Barbier, Rolonie, (Seograpljie,

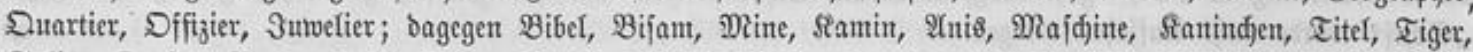

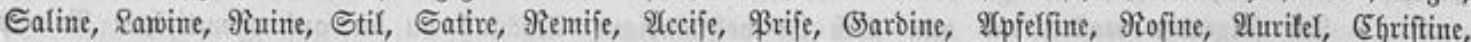

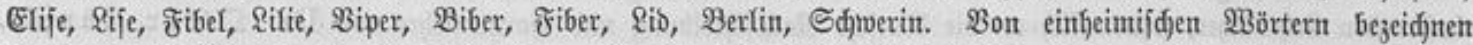

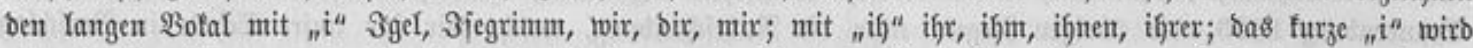

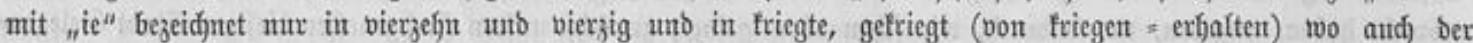

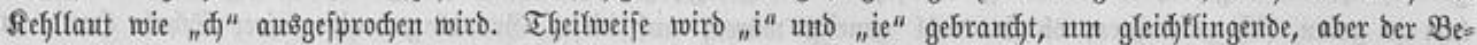

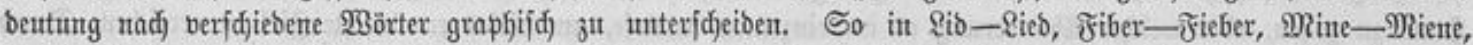

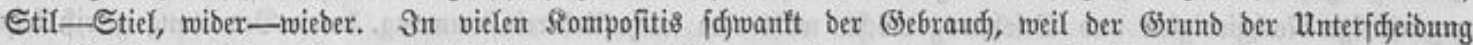

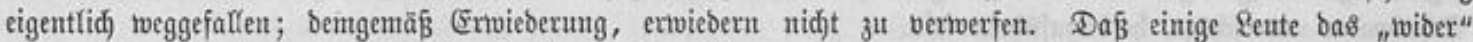

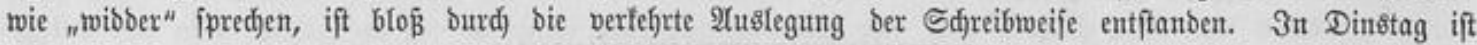

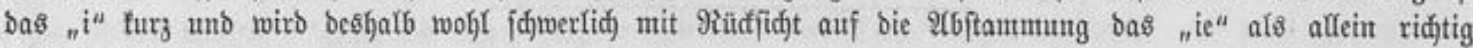
zu bezeidjnen fein.

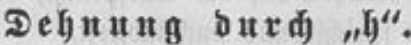

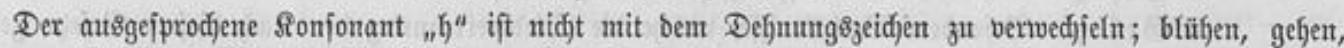

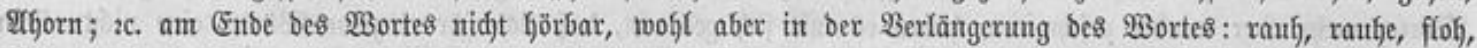

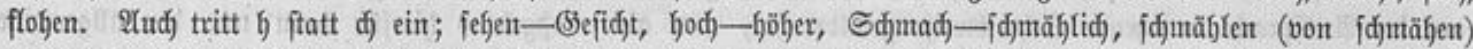

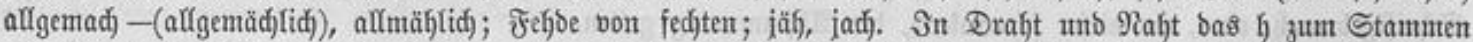

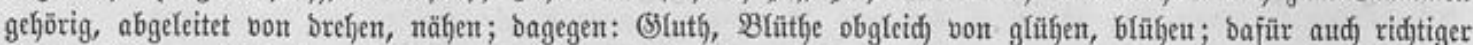

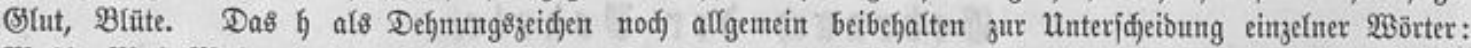
Mahl-Mal, Mäfre (mho. märch) - Märe (Sage), uhr-ur, Bunahme-3uname, mahłen-malen, Sohle-

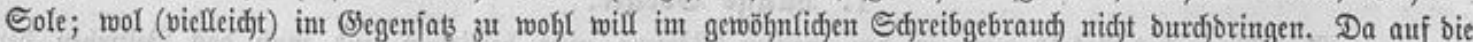

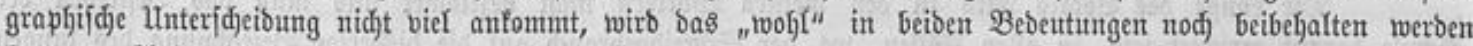

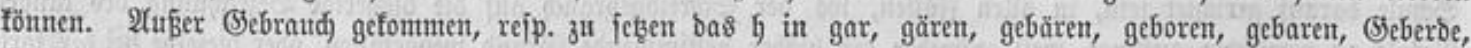

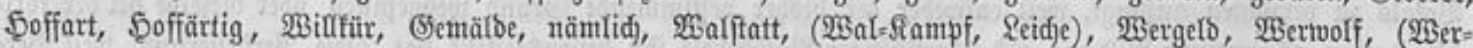

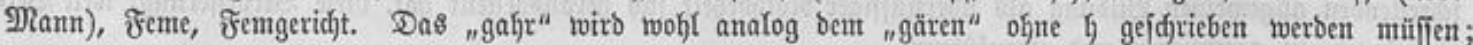

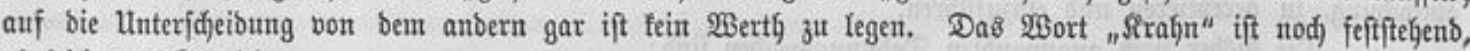
obgleid) bon Sranidid.

"th". (\$ecrberwalter.)

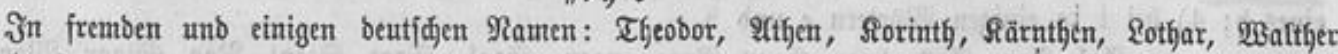




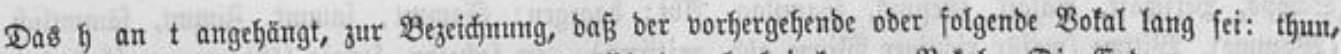

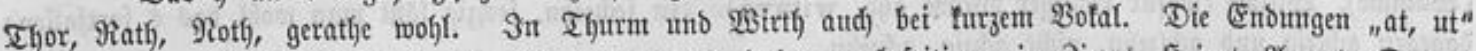
meift ofne h. Monat, 5eimat, Wermut. Sdjwantento, Daher ju befeitigen, in Sierat, ఏeirat, 21rmut, Demut;

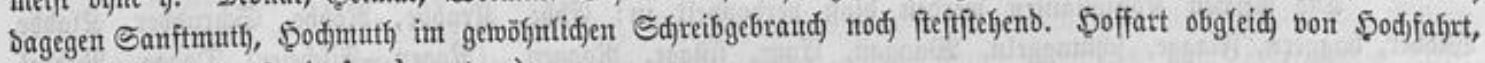
hoffärtig, (fährtig, fertig hochvertec.)

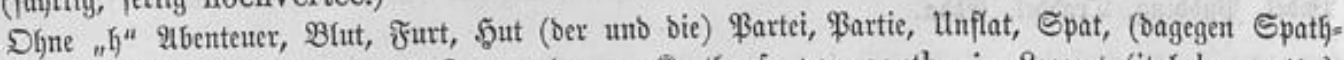

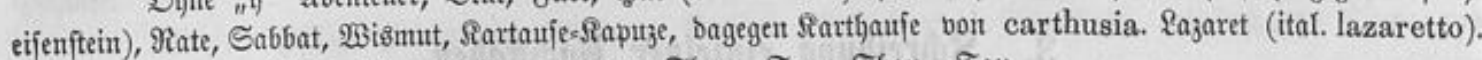
Der graphijdjen ltnteridjeibung twegen: Thon-Ton; Thau-Taut.

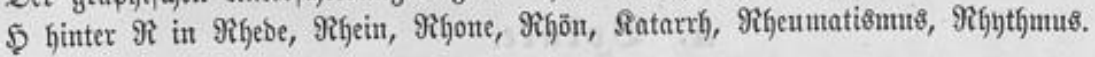

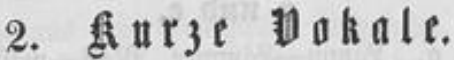

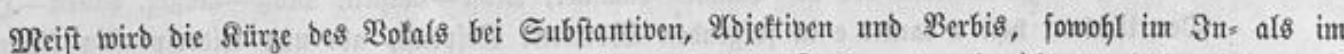

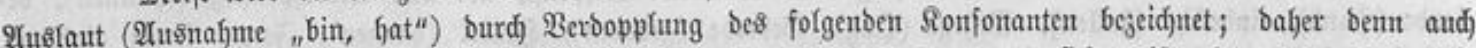

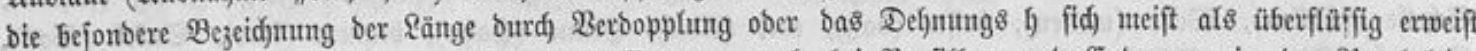

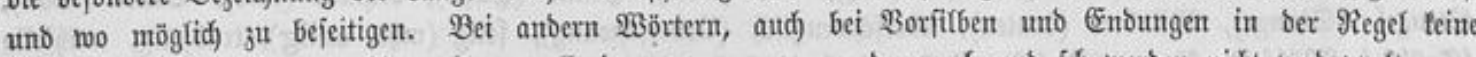

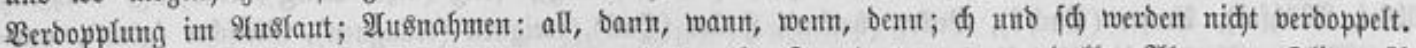

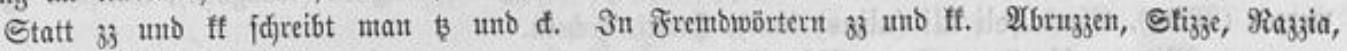
Saleaz30, Soj30, Maroffo, Metfa.

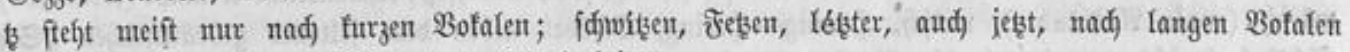
bagegen z, Sđđjweiz, Rauz, búzen: (Dúţ̧ent, verbúţ̧t) heizent.

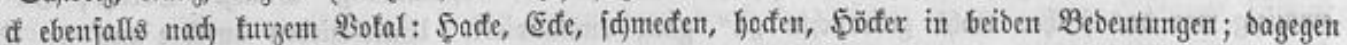

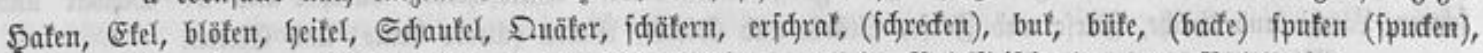

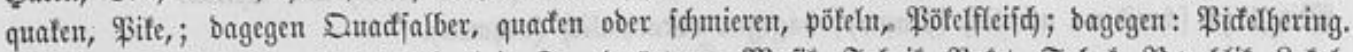

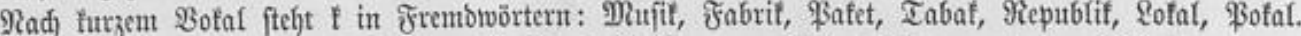

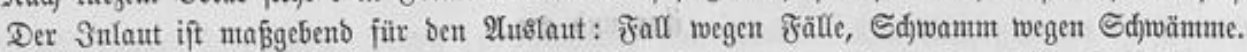

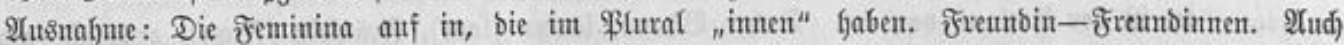

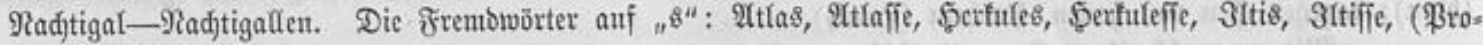
foв, ஒrofoie.)

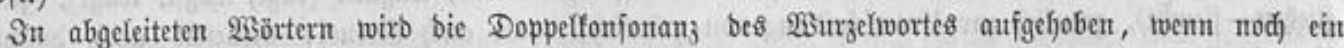

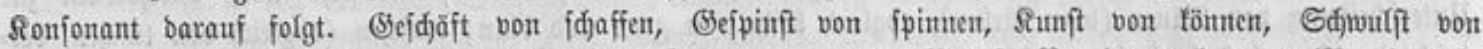
jđ̈wellen, (5unft vont gönten, triftig von treffen, Sunbe von fennen, Brumft, Branb von bremen (Branbmarle,

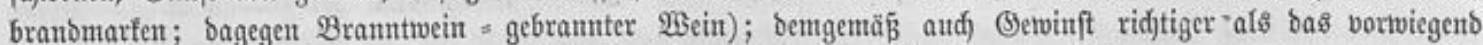

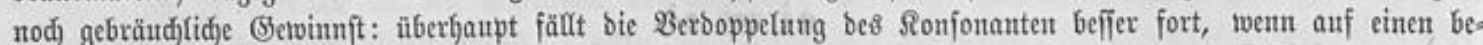
tonten furzen Botal mejrere Sonjonanten folgen: 3 . B. fammt, Sant, Damipiel $x$. Bufammenję̧ungent

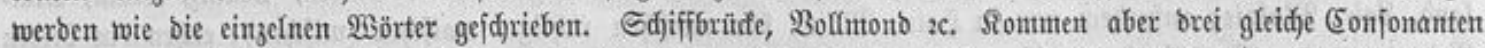

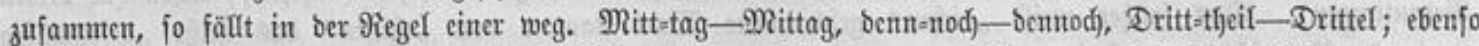
Etilleben, Sdjwinmeifter, Sdjnellauf, Sdjiffaf)tt, Brenneffel; bagegent: Sperrab, ftofffrei, 3olllinie, Bettud). Bei Tremungen tritt ber 3 . Ronjonant inmer twieber cin $z$. B. Sdjiff-fahrt. \& $t$ unt b $z$ werben ge=

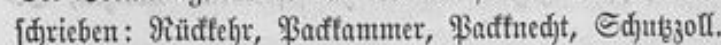

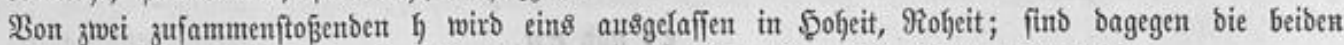
zufammengefetsten $\mathfrak{W o x t e r}$ felbftänbig, fo fteht bas boppelte h. Strohhut, Strohgütte, Strohhalm.

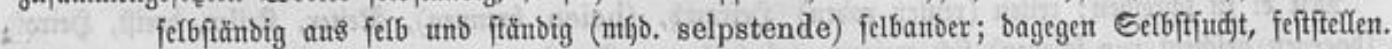

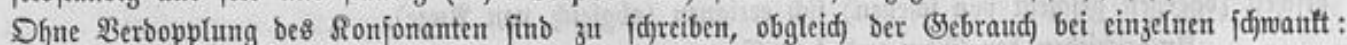

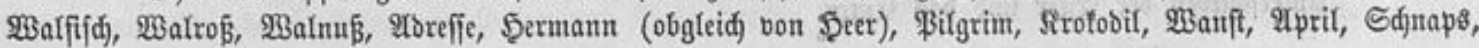




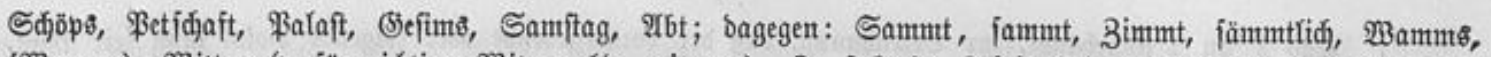

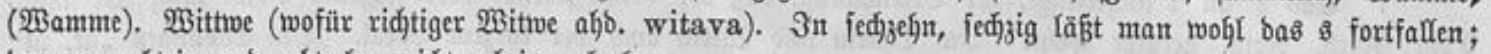
bagegen adjtzig uno adjtzelyn, nidjt adjsig, adjzełn.

Die weidjen fonjonanten werben blö̉ berboppelt in: Ebbe, Strabbe, Robbe, Sdjubber, Rlabbe,

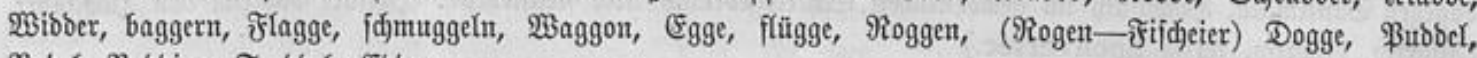
ßubel, ßuboing, Trobocl, Eboba.

\section{Sd)reibung cinzeluer B̧udftaben.}

\section{A. $\mathfrak{B}$ of a le.}

\section{î tuto $e$.}

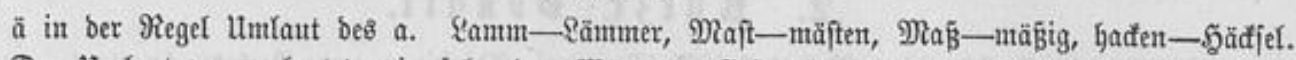

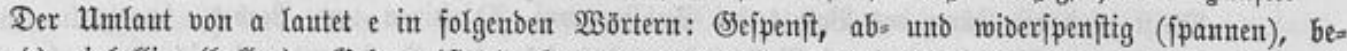

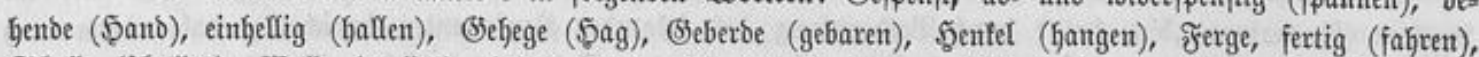

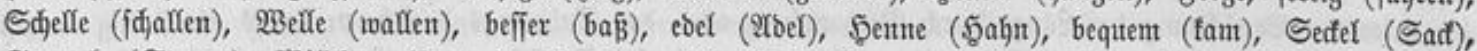

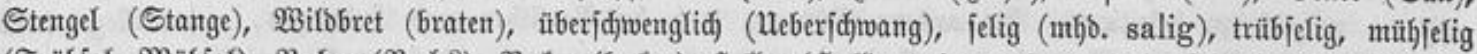

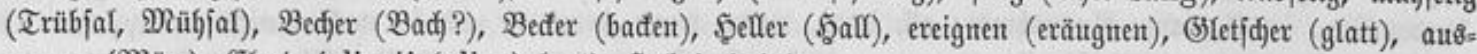

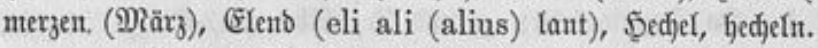

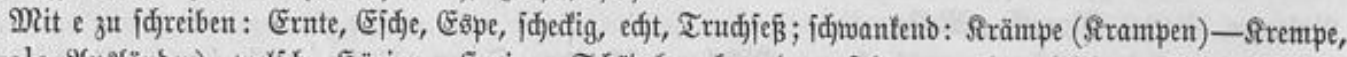

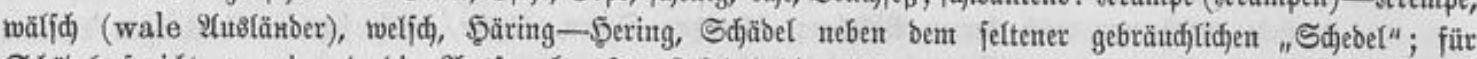

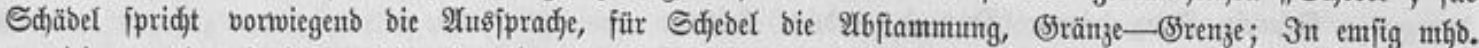

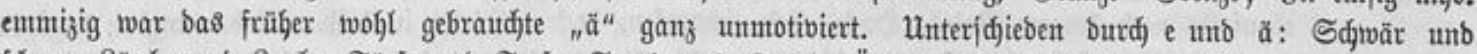

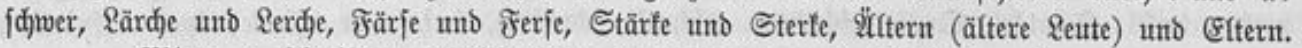

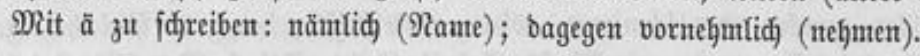

\section{ä ut unb ex.}

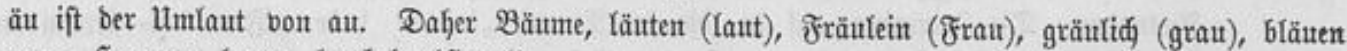
(blau); bagegen ફ̧eu von hauen, heudjeln (ゆauch)).

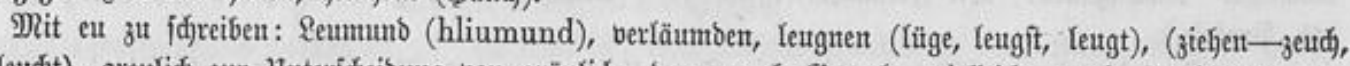

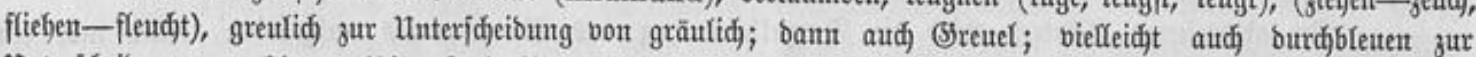

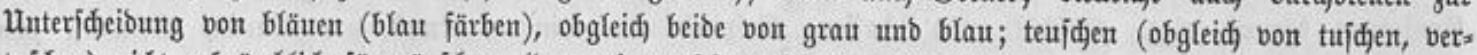

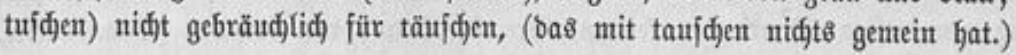

\section{a $i$ und $e i$.}

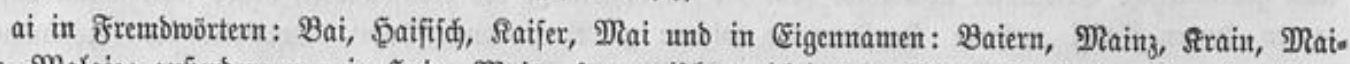

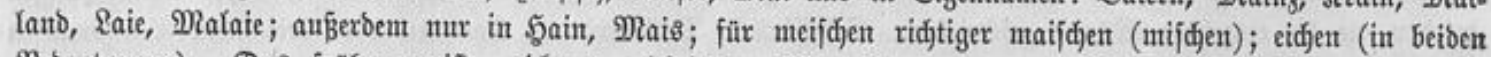

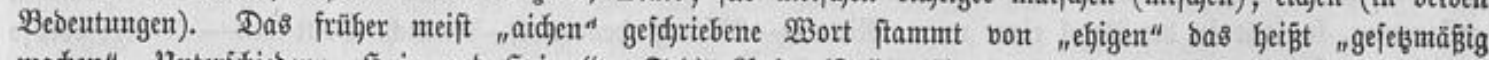

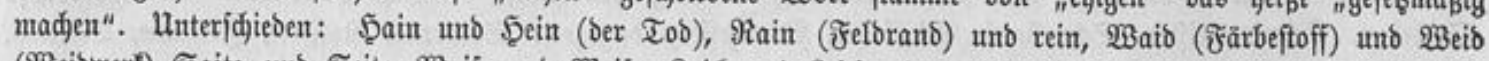

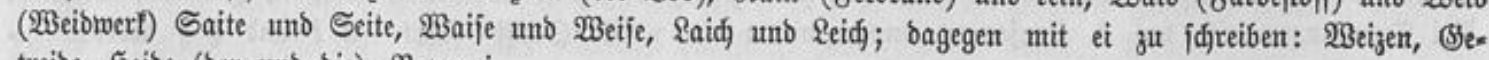
treibe, ફleibe (ber uno bie), \$apagei.

\section{et uno elt.}

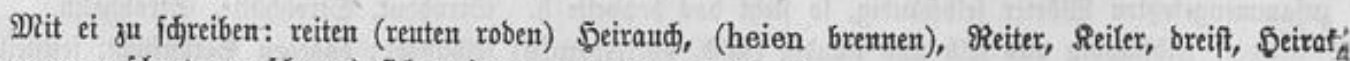

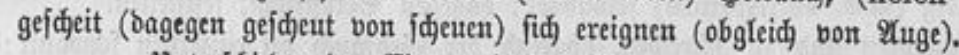

Unterfáieben ber Eiter uno bas Euter. 
$i$ und ï.

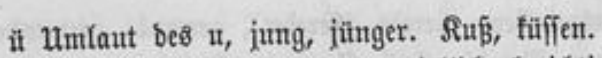

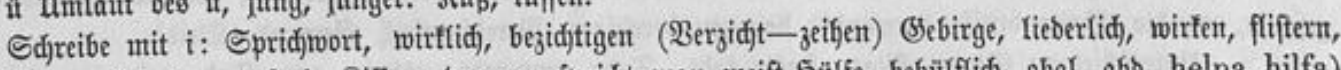

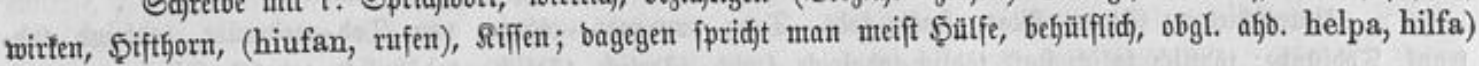
Esę̧ülfe.

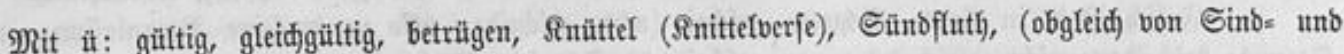
groß̧е F(นth). MRinze-Mänze.

\section{y.}

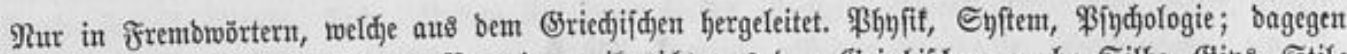

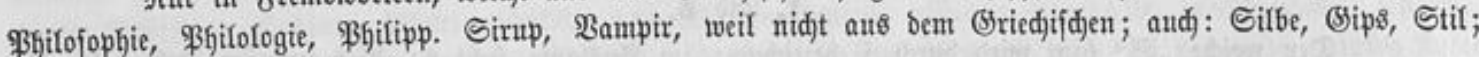
(stilus); bagegen Stiel ber $\mathscr{2}$ (̧̧t.

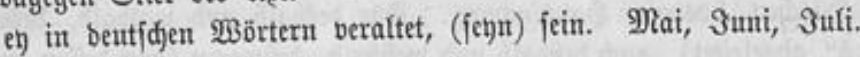

\section{B. Sonfonaten.}

c. d.). $\mathrm{f}$.

c mur in Frembroörtern: (Eäjar, (Sitrone, (Eharafter, (Ehronil; in griedjifd)en 20 örtern ftatt $c$ (nid)t

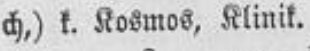

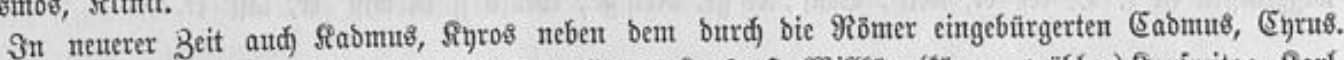

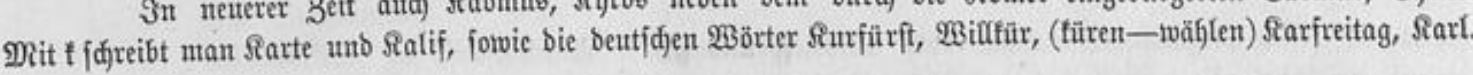

\section{b. p.}

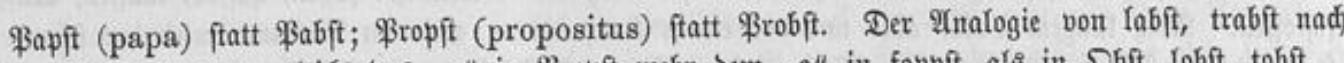

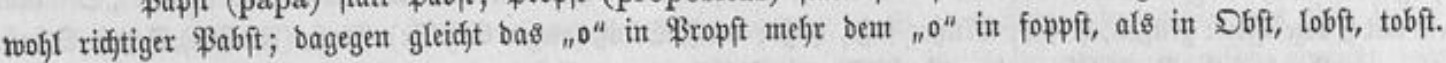

\section{g. d.)}

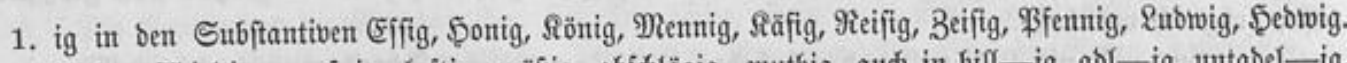

2. in ben 2rojettiven auf ig, hejtig, mäßig, abjd)lägig, muthig, aud́) in bill-ig, abl-ig, untabel-ig, unzähl-ig, mant-igfad), mannigfaltig.

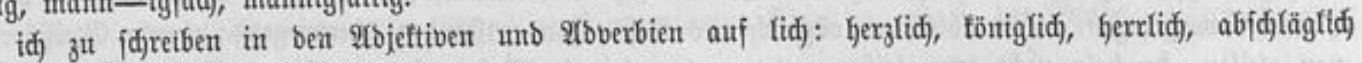

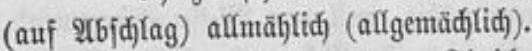

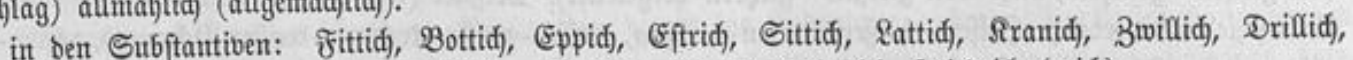

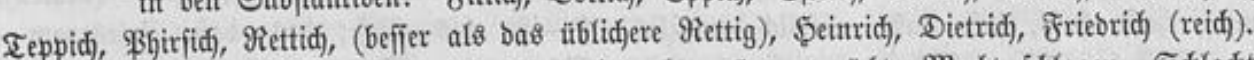

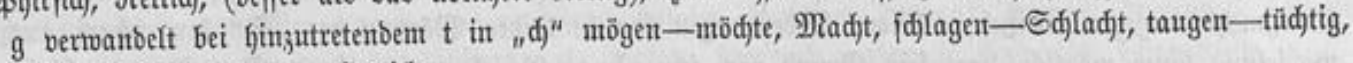
(d)weigen-bejd)widjtigen, wiegen-(Semid)t.

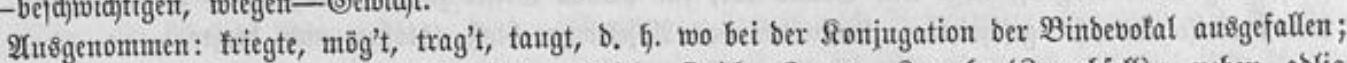

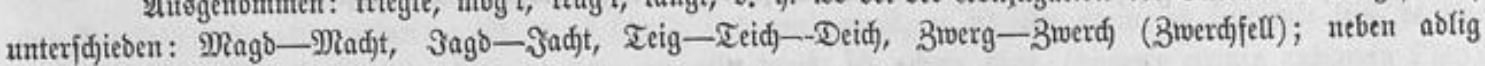
finbet fid ablid) (aus abelfid).

\section{f. v. ph.}

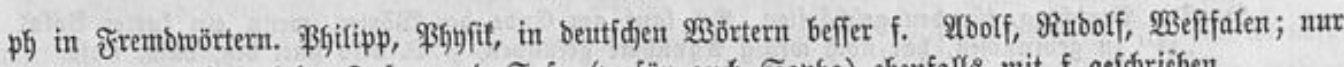

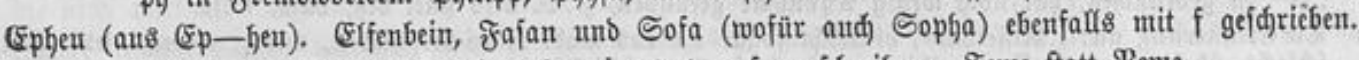

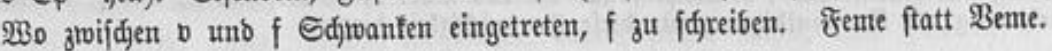




\section{๖. t. Dt.}

ot, wo jwifden o unb $t$ ber Binbebotal e ausgefallen; berebt (berebet), gewanot (gewentbet) fantote,

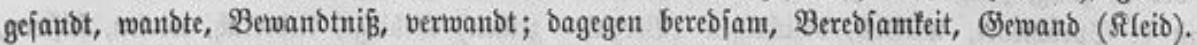

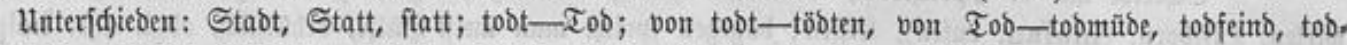

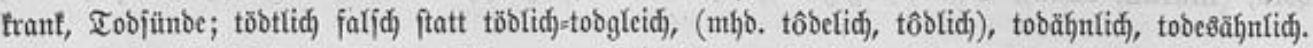

Jalidh ift of in Ernte, Edjwert, geidjeit (mb). gejd)ibe; aljo ju ot feinte Beranlaffung; vom felben Stanme bejdciben; nidjt "gejdeib" wegen gejdjeiter") Sdjmieb, 2Brob, (wegen Brobe\&).

Tinte uno Dinte (teţteres überwiegent für Sd)reibbinte, obgleid) von tingere; bagegen Tinte für

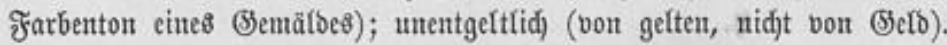

\section{f. utto 3 .}

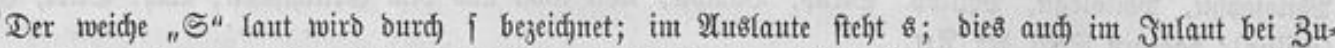

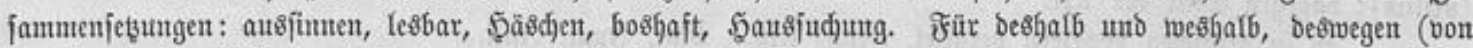

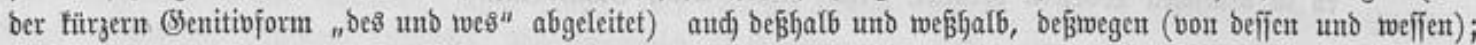

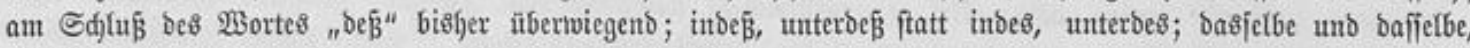

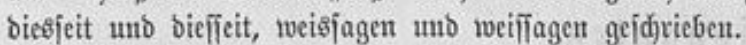

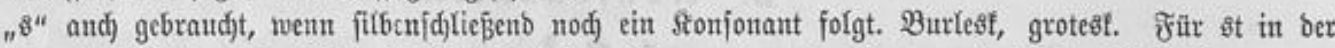

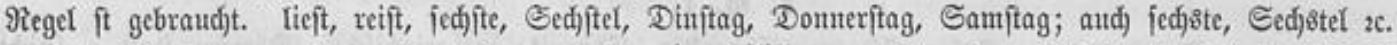

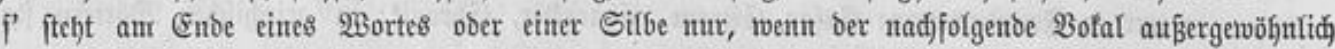

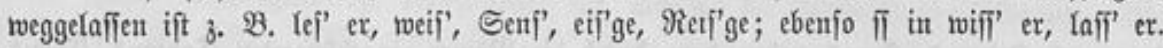

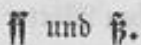

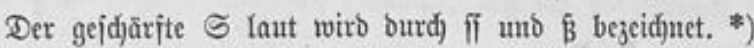

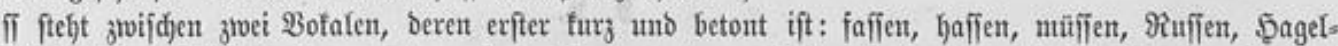

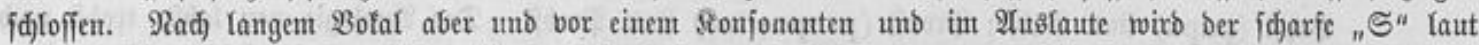

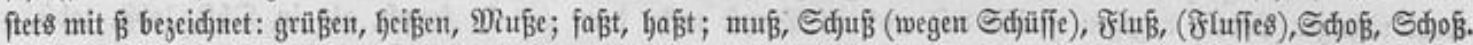

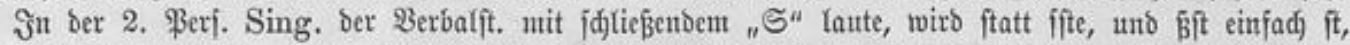
reip. ß̧t ge befte, (obgleid) von baß̄).

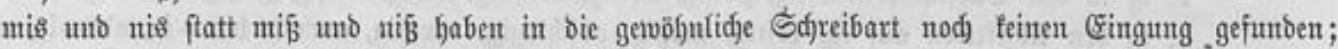

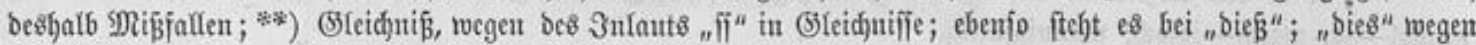

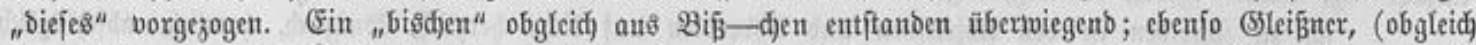

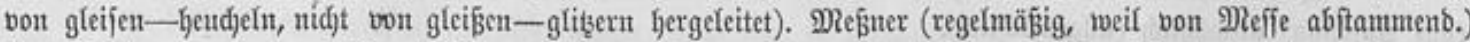

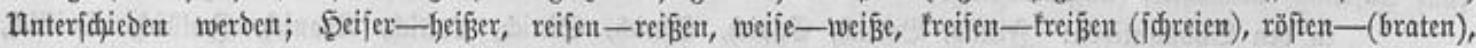

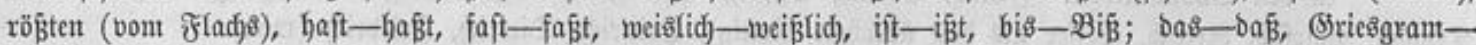

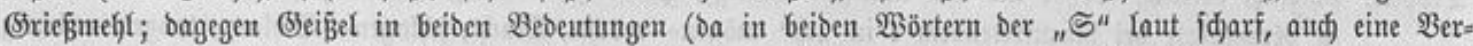

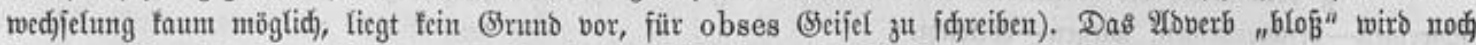

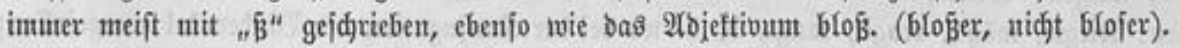

\section{$x$.}

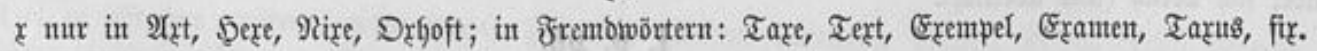

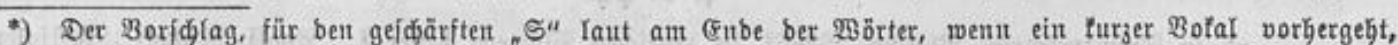

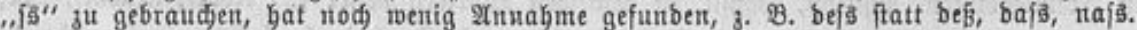

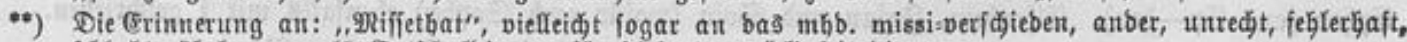

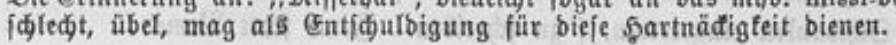




\section{Fremboürter.}

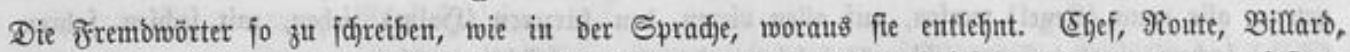
थbrefie, Shalop, \$alaft. Eingebuitgerte Frembwörter finto Brief, Tiegel, Entgef, Stiefel; anbre weroen wenigitenß

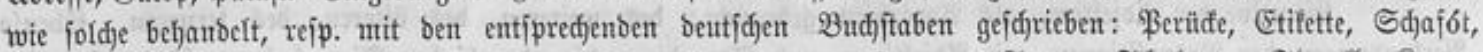
Staffette, nett, viofett, Frabrif, Brojđjüre, Sdjatulle, Gruppe, Irutppe, Suppe, Sdjaluppe, Fitantll, Strepp, Sefretär, populär, bloctieren, ntođteren.

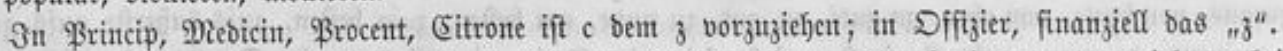

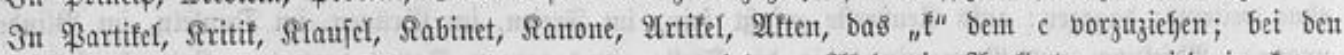

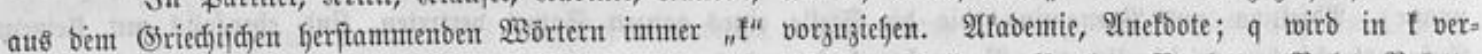
wanbelt: Barfe, Fabrit, Maste, \$afet, Sabet, Fabetten, Ballet, Ballette, Banfet, Bantette, Bafet, Fafette; ebenio Stabriolet, Stabinet, Sfelet; ähntid): nominel, confibenziel, offiziel; nominelle, confibenzielle, offizizlle. Dagegen: Duett, Terzett, Sonett, reell, Raturell, Bantrott, \&afette, Rabatt; auth) bei ben eritgentanten finbet

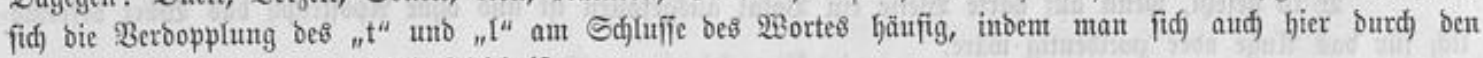

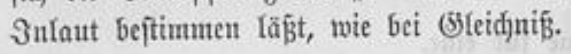

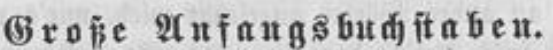

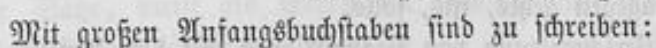

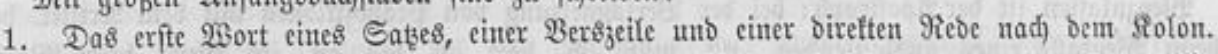

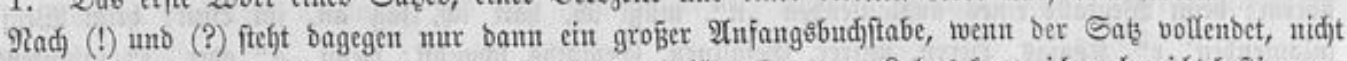

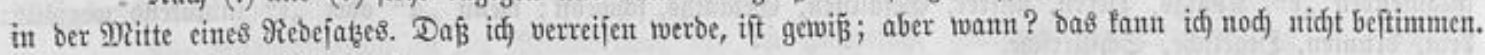

2. $\mathscr{X} \mathfrak{l}_{e}$ Subitantive.

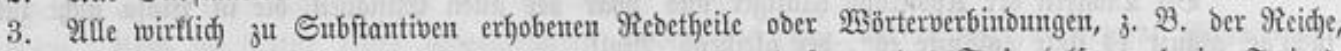
Der Blinbe, Das Duntel, bie F̌erne; bagegen von fern; von naf) unt fern; bas Freie (alfo auth im Freien),

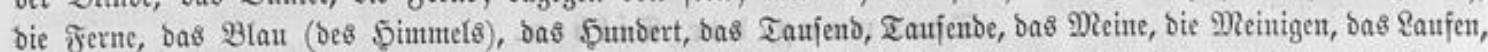
(5ehen; aud) Bronomina, 2lbverbien 2c, wenn fie als einzelne 2Börter, nad) ihrem Begriffe unto ifrer 2(nwentung

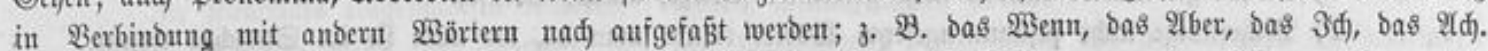

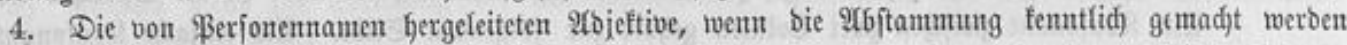

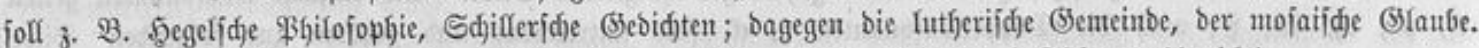

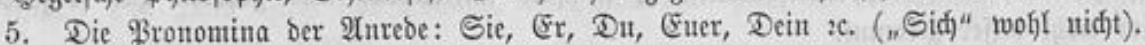

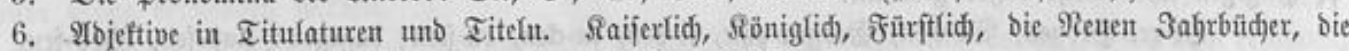

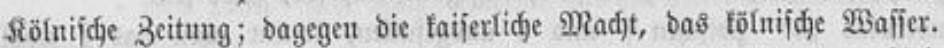

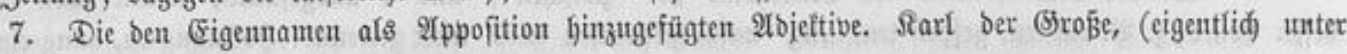
3 einbegriffen.)

Dagegen fint flein zu fdjreiben: Subftantive, bie in bie Bebeutung anbrex Wortflaffen übergegangent.

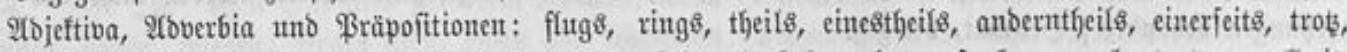
ftatt, frait, laut, baut, um=wiffen, (von)= wegen, jeitents, jufolge, fopfüber, bergauf, bergan, heutjutage, allzeit,

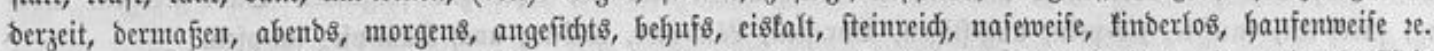

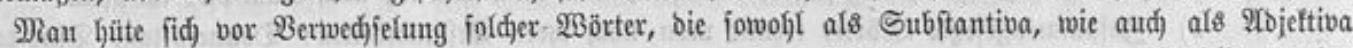
uno ßartifeln gebraudjt werben: 3 . 2B. er ift jojulb, ihm wirb angit, er ift ifjut gram, es thut mir leio, er thut noth), er ift gut freuto (feint), es finbet ftatt, id) gebe preis, id) nehme theil, (bagegen meinen uto mein Iheil),

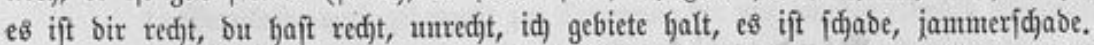

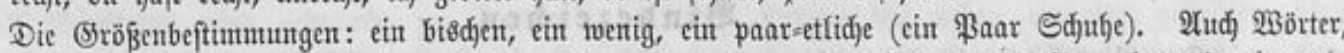
bie nicht wirffid) Subjtantibe futo, fonbern Subjtantibbegriffe bertreten, finb flein ju fidreiben: jentant, nientant, feiner, etwas, nidjts, manther, viel, viele, ber eine, ber anbre, ber exfte, ber letşte unb alle Dronungşafjlen, jebermann, fein anbrer, einige, etlidje, besgleidjen, ettvas, nidjts neut?, alles gute 2 . 


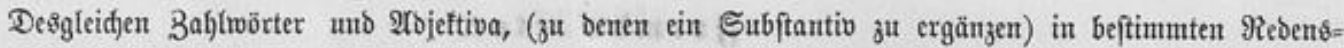
arten: alle neun (Regel) twerfen, auf allen vieren, ben fürzeren (நalm) jiefen, mit fedjen fafjen, Das weite

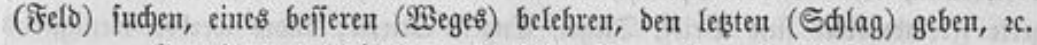

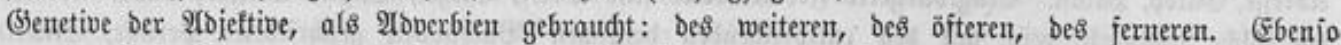

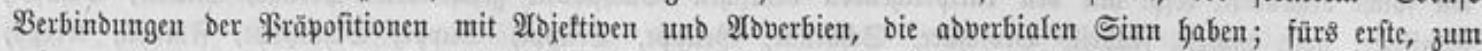
erften, jum anbern, am beften, im allgemeinen, im ganzen, im übrigen, von neutem, vor furzem, bei weitem,

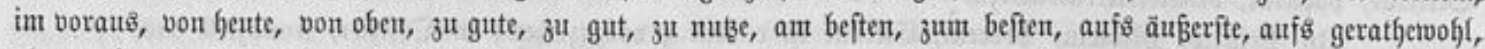

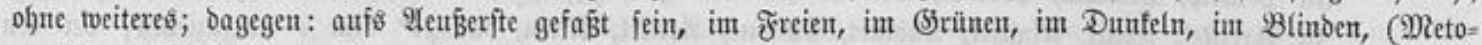
nymie). Tojeftiva unto \$ronomina, bie bie Stelle eines ganzen Saţes bertreten, fino ebenfalls mut fleinem

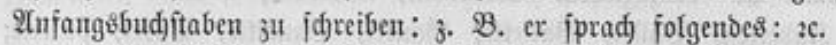

\section{$\mathfrak{A p o i f t x}$ oph.}

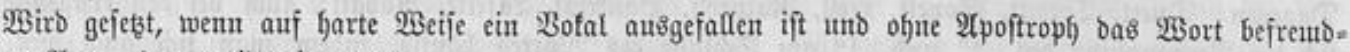
Iid) für bas \&uge oder jweibeutig wäre.

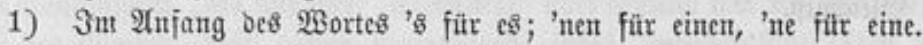

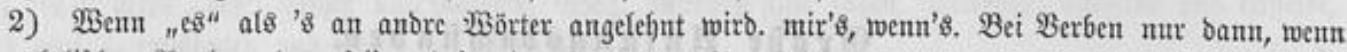

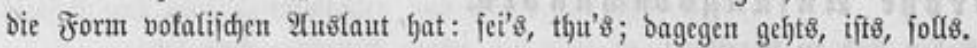

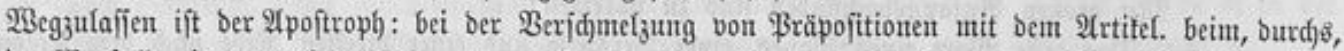

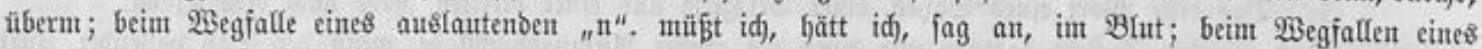

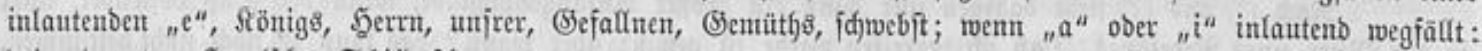
brin, brunten, ছegelidje, Sdjilleridje.

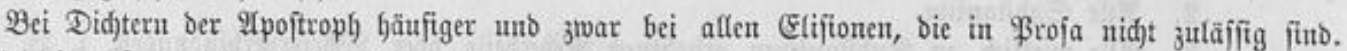

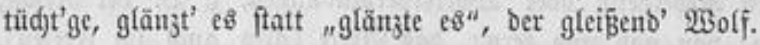

\section{Trenung ber ธilben.}

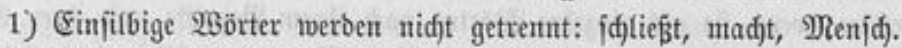

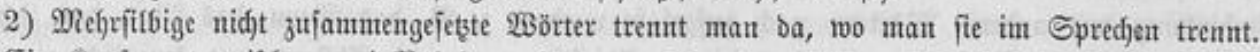

Ein fionjonant jwijden zwei Botalen gejört jur folgenben Silbe. Alß einjadje Ronjonanten gelten:

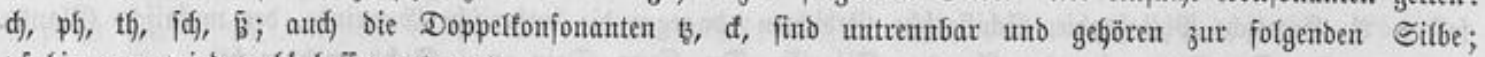
pf fingegen wirb wohl beffer getremt.

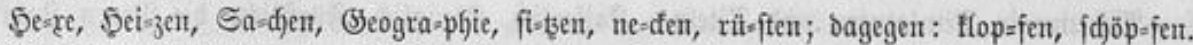

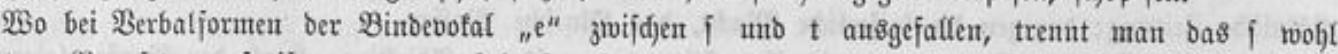

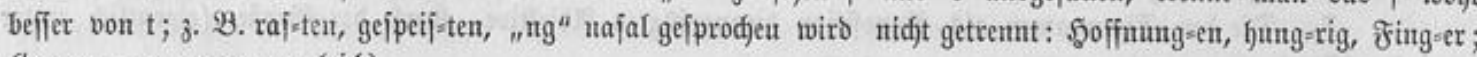
(bagegen um=gern; utt=gleid)).

Dic mit ben Enofilben "ung, at, ig, idjt" 3ujammengejebgten 2 b̈rter werben nidft al\& 3ujamment jeţungen behanbelt; \$ei=mat, bersgig.

3) Bon zुwei ober melgr inlautenben fonjonanten wirb ber leţte jut folgenten Silbe gejogen. Dro=

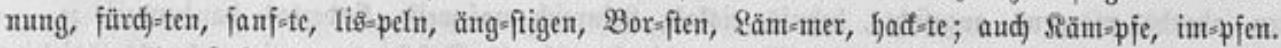

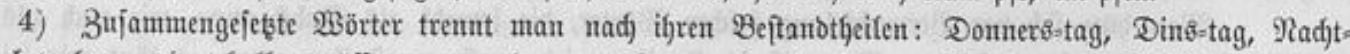

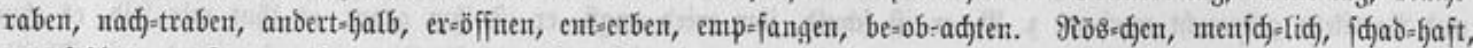
emip-fefflen, ber-jpotten, bar=um, wor=an, bersein.

\section{Bindezeiden.}

Der Binbeftrid) wirb gebraudft:

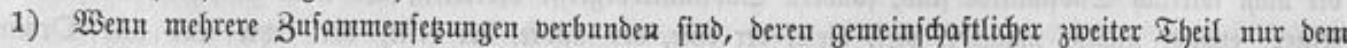

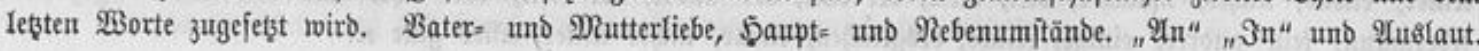


2) bei 3ujammeniebsungen.

a) von CFigennamen. $\Re$ ieu $[=-S d) l e i_{3}$.

b) bic in ein $\mathfrak{B}$ ort gejđjriebent, bem $\mathscr{2}$ uge bejremblid wären. Sdjneesebene, Sec=ente, Thee=ernte. Sonft ift ber Binbejtrid) zu vermeiben. 3. B. Dampfidiffiahrtsgejellidaft. \$autptzollamtôrevifor.

\section{Gutexpuntion.}

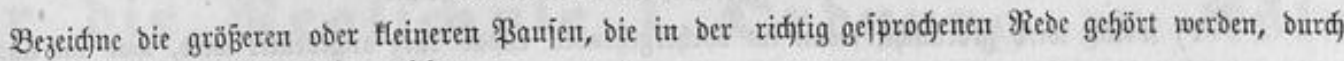

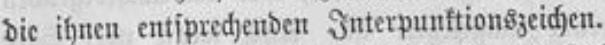

1. Der \$unft bejeidjnet bie längite \$aulfe, meld)e zugleid) burd Sentung ber Stimume angebeutet wiro.

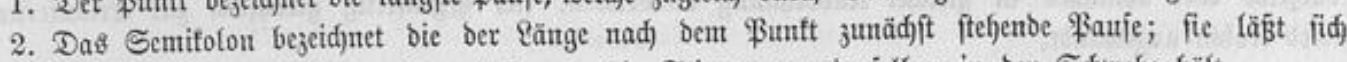

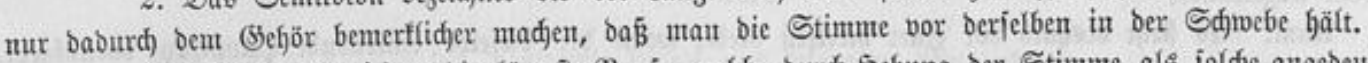

Das fonmta bezeifjnet bic fürjefte \$aufe, weldje butrd \$̧ebung ber Stimute als joldje angebeutet wirb.

\section{Spezielle Regeln.}

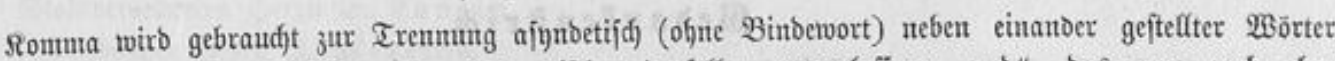

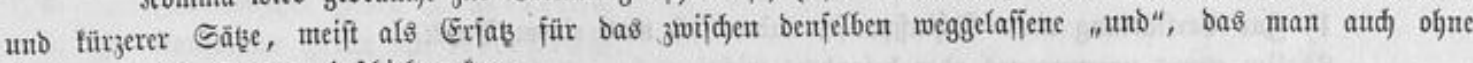
Tenterung bes Sinnes einjujicbent tann.

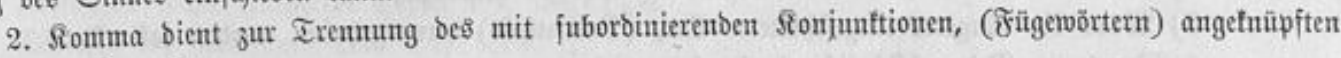

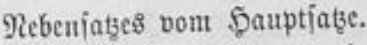

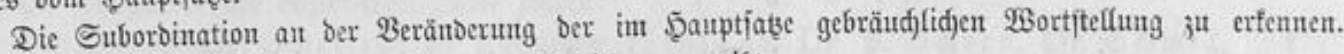
Er gibt funt. Weit er tuno gibt; er gibt vor; obgleid) er vorgibt.

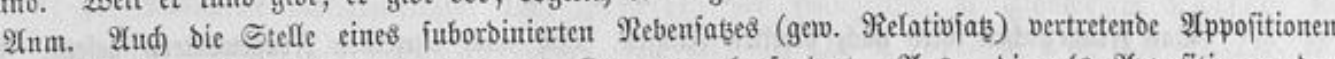

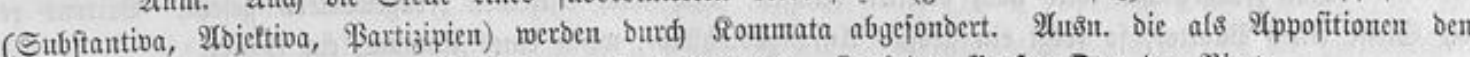

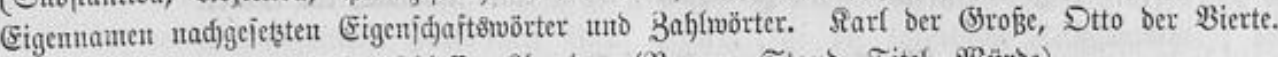

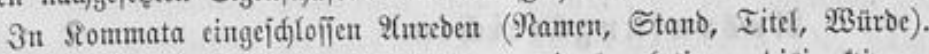

3) Siomma bient jur Trentung ber mit topulativen, bisjunttiven unt abverjativen fonjunttionen (Bindewörtern) verbunbenten Sätze.

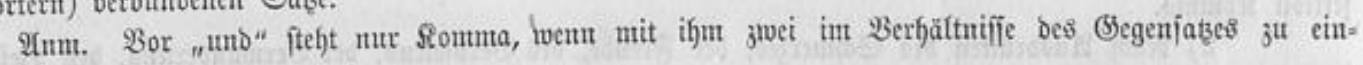
anbser ftef̧ende Cäţe verbutben werben.

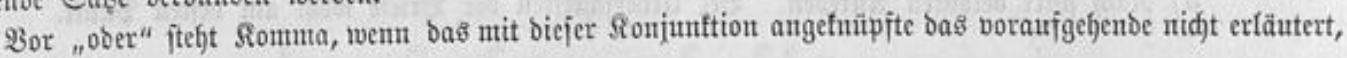

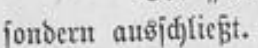

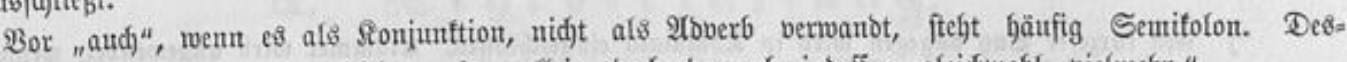

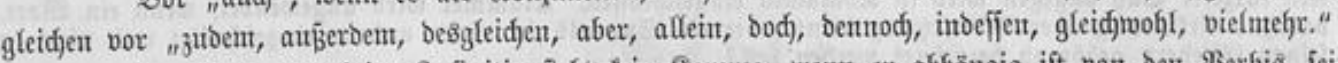

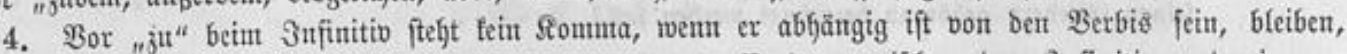
ftefen, jđeinen, Gaben, pflegen; ferner nidjt, went bas regierenbe Berbum jwijden ben Infuntitio uno ein bon

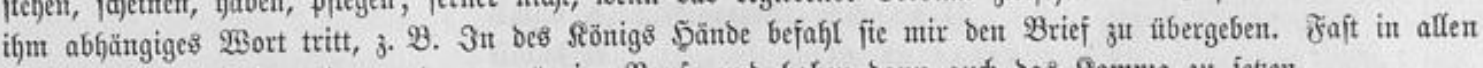

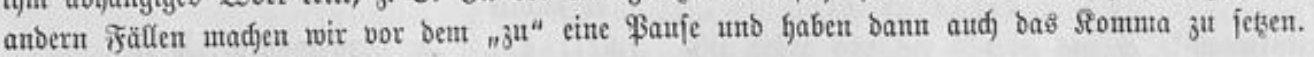

\section{Stridpunt (Semifolon).}

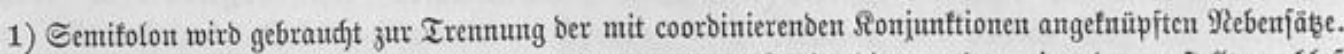

2) Semifolon wirb gebraudjt jut Iremung ber ohne Sonjunltion neben einanber geftellten, bló

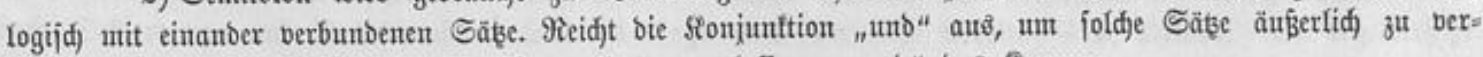
binben, fo genügt aud hier zur Bezeidjnuttg bes weggelaifenen "und" bas Somma.

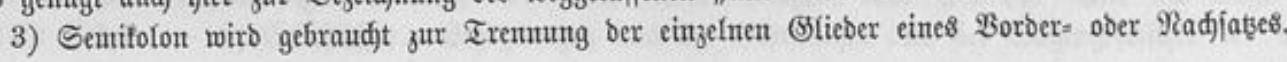




\section{Butt.}

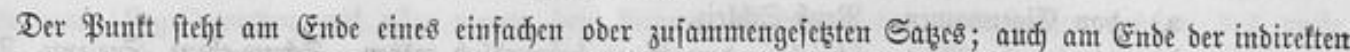

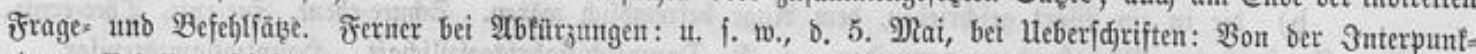
tion. Bei Unteriffriftent: Der Berfafier.

\section{Doppelpunt. Siolou.}

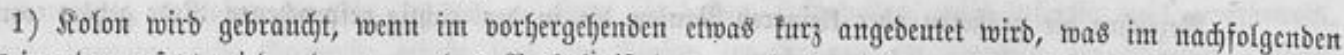

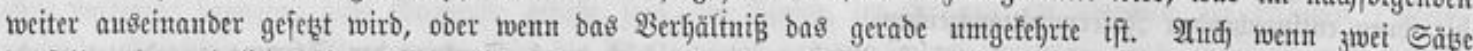

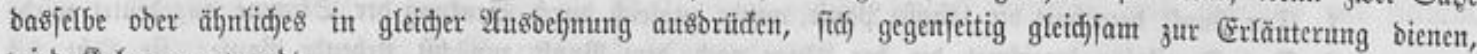
wiro Solon angewantot. uno bei ใ̛f

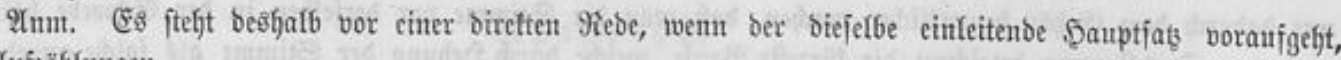

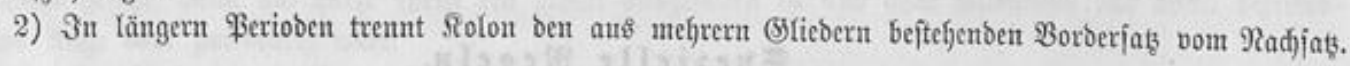

\section{(Ge ba $n$ fentt $x$ id.}

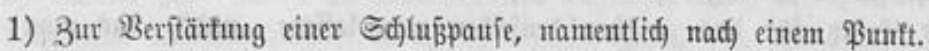

2) Utu etwas unerwartetes ober bejonbers widjtiges hervorzutheben.

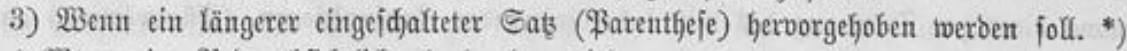

4 went eine Rebe abjidftlid) abgebrodjen wirb.

\section{ซ́tagezeiden.}

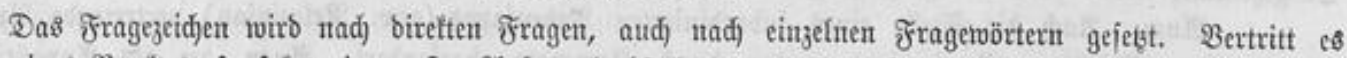

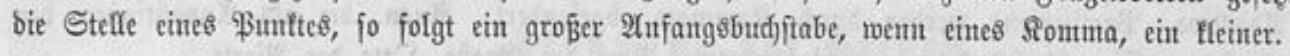

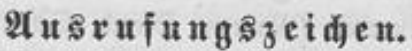
iettion siomuta.

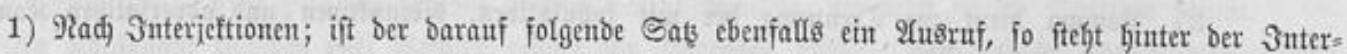

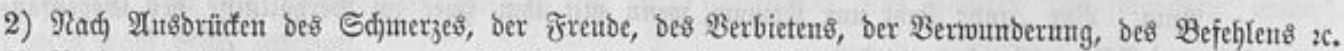

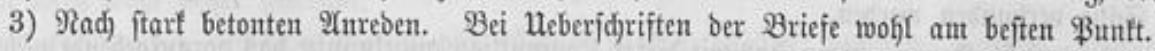

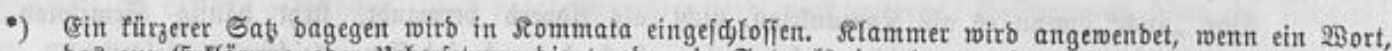

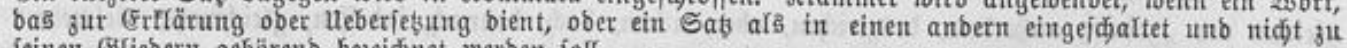
feinen (ङfiebern gehörenb bejeidnet werben joll. 